\title{
Response of the Hanford
}

Combination Neutron Dosimeter in Plutonium Environments
A. W. Endres
L. W. Brackenbush
W. V. Baumgartner
J. J. Fix
B. A. Rathbone

February 1996

Prepared for

the U.S. Department of Energy

Contract DE-AC06-76RLO 1830

Pacific Northwest National Laboratory

Operated for the U.S. Department of Energy

by Battelle 


\section{DISCLAIMER}

This report was prepared as an account of work sponsored by an agency of the United States Government. Neither the United States Government nor any agency thereof, nor Battelle Memorial Institute, nor any of their employees, makes any warranty, express or implied, or assumes any legal liability or responsibility for the accuracy, completeness, or usefulness of any information, apparatus, product, or process disclosed, or represents that its use would not infringe privately owned rights. Reference herein to any specific commercial product, process, or service by trade name, trademark, manufacturer, or otherwise does not necessarily constitute or imply its endorsement, recommendation, or favoring by the United States Government or any agency thereof, or Battelle Memorial Institute. The views and opinions of authors expressed herein do not necessarily state or reflect those of the United States Government or any agency thereof.

\section{PACIFIC NORTHWEST LABORATORY operated by BATTELLE MEMORIAL INSTITUTE for the \\ UNITED STATES DEPARTMENT OF ENERGY under Contract DE-AC06-76RLO 1830}

Printed in the United States of America

- Available to DOE and DOE contractors from the Office of Scientific and Technical Information, P.O. Box 62, Oak Ridge, TN 37831; prices available from (615) $576-8401$.

Available to the public from the National Technical Information Service, U.S. Department of Commerce, 5285 Port Royal Rd., Springfield, VA 22161 

A. H. Endres
L. W. Brackenbush
W. V. Baumgartner
J. J. Fix
B. A. Rathbone

February 1996

Prepared for

the U.S. Department of Energy

under Contract DE-AC06-76RLO 1830

Pacific Northwest National Laboratory

Richland, Hashington 99352 



\section{EXECUTIVE SUMMARY}

This report documents response characteristics and the development of dose algorithms for the Hanford Combination Neutron Dosimeter (HCND) implemented on January 1, 1995. The HCND was accredited under the U.S. Department of Energy (DOE) Laboratory Accreditation Program (DOELAP) during 1994. The HCND employs two neutron dose components consisting of 1) an albedo thermoluminescent dosimeter (TLD), and 2) a track-etch dosimeter (TED). Response characteristics of these two dosimeter components were measured under the low-scatter conditions of the Hanford 318 Building Calibration Laboratory, and under the high-scatter conditions in the workplace at the PTutonium Finishing Plant (PFP). The majority of personnel neutron dose at Hanford (currentiy and historically) occurs at the PFP.

National Institute of Standards and Technology (NIST) traceable sources were used to characterize dosimeter response in the laboratory. At the PFP, neutron spectra and dose-measuring instruments, including a multisphere spectrometer, tissue equivalent proportional counters, and specially calibrated rem meters, were used to determine the neutron dose under several configurations from three different plutonium sources: 1) plutonium tetrafluoride, 2) plutonium metal, and 3) plutonium oxide. In addition, measurements were performed at many selected work locations. The HCNDs were included in all measurements. Comparison of dosimeter- and instrumentmeasured dose equivalents provided the data necessary to deveiop HCND dose algorithms and to assess the accuracy of estimated neutron dose under actual work conditions.

The plutonium tetrafluoride source data is of special importance because it is the same source that was used to calibrate instruments and neutron dosimeters at Hanford from 1958 to 1981 in various exposure configurations. In these measured neutron fields, neutron dosimeters were exposed on the same acrylic plastic phantoms used in DOELAP accreditation. Measurements were also 
performed with selected thicknesses of acrylic plastic positioned between the neutron source and the detectors to simulate glove boxes and neutron shielding windows.

Various approaches were used to develop dose algorithms for the TLD component of the HCNDs. For the algorithms finally developed, the dose evaluated for bare sources and for sources with less than $2.5 \mathrm{~cm}$ (1 in.) of acrylic plastic shielding in high-scatter conditions typical of glove-box operations are reasonably accurate, as expected. The HCND algorithms are also accurate in estimating the dose when dosimeters are exposed to moderated neutrons from sources with $5 \mathrm{~cm}$ to $10.2 \mathrm{~cm}$ (2 in. to 4 in.) of acrylic plastic shielding. These results were obtained by using dose calculation algorithms that use the measured dose equivalent response of this dosimeter in various spectra.

An algorithm was developed for the TED component of the HCND, based on data obtained in the laboratory and PFP exposures. Because this dosimeter component has no significant response to beta and/or photon radiation, the dose algorithm was quite simple. The TED component consists of two CR-39 foils. These foils are electrochemically etched using standard laboratory procedures. The dose results indicate the TED component is accurate for both bare and slightly moderated neutron sources. However, the accuracy of the TEDs decreases with increasing moderator thickness because an increasingly large fraction of the neutrons reaching the dosimeters have energies below the approximate $100-\mathrm{keV}$ threshold for detection of fast neutrons by the CR-39. In the background and glove-box measurements made at the PFP, the CR-39 dose results were under estimated by as much as a factor of six, based on a bare ${ }^{252} \mathrm{Cf}$ calibration.

To test the accuracy of the dose equivalent algorithms, a series of measurements were performed using dosimeters exposed on acrylic plastic phantoms in workplace locations where the neutron dose and energy spectrum were characterized by measurements with TEPCS, the multisphere spectrometer and specially calibrated rem-meters. A preliminary survey was performed to determine the extremes of the neutron energy spectra that were encountered at the PFP. Locations were selected that were representative of typical spectra 
and of the extremes in the neutron energy spectra. More detailed measurements were made at these locations to compare the dosimeter response to the dose equivalent derived from spectrometric measurements. In general, the dose equivalent evaluated from the HCND agreed reasonably well with the dose equivalent from the spectral measurements. The only significant differences were observed for the very low-energy (soft) spectra encountered in the vault area, where the HCND overestimated dose equivalent. There were no situations encountered where the HCND significant7y underestimated dose equivalent. Conclusions developed in the course of this work include the following:

- Periodic field measurements are necessary to validate the continued accuracy of HCND neutron dose under the complex work environments at the PFP, or any other Hanford work environment where there is significant neutron exposure. Importantly, measurements should be performed to support any significant change in operations or in the quantity of plutonium handled.

- Field neutron spectra and dose instrument measurements are the only methods available to assure the credibility of routine personnel neutron dose results.

- Because of technical limitations in available personnel neutron dosimeters, routine dose estimates should be conservative to avoid any significant under-reporting of personnel neutron dose.

- Based on measurements performed, the HCND TLD-albedo component generally overestimates neutron dose, using the calibration and algorithm described in this report. This type of dosimeter is very sensitive to lower-energy neutrons.

- Generally, the TLD-albedo component provides more accurate results, compared to the TED component, at low doses (e.g., below about $0.5 \mathrm{mSv}$ ). The TLD also has a satisfactory angular response.

- The TED component of the HCND tends to underestimate neutron dose in current PFP work environments because of the significant fluence of lower-energy neutrons ( $<100 \mathrm{keV})$ and perhaps because of its relatively poor angular response. However, the TED is more accurate for higherenergy neutrons, particularly for anterior-posterior exposures from a source of neutrons.

- The HCND TED component has a relatively energy-independent response, above the lower-energy threshold, which will provide more accurate neutron dose estimates if the HCND is subjected to widely varying neutron fields. 



\section{ACRONYMS}

ABS Acrylonitrile-Butadiene-Styrene

CPMR Count Per Millirem

DOE U.S. Department of Energy

DOELAP U.S. Department of Energy Laboratory Accreditation Program

ECC Element Correction Coefficients

EPA U.S. Environmental Protection Agency

FN Fast Neutrons

HCND Hanford Combination Neutron Dosimeter

HEDP Hanford External Dosimetry Project

HSD Hanford Standard Dosimeter

IAEA International Atomic Energy Agency

LET Linear Energy Transfer

LLD $\quad$ Lower-Leve1-of-Detection

NIST National Institute of Standards and Technology

NVLAP National Voluntary Laboratory Accreditation Program

PFP Plutonium Finishing P7ant

- PNNL Pacific Northwest National Laboratory

PTFE Polytetrafluroethylene

QC Quality Control

RCF Reader Calibration Factors

REX Radiological Exposure Record System

RL DOE Richland Operations Office

RRF Relative Response Factor

SN Slow Neutrons

TE Tissue Equivalent

TED Track-Etch Dosimeter

TEPC Tissue-Equivalent Proportional Counter

TLD Thermoluminescent Dosimeter 



\section{CONTENTS}

EXECUTIVE SUMMARY ...................... .

ACRONYMS ........................ . . vi

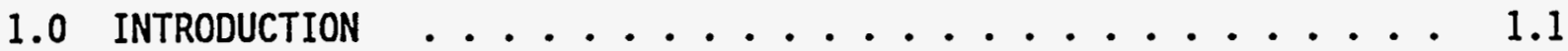

1.1 SOURCES AND CALIBRATION FACTORS . . . . . . . . 1.2

1.2 NEUTRON MEASUREMENTS . . . . . . . . . . . . . 1.3

1.3 RADIATION PROTECTION STANDARDS . . . . . . . . . 1.5

1.4 STRUCTURE OF THIS REPORT . . . . . . . . . . 1.6

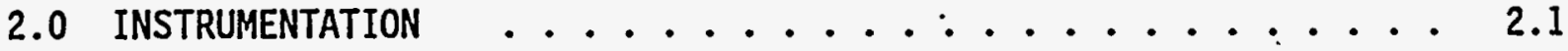

2.1 MULTISPHERE SPECTROMETER $\ldots$. . . . . . . . . . 2.1

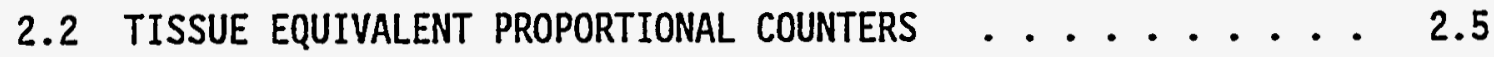

2.3 PERSONNEL NEUTRON DOSIMETERS $\ldots \ldots . . . \ldots$

2.3.1 TLD-Albedo Dosimeters _. . . . . . . 2.9

2.3.2 CR-39 Nuclear Track Dosimeters . . . . . . . 2.12

3.0 LABORATORY MEASUREMENTS $\ldots \ldots \ldots \ldots . \ldots . \ldots . \ldots . \ldots$

4.0 WORKPLACE MEASUREMENTS . . . . . . . . . . . . . . 4.1

4.1 PLUTONIUM TETRAFLUORIDE MEASUREMENTS $\ldots$. . . . . . 4.1

4.1.1 Dose Equivalent Determinations from

Plutonium Tetrafluoride Source ........ 4.2

4.1.2 Multisphere Spectrometer Measurements with the Plutonium Tetrafluoride Source ......... 4.2

4.2 PLUTONIUM DIOXIDE MEASUREMENTS . . . . . . . . . . 4.6

4.2.1 Dose Equivalent Determinations from the
Plutonium Dioxide Source . . . . . . . 4.7 4.7

4.2.2 Multisphere Spectrometer Measurements with the
Plutonium Dioxide Source .......... 4.7

4.3 PLUTONIUM METAL MEASUREMENTS . . . . . . . . . . 4.9 
4.3.1 Dose Equivalent Determinations from the Plutonium Metal Source ........... 4.9

4.3.2 Multisphere Spectrometer Measurements with the Plutonium Metal Source ........... 4.9

4.4 THERMOLUMINESCENT DOSIMETER AND CR-39 RESULTS COMPARED TO INSTRUMENTATION $\ldots \ldots \ldots . \ldots . \ldots . . \ldots . . \ldots$

5.0 HANFORD COMBINATION NEUTRON DOSIMETER ALGORITHM DEVELOPMENT $\quad$ • 5.1

5.1 ALGORITHM BASED $0{ }^{252} \mathrm{CF} \ldots \ldots \ldots \ldots . \ldots \ldots$

5.2 ALGORITHM BASED ON PuF $\ldots \ldots \ldots \ldots . \ldots \ldots$

5.2.1 Dose Calculation for the Unmoderated Condition . . 5.7

5.2.2 Dose Calculation for the Partially Moderated Condition ................. 5.8

5.2.3 Dose Calculation for the Highly Moderated Condition ................. 5.8

5.3 CR-39 TRACK-ETCH DOSIMETER ALGORITHM . . ..... 5.10

6.0 SUPPLEMENTAL HORKPLACE MEASUREMENTS $\ldots \ldots \ldots \ldots . \ldots \ldots$

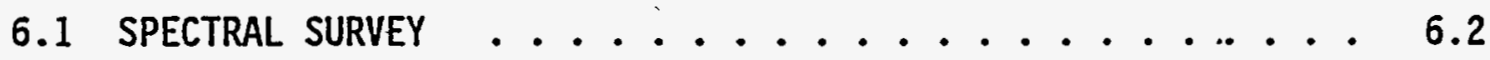

6.2 Z-VAULT MEASUREMENTS $\ldots \ldots \ldots \ldots . \ldots . \ldots . \ldots . \ldots$

6.3 "FRONTSIDE" MEASUREMENTS .............. . . 6.12

6.4 "BACKSIDE" MEASUREMENTS .................. 6.15

7.0 CONCLUSION $\ldots \ldots \ldots \ldots \ldots . \ldots \ldots . \ldots \ldots$

7.1 PLUTONIUM FINISHING PLANT NEUTRON FIELDS . . . . . 7.1

7.2 THERMOLUMINESCENT-DOSIMETER ALBEDO RESPONSE CHARACTERISTICS 7.1

7.3 TRACK-ETCH DOSIMETER RESPONSE CHARACTERISTICS . . . . 7.3

7.4 OVERALL RESPONSE OF HANFORD COMBINATION NEUTRON DOSIMETER • 7.4

8.0 REFERENCES $\ldots \ldots \ldots \ldots . \ldots \ldots . \ldots . \ldots . \ldots . \ldots$

APPENDIX A - MULTISPHERE SPECTROMETER DATA . . . . . . . A.1 


\section{- FIGURES}

1.1 Laboratory Meásured Neutron Energy Spectra for $\mathrm{PuF}_{4}, \mathrm{PuO}_{2}$,

2.1 Typical Spectrum Recorded from a TEPC Operated with a 2-pm Equivalent Diameter Exposed to Neutrons and Gamma Rays . . . . 2.7

2.2 Energy Dependence of Various TLD-Albedo Dosimeters . . . . 2.11

2.3 Hanford Combination Neutron Dosimeter Showing Neutron (7eft) and beta/photon (right) Dosimeter Components .........

4.1 Neutron Flux per Unit Lethargy at $50 \mathrm{~cm}$ from the Bare PuF Source Measured by the Multisphere Spectrometer . . . . . . 4.5

4.2 Neutron Flux per Unit Lethargy at $100 \mathrm{~cm}$ from the Bare $\mathrm{PuF}_{4}$ Source Measured by the Multisphere Spectrometer ...... 4.5

4.3 Neutron F]ux per Unit Lethargy at $50 \mathrm{~cm}$ from the Bare $\mathrm{PuO}_{2}$ Source Measured by the Multisphere Spectrometer . . . . . . 4.8

4.4 Neutron Flux per Unit Lethargy at $50 \mathrm{~cm}$ from the Bare Plutonium Metal Source Measured by the Multisphere Spectrometer ....

6.1 Correlation Between the Average Neutron Energy Determined from Multisphere Spectrometer Measurements and the Ratio of the Count Rates from the 8-in. and 3-in. Diameter Spheres . . 6.3

6.2 Correlation Between the Dose Equivalent Calibration Constant and the Ratio of the Count Rates from the 8-in. and 3-in.

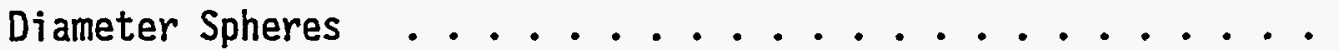

6.3 Neutron Energy Spectrum Measured by the Multisphere Spectrometer in Vault 1 of the $2736-$ ZB Building .......... 6.8

6.4 Neutron Energy Spectrum Measured by the Multisphere Spectrometer in Vault 2 of the $2736-Z B$ Building ............

6.5 Neutron Energy Spectrum Measured by the Multisphere Spectrometer in Vault 3 of the 2736-ZB Building ...........

6.6 Neutron Energy Spectrum Measured by the Multisphere Spectrometer in Vault 4 of the $2736-Z B$ Building ...........

6.7 Neutron Energy Spectrum Measured by the Multisphere Spectrometer in the Hallway Outside of the Vaults in the 2736-ZB Building . . 6.10 
6.8 Neutron Energy Spectrum Measured by the Multisphere Spectrometer at Location $Q$ in the Storeroom Near the Office Areas on the Third Floor on the "Frontside" of the 234-5 Building . . . . . .

6.9 Neutron Energy Spectrum Measured by the MuTtisphere Spectrometer at Location I Near the Shops and Control Room on the Third Floor At the "Frontside" of the 234-5 Building ...........

6.10 Neutron Energy Spectrum Measured by the Multisphere Spectrometer at Location S Near the Fluorinator on the "Backside" of the 234-5 Building

6.11 Neutron Energy Spectrum Measured by the Multisphere Spectrometer at Location $V$ Near the Fluorinator on the "Backside" or Process Area of the 234-5 Building

A.1 Neutron Flux Density per Unit Lethargy Measured by the

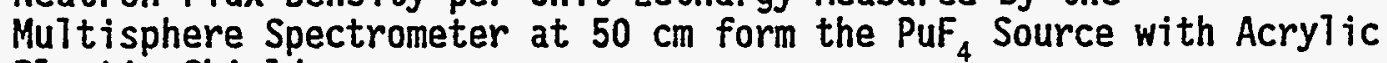
Plastic Shields ..................

A.2 Neutron Flux per Unit Lethargy Measured by the Multisphere Spectrometer at a.Distance of $50 \mathrm{~cm}$ and $100 \mathrm{~cm}$ from the Unshielded PuF ${ }_{4}$ Source .....................

A.3 Neutron Flux Density Measured by the Multi.sphere Spectrometer at $50 \mathrm{~cm}$ from the $\mathrm{PuF}_{4}, \mathrm{PuO}_{2}$, and Plutonium Metal Sources 


\section{TABLES}

2.1 Relationship Between Quality Factor and Lineal Energy

Transfer

2.2 Description of the Filtration Used in the Hanford Combination Neutron Dosimeter Component

2.3 Description of Filtration Used in the Hanford Combination Dosimeter Beta/Photon component

3.1 Summary of Verification Measurements at the PNL Cal ibration Laboratory ............... 3.3

4.1 Results of Neutron Measurements Performed on the PuF $_{4}$ Source at the Plutonium Finishing Plant

4.2 Summary of the Multisphere Spectrometer Measurements with the PuF $_{4}$ Source

4.3 Results of Neutron Measurements Taken at $50 \mathrm{~cm}$ from the $\mathrm{PuO}_{2}$ Source at the Plutonium Finishing Plant . . . . . . . 4.8

4.4 Summary of the MuTtisphere Spectrometer Measurements with the $\mathrm{PuO}_{2}$ Source ................... 4.8

4.5 Results of Neutron Measurements Taken at $50 \mathrm{~cm}$ from the P1utonium Metal Source

4.6 Summary of the Multisphere Spectrometer Measurements Taken at $50 \mathrm{~cm}$ from the Plutonium Metal Source ........

4.7 Dose-Equivalent Rates as a Function of Distance for Shielded Plutonium Sources ..................

4.8 Dose Equivalent Rates as a Function of Distance for Shielded Plutonium Sources with New Algorithm Applied to 8816 Dosimeter

4.9 Comparison Between Dosimeter Evaluation and Insturment Measurements

6.1 Summary of Neutron Survey Measurements at the Plutonium Finishing Plant to Determine the Range of Neutron Energies at Locations Where Horkers are Exposed . . . . . . 6.5

6.2 Dose Equivalent Rates from Multisphere and Tissue Equivalent Proportional Counter Measurements in the 2736-ZB Vaults . . . .

6.3 Results of the Dosimeter Exposures in the 2736-ZB Vaults . . . 6.12 
6.4 Results of the Dosimeter Exposures on the "Frontside" of

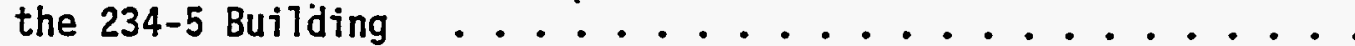

6.5 Results of the Hanford Combination Neutron Dosimeter Exposures on the "Backside" of the 234-5 Building ...........

A.1 Neutron Flux, Absorbed Dose, and Dose Equivalent Distributions Determined from Multisphere Spectrometer Measurements at $50 \mathrm{~cm}$ from the Bare $\mathrm{PuF}_{4}$ Source

A.2 Neutron Flux, Absorbed Dose, and Dose Equivalent Distributions Determined from Multisphere Spectrometer Measurements at $50 \mathrm{~cm}$ from the $\mathrm{PuF}_{4}$ Source with 1-in. Acrylic Plastic Shield

A.3 Neutron Flux, Absorbed Dose, and Dose Equivalent Distributions Determined from Multisphere Spectrometer Measurements at $50 \mathrm{~cm}$ from the $\mathrm{PuF}_{4}$ Source with 2-in. Acrylic Plastic Shield

A.4 Neutron Flux, Absorbed Dose, and Dose Equivalent Distributions Determined from Multisphere Spectrometer Measurements at $50 \mathrm{~cm}$ from the $\mathrm{PuF}_{4}$ Source, with 3-in. Acrylic Plastic Shield

A.5 Neutron Flux, Absorbed Dose, and Dose Equivalent Distributions Determined from Multisphere Spectrometer Measurements at $50 \mathrm{~cm}$ from the $\mathrm{PuF}_{4}$ Source with 4-in. Acrylic Plastic Shield

A.6 Neutron Flux, Absorbed Dose, and Dose Equivalent Distributions Determined from Multisphere Spectrometer Measurements at $100 \mathrm{~cm}$ from the Bare $\mathrm{PuF}_{4}$ Source

A.7 Neutron Flux, Absorbed Dose, and Dose Equivalent Distributions Determined from Multisphere Spectrometer Measurements at $100 \mathrm{~cm}$ from the $\mathrm{PuF}_{4}$ Source with 1-in. Acrylic Plastic Shield

A.8 Neutron Flux, Absorbed Dose, and Dose Equivalent Distributions Determined from Multisphere Spectrometer Measurements at $100 \mathrm{~cm}$ from the $\mathrm{PuF}_{4}$ Source with 2-in. Acrylic Plastic Shield

A.9 Neutron Flux, Absorbed Dose, and Dose Equivalent Distributions Determined from Multisphere Spectrometer Measurements at $100 \mathrm{~cm}$ from the $\mathrm{PuF}_{4}$ Source with 3-in. Acrylic Plastic Shield 
A.10 Neutron Flux, Absorbed Dose, and Dose Equivalent Distributions Determined from Multisphere Spectrometer Measurements at $100 \mathrm{~cm}$ from the $\mathrm{PuF}_{4}$ Source with 4-in. Acrylic Plastic Shield ...................... A

A.11 Neutron Flux, Absorbed Dose, and Dose Equivalent Distributions Determined from Multisphere Spectrometer Measurements at $50 \mathrm{~cm}$ from the Bare $\mathrm{PuO}_{2}$ Source . . . . . . . A.15

A.12 Neutron Flux, Absorbed Dose, and Dose Equivalent Distributions Determined from Multisphere Spectrometer Measurements at $50 \mathrm{~cm}$ from the Bare Plutonium Metàl Source 



\section{1:0 INTRODUCTION}

This study documents the performance of the Hanford Combination Neutron Dosimeter (HCND) in the low-scatter conditions of the Hanford Calibration Laboratory and in the high-scatter conditions of the Plutonium Finishing Plant (PFP). The HCND was accredited under the U.S. Department of Energy (DOE) Laboratory Accreditation Program (DOELAP) during 1994. The dosimeter was implemented for routine use on January 1, 1995, and provides the official dose of record for Hanford workers. Pacific Northwest National Laboratory (PNNL) $^{(a)}$ administers the Hanford External Dosimetry Project (HEDP) which provides dosimeter processing and technical support to Hanford contractor organizations. This study documents the accuracy of the HCND under actual work environments.

The HCND has three dosimetric components as follows:

- a beta/photon thermoluminescent dosimeter (TLD) component referred to as an 8825-TLD,

- a neutron TLD aTbedo component referred to as an 8816-TLD, and

- a neutron track-etch dosimetry (TED) component referred to as an 8816-TED.

The HCND consists of two dosimeters (i.e., 8825 and 8816) inserted into a single, Hanford-specific, plastic holder. The TED component consists of two CR-39 foils which are contained within the 8816 TLD holder. The specifics of the HCND design are provided in Section 2.0 of this report. The HCNDs are provided to Hanford contractor dosimetry staff for assignment to their workers. Dosimeters are returned to HEDP staff for processing, dose calculation, and reporting.

(a) The Pacific Northwest National Laboratory is operated for the U.S. Department of Energy by Battelle Memorial Institute under contract DEAC06-76RLO 1830. 
The objectives of this report include the following:

- evaluate and document the response characteristics of the HCND in laboratory and Hanford work environments,

- describe the process and data associated with development of the HCND dose algorithms, and

- provide a technical basis for the use of the HCND to assess dose for Hanford workers

The PFP provides (currently and historically) the vast majority of personne] neutron dose at Hanford. Several locations within the PFP were selected to evaluate radiation fields with a variety of neutron spectra and dose measuring instruments, including a multisphere spectrometer, tissue equivalent proportional counters (TEPCS), and specially calibrated rem meters. The dose equivalent rates from plutonium tetraflouride, plutonium oxide, and plutonium metal sources were measured under various shielding configurations using these instruments. Results from the instrument measurements were compared to the measured dose with the HCND 8825-TLD beta/photon, 8816-TLD neutron, and 8816-TED neutron dosimeter components. Dosimeters were mounted on acrylic plastic phantoms to simulate the effect of a person wearing the dosimeter. Measurements were also performed with various thicknesses of acrylic plastic to simulate the effect of shielding materials on the dosimeter response.

\subsection{SOURCES AND CALIBRATION FACTORS}

Radiation sources used for calibrating Hanford personnel dosimeters are traceable to National Institute of Standards and Technology (NIST) standards. For the HCND, primary calibration is routinely based on:

- on-phantom ${ }^{137}$ Cs irradiations for the deep-dose equivalent photon component, and

- on-phantom ${ }^{252} \mathrm{Cf}$ irradiations for the fast-neutron component. 
The HCND shallow and deep dose algorithms for beta and photon radiation incorporate response factors determined from dosimeter irradiations to selected $\mathrm{K}$-fluorescent and filtered $\mathrm{x}$-ray techniques, beta sources, and gamma sources. In general, dose factors determined from the respective NIST traceable calibration sources are used directly to determine dose in Hanford work environments, without any modification for field conditions, with the exception of neutron dose. For neutron dose, two dose formulations are used. The standard calibration is based on dosimeter response data determined from a NIST traceable ${ }^{252} \mathrm{Cf}$ source. These irradiations are performed in the Hanford Calibration Laboratory. A Hanford-specific plutonium environment calibration is based on dosimeter irradiations at the PFP using plutonium sources.

\subsection{NEUTRON MEASUREMENTS}

The most significant source of personnel neutron dose at Hanford involves activities associated with the handling and storage of plutonium. Three plutonium sources were used for the measurements described in this report: a sealed plutonium tetraflouride $\left(\mathrm{PuF}_{4}\right)$ source, a plutonium oxide $\left(\mathrm{PuO}_{2}\right)$ source, and a plutonium metal source. These sources are typical of the plutonium handled at Hanford. The sources are described in more detail in Section 3.3 of a report by Brackenbush, Baumgartner, and Fix (1991).

The PuF $_{4}$ source is of special interest. It was used as the calibration source for Hanford neutron dosimeters from 1958 until August 14, 1981, when it was replaced by a ${ }^{252} \mathrm{Cf}$ source. A significant contribution to personne] neutron dose at Hanford was the result of processing $\mathrm{PuF}_{4}$, which is an intermediate step in the purification of plutonium. Alpha particles from plutonium interact with fluorine to produce neutrons, thus increasing the neutron yield by a factor of 100 or more.

Laboratory measurements of the neutron energy spectra have been made on similar plutonium sources, as presented in BNHL-1262, Neutron Spectra of P7utonium Compounds, Part 1: ${ }^{3} \mathrm{He}$ and ${ }^{6} \mathrm{Li}$ Spectrometer Measurements (Brackenbush and Faust 1970). The results of these measurements are shown in Figure 1.1, which gives the fast neutron energy spectrum for sources of $\mathrm{PuF}_{4}$ (average energy 1.4 MeV), $\mathrm{PuO}_{2}$ (average energy $2.0 \mathrm{MeV}$ ), and plutonium metal (average energy $2.0 \mathrm{MeV}$ ). These measurements were made under carefulty 
controlled conditions in the laboratory and provide the energy spectra from a bare source (i.e., no scatter from shielding or within the room was measured).

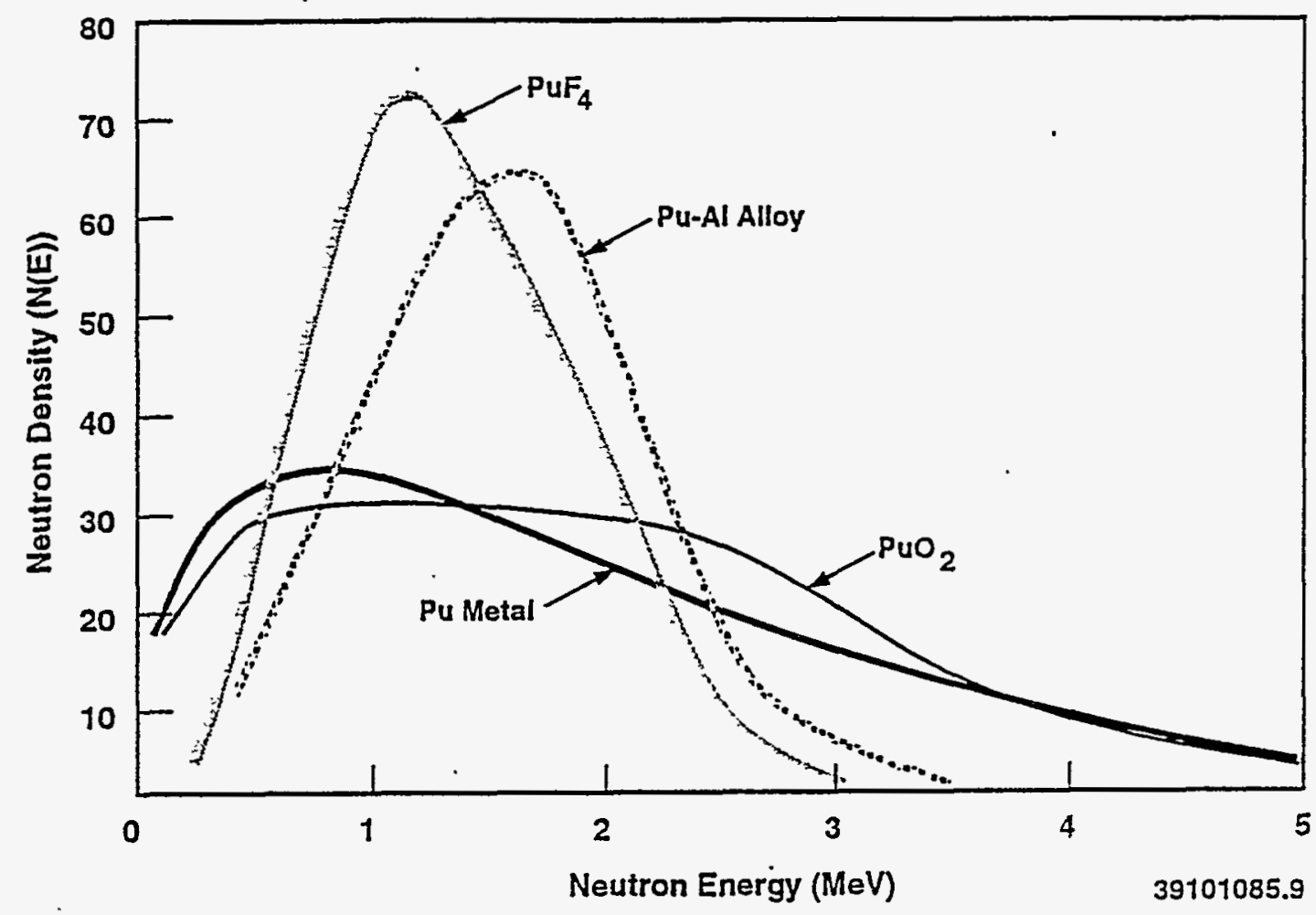

FIGURE 1.1 Laboratory Measured Neutron Energy Spectra for $\mathrm{PuF}_{4}, \mathrm{PuO}_{2}$, and Plutonium Metal Sources (Brackenbush and Faust 1970)

However, these spectra are not typical of neutron energy spectra in the workplace, where the plutonium is processed in glove boxes. Shielding provided by glove boxes, concrete walls and floors, and process equipment results in a significant fraction of neutrons being scattered to lower energies. This results in significant dosimetry effects. For example, a TLDalbedo neutron dosimeter is 100 times more sensitive to these low-energy neutrons than to $1-\mathrm{MeV}$ neutrons, so these low-energy scattered neutrons are very important to the dosimeter response. Although low-energy scattered neutrons contribute very little to personnel dose, they often dominate the response of the TLD-aTbedo dosimeter. 


\subsection{RADIATION PROTECTION STANDARDS}

These measurements demonstrate compliance with existing radiation protection standards and provide data which wi11 be of interest for future changes. In "Federal Radiation Protection Guidance to Federal Agencies for Occupational Exposure" (52 FR 2822-2834), the President has accepted the Environmenta1 Protection Agency (EPA) guidance that Federal agencies adopt the methodology of the International Commission on Radiological Protection (ICRP) Pub7ication 26 (ICRP 1977) for determining effective dose equivalent. This guidance provides a mechanism for adding internal and external dose, but does not explicitly deal with determination of effective dose equivalent from externa1 sources. The ICRP Publication 51, Data for Use in Protection Against External Radiation (ICRP 1987), provides some guidance and dose conversion factors which can be used to determine effective dose equivalent for external radiations. The DOE has traditionally followed the recommendations of the ICRP and the National Council on Radiation Protection and Measurements (NCRP) (1971) to calculate personnel dose equivalent. Currently, neutron dosimetry practices must comply with the requirements of Occupational Radiation Protection, Title 10 of the Code of Federal Regulations, Part 835 (1993) that regulates $D O E$ and its contractors. The quality factors and conversion coefficients contained in Part 835, paragraph 835.2 of Subpart A, are identical to those found in Table 2 in NCRP Report 38 (1971) and are flux-todose equivalent conversion factors, not the conversion coefficients for effective dose equivalence found in ICRP Publication 26 (1977) or ICRP Publication 51 (1987).

Field neutron spectra and dose measurements are critically important to the technical basis for personnel neutron dose because of the following:

- increased accuracy is achieved using field calibration factors based on dose measurements, and

- dose and spectral measurements provide a basis for recalculation of dosimetric quantities for future changes in radiation protection standards. 
Increased accuracy can be achieved by field calibration of personnel dosimeters and instruments. Neutron dosimeters are typically calibrated in. the laboratory under carefully controlled conditions. However, the neutron energy spectrum and irradiation geometry in the workplace are usually quite different than those in the calibration laboratory. A correction factor must be applied to account for these differences. Correction factors specific to actual work locations are determined by irradiating dosimeters on a phantom at locations where the neutron dose has been determined from spectral measurements.

\subsection{STRUCTURE OF THIS REPORT}

Section 2.0 describes the instrumentation used to obtain exposure estimates. Laboratory measurements are described in Section 3.0 and workplace measurements in Section 4.0. Section 5.0 describes the development of algorithms to be used with the HCND. Additional field measurements conducted to validate and refine the HCND algorithms in PFP work environments are presented in Section 6.0 . 


\section{$\cdot 2.0$ INSTRUMENTATION}

This section describes the instruments and dosimeters used to perform the spectrai measurements and dose equivalent evaluations. The instruments and dosimeters used in the current measurements include the following:

- multisphere or Bonner sphere spectrometers, which provide low-resolution neutron energy spectra covering an energy range of thermal to $20 \mathrm{MeV}$

- tissue equivalent proportional counters (TEPCS) to measure the lineal energy transfer (LET), so that quality factors and dose equivalence.can be calculated from their definitions

- a microrem meter to measure low-level gamma dose equivalent rates

- personnel neutron dosimeters, including the TLD albedo and CR-39 foil components of the HCND.

The following sections briefly describe the instrumentation, dosimeter design, and concepts used in these measurements (see PNL-7881, Section 2, for detailed information on the TEPC and multisphere theory and application [Brackenbush, Baumgartner, and Fix 1991]).

\subsection{MULTISPHERE SPECTROMETER}

This section of the report discusses the multisphere spectrometer used to determine the neutron energy spectrum and determine the correct neutron dose equivalent rate in the office areas of the 234-5 Building. The construction of the spectrometer and method of spectral unfolding is reviewed. If more detailed information is required, see Appendix B of PNL-7881 (Brackenbush, Baumgartner, and Fix 1991).

The multisphere or Bonner sphere spectrometer (Bramblett, Ewing, and Bonner 1960) is the neutron spectrometer system most often used by health physicists for neutron energy spectrum measurements. Multisphere spectrometers are typically used for measuring neutron energy spectra over a wide energy range from thermal energies to over $20 \mathrm{MeV}$, al though detailed energy spectra are not obtained. With the use of an appropriate spectrum unfolding code, the multisphere system will determine the average neutron energy, dose equivalent rate, total flux, and kerma and provide graphical

\section{1}


plots of 1) differential flux versus energy and 2) dose equivalent distribution versus energy.

The multisphere spectrometer system includes a set of five polyethylene spheres with holes drilled to the center for placement of a slow neutron detector. The polyethylene spheres have $7.6-\mathrm{cm}(3-\mathrm{in}),. 12.7-\mathrm{cm}(5-\mathrm{in}$.$) ,$ 20.3-cm (8-in.), 25.4-cm (10-in.), and 30.5-cm (12-in.) diameters. The 3-in. and 5-in. diameter spheres are covered with 30 mils $(0.08 \mathrm{~cm})$ of cadmium to help suppress the slow neutron response and improve the energy response above the cadmium cutoff $(0.4 \mathrm{eV})$. The detector used in the PNNL system is a cylindrical ${ }^{6} \mathrm{Li}(\mathrm{Eu})$ scintillation crystal, $1.27 \mathrm{~cm}(0.5 \mathrm{in}$.$) in diameter by$ $1.27 \mathrm{~cm}$ ( 0.5 in.) high, optically coupled to a photomultiplier tube by a $20.3 \mathrm{~cm}$ ( 8 in.) long light pipe. The detector and light pipe are hermetically sealed into an aluminum tube with $0.16 \mathrm{~cm}(0.063$ in.) thick wal7s. The detector is based on a Lawrence Livermore National Laboratory design and is available commercially.

Data for the neutron energy spectrum analysis are obtained by taking counts with 1) a bare, unshielded scintillation crystal, 2) the detector covered by a $0.051 \mathrm{~cm}$ ( 0.020 in.) thick cadmium sleeve, and 3) the detector in the center of the five diameter polyethylene spheres. The output from the scintillator detector is recorded by a multichannel analyzer, and files are transferred to a personal computer for permanent data storage. A region of interest is set up for the peak resulting from the absorption of slow neutrons by the ${ }^{6} \mathrm{Li}(n, \alpha)^{3} \mathrm{H}$ reaction. The net areas per unit time (i.e., the count rates) are used as input to spectral unfolding codes.

A simplistic explanation of how the spectrometer functions is that the smaller spheres detect lower-energy neutrons, and the larger spheres moderate and then detect higher-energy neutrons. For example, thermal neutrons are readily detected with the bare detector, and almost every thermal neutron entering the bare lithium iodide detector produces a count. When the lithium iodide scintillator is placed at the center of the $30.5-\mathrm{cm}$ (12-in.) diameter sphere, almost every thermal neutron is absorbed before reaching the center of the sphere. Likewise, if a $10 \mathrm{MeV}$ neutron strikes the bare lithium iodide crystal, very few counts are produced because the cross-section for the ${ }^{6} \mathrm{Li}(n, \alpha)$ reaction is very small, typically over a thousand times less than the 
cross-section for thermal neutrons. However, in the center of the 12-in. diameter sphere of polyethylene, there is sufficient moderator to thermalize a large fraction of incident $10-\mathrm{MeV}$ neutrons.

One of the primary drawbacks of the multisphere spectrometer is the mathematical problem of unfolding the neutron energy spectrum. Typically, seven detector/moderator combinations are used to determine the neutron energy spectrum in 26 logarithmically spaced energy bins covering the entire energy range from thermal to $20 \mathrm{MeV}$. This is a mathematically undefined problem, and an infinite number of coupled solutions is possible. Thus, a mathematically unique solution is not possible. However, it is possible to determine a physically meaningful solution with non-negative fluxes, continuous derivatives, and proper smoothing.

The basic equation for this unfolding problem is as follows:

$$
C_{k}=\sum_{i=1}^{n} \varphi_{i} R_{i k}
$$

where $c_{k}=$ the count rate for the $k_{t h}$ detector/moderator configuration

$\varphi_{i}=$ the neutron flux in the $i_{\text {th }}$ energy bin

$R_{i k}=$ the response function value relating the $k_{t h}$ detector to the flux in the $i_{\text {th }}$ energy bin

$n=$ number of energy bins.

Equation (2.1) must be solved for all seven detector/moderator configurations. This group of seven equations is known as the discrete form of the Fredholm Integral Equation of the First Kind. A number of mathematical techniques can be used to solve these equations. Iterative least squares techniques are used by the LOUHI code (Routi and Sandberg 1978), and iterative perturbation is used by the YOGI code (Johnson and Gorbics 1981).

A new type of method for solving the Fredholm Equation was suggested by Doroshenko et al. (1977), based on information theory and statistics to give the "most probable solution." This algorithm is based on an iterative technique using the following equation: 


$$
\varphi_{i, 1+1}=\frac{\varphi_{1,1}}{\sum_{j=1}^{m} R_{i j}} \sum_{k=1}^{m} R_{i k} \frac{C_{k}}{N_{k, 1}}
$$

where $m=$ the number of detector/moderator configurations

$C_{k}=$ the measured count rates

$N_{k, 1}=$ the recalculated count rates for the 1th iteration found by the following equation:

$$
\mathrm{N}_{k, 1}=\sum_{i=1}^{\mathrm{n}} \varphi_{i+1} R_{i k}
$$

$\varphi_{i}=$ the neutron flux in the $i_{\text {th }}$ energy bin

$R_{i k}=$ the response function value relating the $k_{\text {th }}$ detector to the flux in the $i_{\text {th }}$ energy bin.

The algorithm of Doroshenko has been incorporated into a code called SPUNIT (Brackenbush and Scherpelz 1984). SPUNIT has been thoroughty tested and gives results essentially in agreement with the least-squares code LOUHI. However, SPUNIT is hundreds of times faster and has been implemented on personal computers.

Testing of the code revealed that accurate differential spectra cannot always be obtained, but that integral quantities (total fluence and dose equivalent) are usually quite accurate. The resolution at higher energies is I imited because of the wide bin structure. (SPUNIT uses the logarithmic bin structure of YOGI; for example, for bin number 22, the average energy is $1.29 \mathrm{MeV}$ and the bin width is $0.92 \mathrm{MeV}$.) Thus, the average energy is useful only as a general indicator because a few counts difference at higher energies produce wide variations in the average energy. Also, there is no mathematically unique, physically correct solution. Solutions to the Fredholm. Integra] Equation tend to follow the initial guess used in the unfolding algorithm, unless some sort of smoothing is used. From a prior knowledge about the neutron source, it is often possible to make a good initial guess, and the code 
then produces physically meaningful spectra. For instance, a good guess for the initial spectra for plutonium sources surrounded by a small amount of moderator is a fission spectrum with a $1 / E$ "tail" extending to low energies.

Thus, the multisphere spectrometer data must be viewed as providing estimates of the differential energy spectra because the detectors used do not have good energy resolution in the intermediate neutron energy region below $100 \mathrm{keV}$. Large differences in the neutron flux distribution with energy produce only small changes in the count rates from each of the detectors. However, the total flux and dose equivalents are usually accurate because intermediate energy neutrons typically contribute little to the total number of neutrons or to the dose equivalent: The portions. of the spectrum (above $100 \mathrm{keV}$ ) that contribute the most to dose equivalent are determined more accurately.

\subsection{TISSUE EQUTVALENT PROPORTIONAL COUNTERS.}

Tissue equivalent proportional counters provide an absolute measurement of absorbed dose in a tissue-like material. With appropriate argorithms, TEPCs also provide an estimate of LET distributions and quality factors. Thus, a single TEPC measurement can provide an estimate of dose equivalent. For fission energies, existing algorithms for determining quality factors from absorbed dose distributions measured by the TEPC are reasonably accurate. For example, when a TEPC is exposed to a NIST-calibrated neutron source, the dose equivalent determined from the TEPC is usual1y within about $10 \%$ of the dose equivalent value calculated from the neutron flux and neutron fluence-to-dose-equivalent conversion factors recommended by NIST (Schwartz and Eisenhauer 1982).

Few health physicists are familiar with the microdosimetric concepts used in analyzing data from TEPCs. A complete explanation of the terminology is given in ICRU Publication 36, Microdosimetry (ICRU 1983).

The TEPC consists of a hollow sphere of tissue equivalent (TE) plastic filled with TE gas. Exact compositions of the TE plastic walls and fill gas can be found in Appendix C of ICRU Publication 36 (ICRU 1983). The pressure of the TE gas is adjusted so that the sphere of TE gas has the same mass 
stopping power as a sphere of solid tissue a few micrometers in diameter. For. example, the spherical TEPC used in the PFP measurements had an internal diameter of $127 \mathrm{~mm}$ ( $5 \mathrm{in.}$ ) and was filled with a methane-based TE gas at.a pressure of 11.3 torr (a near vacuum). The TE gas has the same stopping power as a 2- $\mu \mathrm{m}$ sphere of solid tissue.

Neutrons and other radiations interact with the TE plastic walls to produce secondary charged particles, which deposit energy in the sphere of TE gas and create ions. The TE gas is the active volume of a proportional counter, which produces a putse proportional to the number of ions or the energy deposition. For neutrons with energies below about $20 \mathrm{MeV}$, electronic equilibrium exists, and the ionization in the gas cavity provides an absolute measurement of absorbed dose. Because the composition of the walls and gas are tissue equivalent, the energy deposition measured in a known mass of TE gas provides an absolute measurement of absorbed dose in tissue.

Unlike most neutron dosimeters, it is not necessary to calibrate the TEPC to a NIST-standard neutron source, but it is necessary to relate the pulse height from the TEPC to energy deposition. This can be accomplished by at least two methods. The first is to use an internal alpha source of known energy. (and known LET) to calculate the energy deposited in the counter. The second is to use the characteristic "proton edge" or "proton drop point," which is produced when the TEPC is exposed to neutron sources. From a simplistic point of view, the energy deposited in the TE counter is the product of the LET of the proton recoil times the path length. The maximum energy deposition possible in the gas cavity is the product of the maximum LET (the Bragg peak of the proton) times the diameter of the sphere. This maximum energy deposition for a proton recoil corresponds to an "edge" or discontinuity in the energy deposition spectrum at a 7 ineal energy of 147 $\mathrm{keV} / \mathrm{\mu m}$ for methane-based TE gas.

Figure 2.1 shows a typical energy deposition spectrum measured by a TEPC exposed to gamma rays from a ${ }^{60} \mathrm{Co}$ source and $1.3-\mathrm{MeV}$ neutrons produced by an accelerator. It is easy to differentiate gamma rays from neutrons because gamma rays can deposit only a limited amount of energy (event sizes of $10 \mathrm{keV} / \mathrm{\mu m}$ or lineal energies of $15 \mathrm{keV} / \mu \mathrm{m})$. The dose distribution is easity calculated from the pulse-height data recorded from the TEPC. For a given 
event size or lineal energy, the absorbed dose contribution is the number of pulses or events multiplied by the size of the event. The total absorbed dose can be found by summing each contribution over the appropriate event sizes or lineal energies.

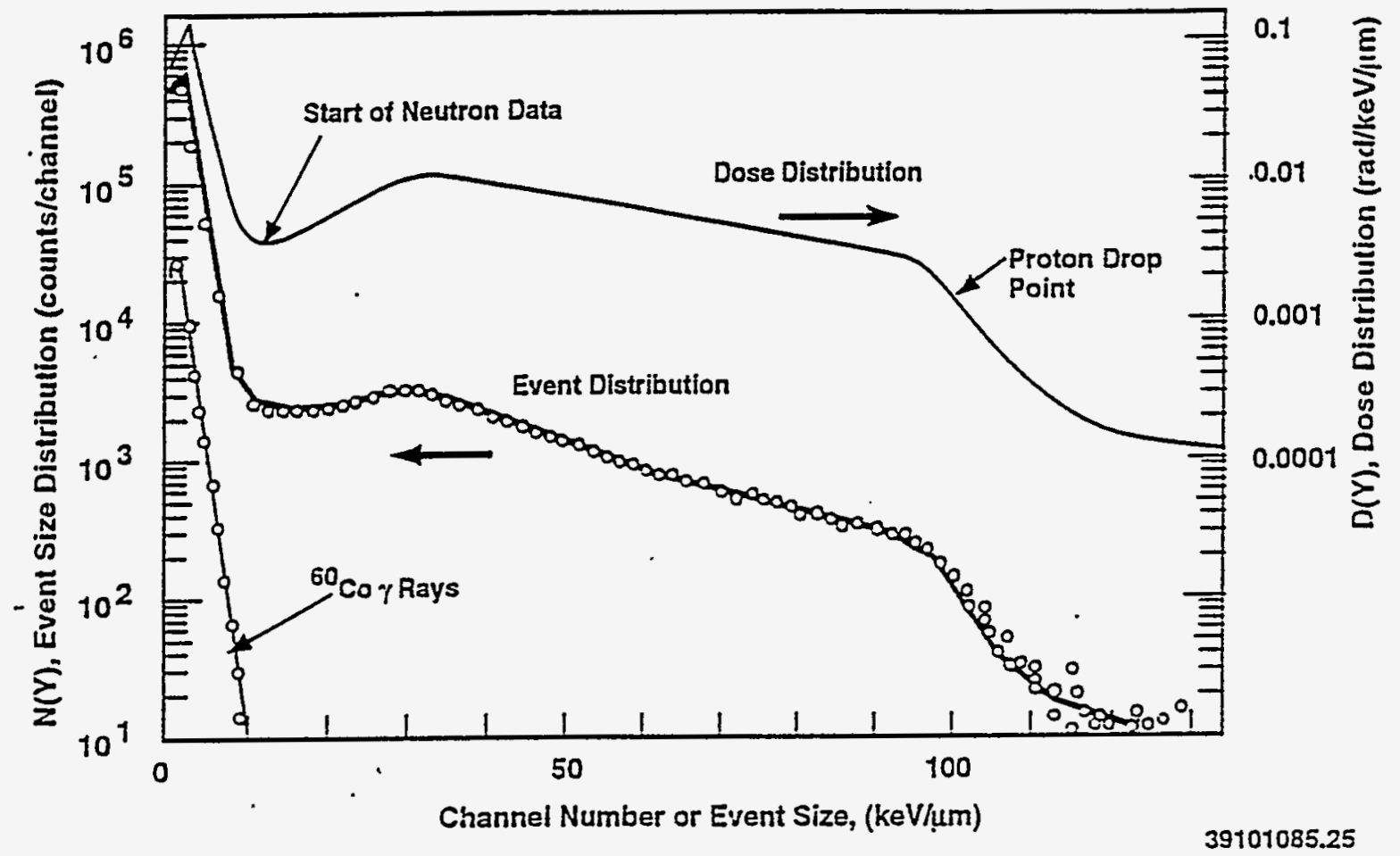

FIGURE 2.1 Typical Spectrum Recorded from a TEPC Operated with a 2- $\mu$ m Equivalent Diameter Exposed to Neutrons and Gamma Rays

The absorbed neutron dose (D) can be found from Equation (2.4):

$$
D=\left(\frac{c}{m}\right) \sum N(E) E
$$

where $m=$ mass of gas in the cavity (the product of the volume times the gas density)

$c=$ constant of proportionality relating the energy deposition to the event size or channel number

$N(E)=$ number of events of energy $E$ measured by the TEPC 


$$
\begin{aligned}
& E=\text { energy deposited in terms of the channel number in a } \\
& \text { multichannel analyzer. }
\end{aligned}
$$

The most difficult problem in analyzing the data from a TEPC measurement is converting absorbed dose distributions to LET distributions, so that quality factors can be determined. At the present time in the United States, quality factors are defined as a function of LET (NCRP 1971, DOE 1994). The definition of this relationship is given in Table 2.1.

TABLE 2.1 Relationship Between Quality Factor and Lineal Energy Transfer

\begin{tabular}{|c|c|}
\hline Quality Factor & $\begin{array}{c}\text { Lineal Energy Transfer } \\
(\mathrm{keV} / \mathrm{\mu m})\end{array}$ \\
\hline 1 & $<3.5$ \\
\hline 2 & 7 \\
\hline 5 & 23 \\
\hline 10 & 53 \\
\hline 20 & $>175$ \\
\hline
\end{tabular}

Tissue equivalent proportional counters measure lineal energy, i.e., the energy deposited in the site (gas cavity) divided by the mean chord length of the site. For spherical proportional counters, the mean chord length is twothirds of the diameter. For these counters, the theoretical basis for algorithms relating lineal energy (measured by the TEPC) to LET (required for quality factors) was developed 25 years ago by Albrecht Kellerer (1969):

$$
\overline{\mathrm{L}_{D}}=\left(\frac{8}{9}\right) \overline{Y_{D}}
$$

where $\overline{I_{D}}$ is the dose mean LET and $\overline{Y_{D}}$ is the dose mean of the event.spectrum measured by the TEPC (i.e., the average lineal energy or first moment of the dose distribution), so that 


$$
\overline{y_{D}} \equiv \frac{\int y D(y) d y}{\int D(y) d y}
$$

Because of the linear and additive relationship, this relationship is true for al1 values of $L$ to determine a quality factor value for each channel number or event size.

The quality factor for each channel number is found by using the above equation to convert from lineal energy to LET, then linearly interpreting the quality-factor/LET relationship given in Table 2.1. The dose equivalent is then found by summing over all channels or LETs of interest:

$$
H=\Sigma Q(L) D(L)
$$

where $H=$ the dose equivalent

$Q(L)=$ the quality factor interpolated for this channel

$D(L)=$ the differential absorbed dose distribution as a function of LET.

This dose equivalent is determined at a depth corresponding to the wall thickness of the TEPC and is more closely related to ambient dose equivalent than to the effective dose equivalent currently used in dosimetry at DOE sites. For fission neutrons, however, the dose equivalent measured by the TEPC is a good estimation of dose equivalent.

\subsection{PERSONNEL NEUTRON DOSIMETERS}

This section describes two types of personnel dosimeters used at Hanford, TLD-albedo dosimeters and electrochemically etched CR-39 foils, and the energy ranges over which these dosimeters can be used.

\subsubsection{ILD-Albedo Dosimeters}

The TLD-albedo dosimeter is the most widely used personnel neutron dosimeter in DOE facilities. This dosimeter employs a slow neutron detector worn on the surface of the body. Fast neutrons strike the body and are moderated and reflected, and then return to the surface, where they are detected by 
the TLDs. . Because the neutrons are reflected back from the body, the dosimeter is also called "albedo."

A TLD-albedo dosimeter typically includes TLDs containing ${ }^{6} \mathrm{LiF}$ chips. The isotope ${ }^{6} \mathrm{Li}$ absorbs a neutron and creates an alpha particle and a triton, which deposit energy in the TLD. When the TLD is heated, it emits light in proportion to the radiation dose deposited by the neutron-induced events.

The cross-section for the ${ }^{6} \mathrm{Li}(\mathrm{n}, \alpha)^{3} \mathrm{H}$ reaction is inversely proportional to the velocity or the square root of the energy of the neutron absorbed in the reaction. Thus, the TLD chip is very sensitive to thermal neutrons, where the cross-section is about 941 barns. However, the bare TLD is very insensitive to fast neutrons, where the cross-section is less than 1 barn.

The energy sensitivity is reduced by placing the TLD in a dosimeter on the surface of the body (or on a phantom) where many thermal neutrons are produced by the hydrogenous moderator. The TLD chip usually has a cadmium cover on the front side (away from the body) to reduce its sensitivity to incident thermal neutrons. Thus, the TLD chip primarily responds to thermal neutrons moderated and reflected back from the body. This is why they are called TLD-albedo dosimeters, from the reflected or albedo neutrons. However, the TLD-albedo dosimeter is also sensitive to the energy of the incident neutrons, as shown in Figure 2.2. This figure shows the relative response of three different types of TLD-albedo dosimeters as a function of the energy of the incident neutron. A simplified explanation of the energy dependence is that low-energy neutrons enter the body and are easily thermalized and reflected back to the surface, where they are detected by the TLD crystal. High-energy neutrons, however, must penetrate deep into the body before becoming thermalized, and relatively few are able to diffuse back to the TLD crystal to be detected. Most of these neutrons are absorbed in the body before reaching the surface and the TLD chip. This is the reason for the pronounced energy sensitivity of the TLD-albedo dosimeter. A more detailed explanation of TLD-albedo dosimeters can be found in Appendix B of Personal Neutron Dosimetry at Department of Energy Facilities, PNL-3213 (Brackenbush et al. 1980). 


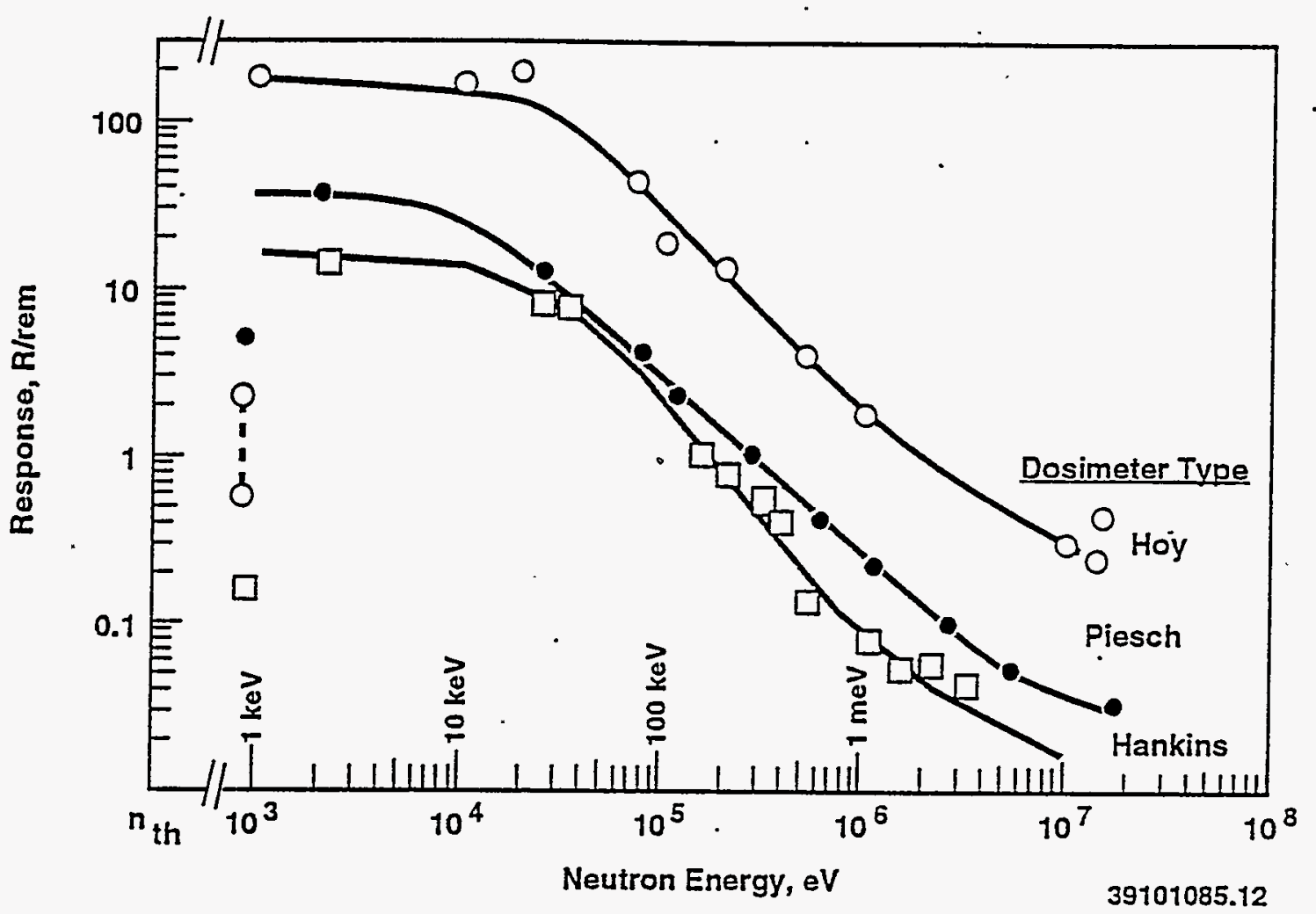

FIGURE 2.2 Energy Dependence of Various TLD-Albedo Dosimeters (Source: Piesch and Burgkhardt 1978)

Most TLD-albedo dosimeters are calibrated under low-scatter conditions to fission spectra from ${ }^{252} \mathrm{Cf}$ neutron sources or $\mathrm{PuF}_{4}$ sources (see Brackenbush et. a7. 1980, page 17). These sources have neutron energy spectra typical of that encountered in the workplace when the workers handle plutonium or plutonium compounds. An example of the neutron energy spectra emitted by plutonium and its compounds is presented in Figure 1.1. The average neutron energy for plutonium metal and oxide is about $2 \mathrm{MeV}$; the average neutron energy for $\mathrm{PuF}_{4}$ is $1.4 \mathrm{MeV}$. It is traditional to calibrate TLD-albedo dosimeters to the "harder" or higher-energy spectra encountered when directly handling plutonium.

When massive amounts of neutron shielding are added, however, the spectrum of neutrons changes. In a typical water-wall shield, $30 \mathrm{~cm}$ (12 in.) thick, the neutron dose rates adjacent to the wall are reduced by over an order of magnitude, but significant neutron dose rates still exist at some 
distance from the shield because neutrons can scatter up and over the water wal1. In general, about half of the neutrons that strike a thick concrete floor or ceiling are reflected back. The energy of these neutrons is much lower, typically with average energies of hundreds of keV. These lower-energy neutrons produce a much higher response per unit dose equivalent, as is evident from Figure 2.1. A typical TLD-albedo dosimeter calibrated to a "hard" or higher-energy spectrum will overestimate dose equivalent when exposed to the very "soft" or lower-energy spectrum typical of heavily shielded sources. The TLD-albedo dosimeter must be carefully calibrated to the actual spectrum in which it is-used. Achieving this involves measuring the neutron energy spectrum and making appropriate corrections or actually exposing the dosimeter to known doses in workplace spectra.

\subsubsection{CR-39 Nuclear Track Dosimeters}

The HCND contains two TLD cards (8816 and 8825) each of which contains four LiF phosphors. One type of LiF phosphor, TLD-600, is isotopica77y enriched to a maximum of $95 \%{ }^{6} \mathrm{Li}$ to provide a high relative response to neutron radiation. The second type of Li phosphor, TLD-700, is isotopically enriched to about $99.993 \%{ }^{7} \mathrm{Li}$ to provide a very low relative response to neutron radiation. Both phosphors have nearly identical response to gamma rays. Filter materials are used on the dosimeter holders to modify the phosphor response for different energies of neutron radiation. Tables 2.2 and 2.3 provide details of the filter materials and dimensions of card position for each phosphor used in the 8816 and 8825 components of the HCND. P7acement of these phospohors is illustrated in Figure 2.3, where the left holder is the albedo neutron 8816 TLD and TED holder and the right holder is the beta-photon 8825 TLD.

The foils are placed, one on top of the other, above the TLD card in the neutron holder with the top side facing towards the front as illustrated in Figure 2.3. Foils are made from clear CR-39 polycarbonate plastic with a thin polyethylene covering. They are approximately $28 \mathrm{~mm}(1.1 \mathrm{in.})$ long, $16 \mathrm{~mm}$ ( 0.6 in.) wide, and $0.64 \mathrm{~mm}(0.025 \mathrm{in.})$ thick. The polyethylene covering protects the CR-39 from alpha radiation exposure as well as providing a dense source of hydrogen atoms necessary for proton recoil. 


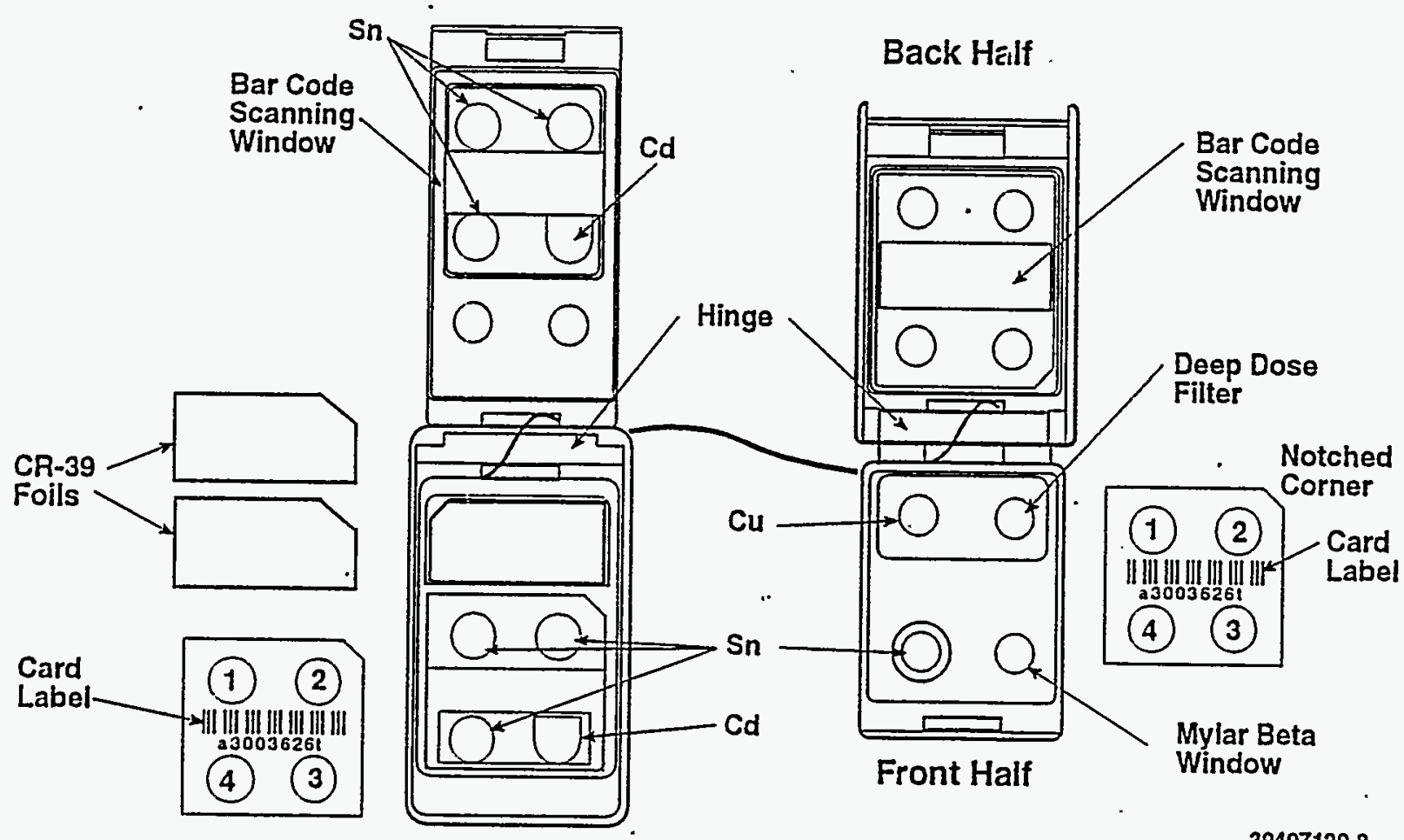

39407129.8

FIGURE 2.3 Hanford Combination Neutron Dosimeter Showing Neutron (left) and Beta/Photon (right) Dosimeter Components

The CR-39 foils in the HCND provide a technique independent from that of the TLD to calculate neutron dose. The CR-39 does not exhibit the severe energy dependence that exists with albedo neutron dosimeters and can provide good results when varied neutron energy spectra are encountered. The CR-39 plastic, with its dense, uniform molecular structure, is susceptible to radiation damage involving scission of the molecular chains. These damage sites produce tracks or "pits" that, when electrochemically etched, can be seen under a microscope. The formation of these tracks is primarity caused by hydrogen recoil with fast neutrons, but can also be caused by alpha particles, protons, and heavy charged particles. Beta and gamma radiations have a low enough LET that a track cannot form, making CR-39 insensitive to these radiation types. To prevent the alpha interaction, a layer of polyethylene covers both sides. 
TABLE 2.2 Description of the Filtration Used in the Hanford Combination Neutron Dosimeter Component

\begin{tabular}{|c|c|c|c|c|}
\hline \multirow{2}{*}{$\begin{array}{l}\text { Dosimeter } \\
\text { Position }\end{array}$} & \multirow{2}{*}{$\begin{array}{l}\text { Phosphor } \\
\text { Type }\end{array}$} & \multirow{2}{*}{$\begin{array}{l}\text { Thickness, mm } \\
\text { (mass density) }\end{array}$} & \multicolumn{2}{|c|}{ Total Holder Fjltration ${ }^{(0)}$} \\
\hline & & & Front & Back \\
\hline 1 & $\begin{array}{l}\text { TLD-700 } \\
.\end{array}$ & $\begin{array}{c}0.38 \\
\left(100 \mathrm{mg} / \mathrm{cm}^{2}\right)\end{array}$ & $\begin{array}{l}464 \mathrm{mg} / \mathrm{cm}^{2} \mathrm{sn} \text { plus } \\
80 \mathrm{mg} / \mathrm{cm}^{2} \text { ABS } \\
\text { plastic }\end{array}$ & $\begin{array}{l}464 \mathrm{mg} / \mathrm{cm}^{2} \text { Sn plus } \\
80 \mathrm{mg} / \mathrm{cm}^{2} \text { ABS } \\
\text { plastic }\end{array}$ \\
\hline 2 & TLD-600 & $\begin{array}{c}0.38 \\
\left(100 \mathrm{mg} / \mathrm{cm}^{2}\right)\end{array}$ & $\begin{array}{l}461 \mathrm{mg} / \mathrm{cm}^{2} \mathrm{Cd} \text { plus } \\
80 \mathrm{mg} / \mathrm{cm}^{2} \text { ABS } \\
\text { plastic }\end{array}$ & $\begin{array}{l}464 \mathrm{mg} / \mathrm{cm}^{2} \mathrm{Sn} \text { plus } \\
80 \mathrm{mg} / \mathrm{cm}^{2} \text { ABS } \\
\text { plastic }\end{array}$ \\
\hline 3 & TLD-600 & $\begin{array}{c}0.38 \\
\left(100 \mathrm{mg} / \mathrm{cm}^{2}\right)\end{array}$ & $\begin{array}{l}464 \mathrm{mg} / \mathrm{cm}^{2} \mathrm{sn} \text { plus } \\
80 \mathrm{mg} / \mathrm{cm}^{2} \text { ABS } \\
\text { plastic }\end{array}$ & $\begin{array}{l}461 \mathrm{mg} / \mathrm{cm}^{2} \text { Cd plus } \\
80 \mathrm{mg} / \mathrm{cm}^{2} \text { ABS } \\
\text { plastic }\end{array}$ \\
\hline 4 & TLD-600 & $\begin{array}{c}0.38 \\
\left(100 \mathrm{mg} / \mathrm{cm}^{2}\right)\end{array}$ & $\begin{array}{l}464 \mathrm{mg} / \mathrm{cm}^{2} \mathrm{Sn} \text { plus } \\
80 \mathrm{mg} / \mathrm{cm}^{2} \text { ABS } \\
\text { plastic }\end{array}$ & $\begin{array}{l}464 \mathrm{mg} / \mathrm{cm}^{2} \text { Sn plus } \\
80 \mathrm{mg} / \mathrm{cm}^{2} \text { ABS } \\
\text { plastic }\end{array}$ \\
\hline
\end{tabular}

TABLE 2.3 Description of Filtration Used in the Hanford Combination Dosimeter Beta/Photon Component

\begin{tabular}{|c|c|c|c|c|}
\hline \multirow{2}{*}{$\begin{array}{l}\text { Dosimeter } \\
\text { Position }\end{array}$} & \multirow{2}{*}{$\begin{array}{c}\text { Phosphor } \\
\text { Type }\end{array}$} & \multirow{2}{*}{$\begin{array}{l}\text { Thickness; mm } \\
\text { (mass density) }\end{array}$} & \multicolumn{2}{|c|}{ Total Holder Filtration ${ }^{(\omega)}$} \\
\hline & & & Front & Back \\
\hline 1 & TLD-700 & $\begin{array}{c}0.38 \\
\left(100 \mathrm{mg} / \mathrm{cm}^{2}\right)\end{array}$ & $\begin{array}{l}242 \mathrm{~cm}^{2} \text { ABS plastic } \\
\text { plus } 91 \mathrm{mg} / \mathrm{cm}^{2} \text { copper }\end{array}$ & $173 \mathrm{mg} / \mathrm{cm}^{2} \mathrm{ABS}$ \\
\hline 2 & TLD-700 & $\begin{array}{c}0.38 \\
\left(100 \mathrm{mg} / \mathrm{cm}^{2}\right) \\
\end{array}$ & $\begin{array}{l}1000 \mathrm{mg} / \mathrm{cm}^{2} \text { ABS and } \\
\text { PTFE plastic }\end{array}$ & $173 \mathrm{mg} / \mathrm{cm}^{2}$ ABS \\
\hline 3 & TLD́-700 & $\begin{array}{c}0.15 \\
\left(40 \mathrm{mg} / \mathrm{cm}^{2}\right)\end{array}$ & $\begin{array}{l}17 \mathrm{mg} / \mathrm{cm}^{2} \text { Teflon and } \\
\text { Mylar }\end{array}$ & $173 \mathrm{mg} / \mathrm{cm}^{2}$ ABS \\
\hline 4 & TLD-700 & $\begin{array}{c}0.38 \\
\left(100 \mathrm{mg} / \mathrm{cm}^{2}\right)\end{array}$ & $\begin{array}{l}240 \mathrm{mg} / \mathrm{cm}^{2} \text { ABS plastic } \\
\text { plus } 463 \mathrm{mg} / \mathrm{cm}^{2} \text { tin }\end{array}$ & $173 \mathrm{mg} / \mathrm{cm}^{2}$ ABS \\
\hline
\end{tabular}

\subsubsection{CR-39 Foils in Dosimeter Construction and Dismantling}

Sheets of CR-39 plastic are procured and Taser-cut to specified dimensions. A notch is cut in one corner to distinguish front from back. A unique five-digit number visible to the eye is etched on each Hanford foil to serve as identification.

Two CR-39 foils are placed in each neutron dosimeter holder before. issue. The foils are randomily selected from the available inventory which has previously been qualified for use. Upon receipt of the neutron dosimeter from 
the field for processing, the TLD card is removed and processed. The CR-39 foils remain in the holder until the TLD processing is complete. Based upon the TLD resuits, foils are selected for processing.

\subsubsection{Processing}

Processing of CR-39 foils is substantially more involved than for TLD cards. (a) Because of this, the CR-39 foils are processed only when the TLD neutron dose exceeds a special threshold level (at Hanford, this has ranged from 0.5 to $2 \mathrm{mSv}$ ), and the response of the TLD indicates neutron spectra of predominantly higher ( $>100 \mathrm{keV}$ ) energies. 'The CR-39 response becomes nonlinear at some point beyond $10 \mathrm{mSv}$ with the routine readout protocol. That is, routine processing uses a lower power microscope setting to count a relatively large area. For high doses, there is inadequate resolution to distinguish between tracks and a higher power is necessary for accurate readout. As such, care must be exercised at higher dose levels. If CR-39 is processed, the CR-39 dose will generally be used as the official neutron dose to be reported.

Processing is conducted with a batch of 24 individual foils. A batch contains a maximum of 20 field foils (i.e., 10 dosimeters). In addition, each batch includes two blank foils and two dosed (3-mSv) foils from which batch background and calibration factors are calculated. Once a batch of foils is loaded into the etching chamber, it undergoes an electrochemical etching process to enlarge the size of the tracks. During reading, each foil is read under a microscope to determine track counts (tracks per square centimeter). A11 foils in a batch are positioned on a tray, which is placed on the microscope's stage. The tray is read using an automated PC-based system. As part of the reading process, the calibration and background factors are calculated.

(a) Hanford procedures for processing CR-39 foils were developed from procedures described by $D$. E. Hankins et a1. (1989). Procedures implemented at PNNL are available in PNL-MA-843, TEDA User's Manual (PNNL internal document). 
The two dosed foils in each batch are used to determine a batch calibration factor that relates mrem to track count; the calibration factor will have units of $\mathrm{mrem} / \mathrm{tracks} / \mathrm{cm}^{2}$. The two blank foils will be used to determine a batch background factor having units of tracks $/ \mathrm{cm}^{2}$. Within the exposure range where CR-39 will be processed, the number of track counts is directly proportional to neutron dose received. The neutron dose in mrem is then calculated by averaging the two foil track counts, subtracting the background factor, and multiplying that result by the calibration factor. This assumes that calibration using a bare californium source is appropriate. However, if the ratio of selected phosphors in the Hanford Combination Neutron Dosimeter's TLD component is greater than a predetermined value, this indicates that bare californium is not an appropriate calibration source. If TLD ratios $R_{2} / R_{3}$ and $R_{4} / R_{3}$ are both greater than a predetermined boundary value, then the energy spectra of the incident neutrons are considered to be too thermalized for using the TED, where

$$
\begin{gathered}
R_{2} / R_{3}=\frac{(\text { adjusted chip } 2 \text {-adjusted chip 1) }}{\text { (adjusted chip 3-adjusted chip 1) }} \\
\text { and } \\
R_{4} / R_{3}=\frac{(\text { adjusted chip } 4 \text {-adjusted chip 1) }}{\text { (adjusted chip 3-adjusted chip 1) }}
\end{gathered}
$$

\subsubsection{Energy Response}

The Tower energy threshold of CR-39 is approximately $100 \mathrm{keV}$. For this reason, care must be exercised when using CR-39 in highly scattered neutron fields where lower-energy neutrons may be a significant component of the personnel dose. The PNNL measurements in the PFP work environments have shown significant under-response for TEDs in highly thermalized neutron fields.

\subsubsection{Dose Response}

Variation in dosimeter response as a function of the degradation of ${ }^{252} \mathrm{Cf}$ and $\mathrm{PuF}_{4}$ source irradiations was measured. Dosimeter and TEPC measurements were taken of the bare source irradiation and with one of several thicknesses of plastic inserted between the source and the dosimeter. These data confirm the excellent energy response characteristics of TED for higher energy neutrons. Excellent comparison was observed between the TED and TEPC data. 
However, once the source degradation became very extreme, such as in the very high-scatter work environments observed at the PFP, the TED began to underestimate significantly the TEPC measured dose. This is assumed to result from a significant fraction of the neutrons being lower than the energy threshold of about $100 \mathrm{keV}$.

\subsubsection{Lower Leve1 of Detection}

There is substantial variability in the low-dosed TEDs. The calculated lower level of detection (LLD), based on the ANSI N13.11 (ANSI 1983, rev. 1993) formulation, is about $0.4 \mathrm{mSv}$. Improved performance in TED data is expected for freshiy prepared CR-39 foils with a minimum of background signal.

\subsubsection{Sensitivity and Linearity}

The sensitivity of the CR-39 plastic is a function of tracks $/ \mathrm{cm}^{2}-\mathrm{mrem}$ and is calibrated against a known exposure to ${ }^{252} \mathrm{C} f$. Determination of sensitivity and linearity is quite complex, being a function of the etching and counting technique. The sensitivity (i.e., different number of tracks $/ \mathrm{cm}^{2}$ ) can be altered by changing either the etching time, temperature, or voltage. Linearity has been observed to about $10 \mathrm{~Sv}\left(4000 \mathrm{tracks} / \mathrm{cm}^{2}\right)$ with the existing Hanford dosimetry system, with a sensitivity of about $4 \mathrm{tracks} / \mathrm{cm}^{2}-\mathrm{mrem}$.

\subsubsection{Fading}

It has been shown that if CR-39 is exposed to ambient light and high temperatures $\left(>50^{\circ} \mathrm{C}\right)$ for prolonged periods, fading and a decrease in sensitivity result. When the foils are protected from light and excessive heat, little if any fading or change in sensitivity will occur.

\subsubsection{Environmenta] BuiTdup}

The CR-39 is relatively unaffected by environmental conditions. However, the background track density on the CR-39 foil will increase with time due to the environmental neutron background and cosmic ray interactions. As the background increases, so does the LLD. During the course of one year, the number of tracks $/ \mathrm{cm}^{2}$ is expected to increase by a factor of about 4 . 



\subsection{LABORATORY MEASUREMENTS}

Measurements were performed at the Hanford Calibration Laboratory in the 318 Building on the Hanford Site to verify the accuracy of the detectors used. These verification measurements were performed using bare and $\mathrm{D}_{2} \mathrm{O}$ moderated ${ }^{252} \mathrm{Cf}$ sources calibrated by NIST. Field measurements were performed at the PFP, using plutonium metal, $\mathrm{PuF}_{4}$, and $\mathrm{PuO}_{2}$ sources. Dosimeters were exposed to bare sources and to sources shielded by acrylic plastic slabs. Details of the facilities and the sources used are presented in. PNL-7881 (Brackenbush, Baumgartner, and Fix 1991), Section 3.0.

The tissue-equivalent proportional counters deteriorate due to outgassing of volatile impurities in the TE plastic walls. For this reason, it is a good idea to check the accuracy of the TEPC by measuring the dose rate from a calibrated neutron source before the field measurements are performed to assure that the TEPC is operating properly. Measurements were also made with the multisphere spectrometer to verify the accuracy of its operation. In addition, a $25.4-\mathrm{cm}(10-$ in.) diameter polyethylene sphere with a $1.3-\mathrm{cm}$ (0.5-in.) diameter ${ }^{6} \mathrm{LiI}(\mathrm{EU})$ scintillation detector was calibrated to correlate the delivered dose equivalent rate with the observed count rate in the slow neutron peak. The net peak area was determined using a logarithmic background subtraction technique (see Appendix B of PNL-788] [Brackenbush, Baumgartner, and Fix 1991]). This section describes these quality assurance measurements.

Pacific Northwest National Laboratory is the primary testing 1aboratory for personnel dosimeter testing under the direction of the NIST, as part of the National Voluntary Laboratory Accreditation Program. It maintains sets of calibrated ${ }^{252} \mathrm{Cf}$ neutron sources that are periodically calibrated for neutron yield and certified for accuracy by NIST. The procedures for calibration and testing are described in the document ANSI 13.11, American National Standard for Dosimetry, Personnel Dosimetry Performance - Criteria for Testing (ANSI 1993). These calibrated neutron sources were used to test the accuracy of the field neutron spectrometer.

Two different neutron sources were used for the measurements in the 318 Building Calibration Laboratory and the ESB Building because the dose rate from one source was too high for the multisphere spectrometer to function 
properly. Measurements were made with two different types of detectors: TEPCs and the multisphere detectors. These devices are absolute dosimeters in the sense that they do not require calibration in neutron fields with known dose equivalent rates. The TEPCs use an internal energy calibration (the proton edge or an internal alpha source). Because the TEPC measures the energy deposited in a known mass of tissue-like material, it directly determines absorbed neutron dose. Hith appropriate mathematical algorithms, it is also possible to determine quality factor and, hence, dose equivalent directly from first principles. The multisphere spectrometer also doès not require a calibrated neutron source. The calibration of the multisphere is built into the response. function, which is included in the spectrum-unfolding code SPUNIT for the 1.3-cm (0.5-in.) diameter by $1.3-\mathrm{cm}(0.5-i n$.$) long { }^{6} \mathrm{LiI}(\mathrm{Eu})$ scintil1ation crysta1. Thus, measurements with these detectors exposed to the NISTcalibrated sources are used only to verify the accuracy of the technique and computer codes used.

Before any measurements were made in the field, the accuracy of the detectors was checked using the NIST-calibrated sources in the 318 Building Calibration Laboratory. The TEPCs were placed on tripods at the centerline distances indicated and positioned at the same height as the source on the tower in the low-scatter room. The results of these measurements are shown in Table 3.1 for different TEPCs (13-cm [5-in.] diameter spherical counters, manufactured by Far West Technology, serial numbers 504 and 185) and one multisphere detector $\left(1.3 \mathrm{~cm}[0.5-i n\right.$.$] diameter { }^{6} \mathrm{Li}[\mathrm{Eu}]$ detector, manufactured by Harshaw Chemical Co., serial number PE322). The multisphere detector was calibrated at the ESB Building to the source ESB-CF1 because of its lower yield, which is low enough not to flood the detector. The Far West TEPC, number 185, was a last-minute substitute for another TEPC that was intended to be used for the measurements and was tested after the field measurements were completed with the bare californium source $318-167$, as indicated in Table 3.1.

The TEPCs numbers 504 and 185 were filled with methane-based TE gas at 11.3-torr pressure, which simulates a 2- $\mu \mathrm{m}$ diameter deposition site in tissue of unit density. 
The results given in Table 3.1 demonstrate that all of the detectors are accurate within $15 \%$ when exposed to the spontaneous fission energy spectrum from the ${ }^{252} \mathrm{Cf}$ neutron sources. In Table 3.1, the numbers in parentheses give the percent deviation from the delivered dose equivalent rate. The TEPCs numbers 504 and 185 used conventional NIM bin electronics with a Canberra Series 35 Plus multichannel analyzer.

TABLE 3.1 Summary of Verification Measurements at the Hanford Calibration Laboratory

\begin{tabular}{|c|c|c|c|c|c|}
\hline \multirow[b]{2}{*}{ Source } & \multirow[b]{2}{*}{ Distance. $\mathrm{cm}$} & \multirow{2}{*}{$\begin{array}{c}\text { Delivered Dose } \\
\text { Equivalent Rate. } \\
\mathrm{mSv} / \mathrm{h}\end{array}$} & \multicolumn{3}{|c|}{ Measured Dose Equivalent Rate, $\mathrm{mSv} / \mathrm{h}$} \\
\hline & & & TEPC 185 & TEPC 504 & Multisphere \\
\hline $318-167$ & 100 & 11.0 & $\begin{array}{c}10.53 \\
(-4.27 \%)^{(0)}\end{array}$ & -- & \\
\hline $318-167$ & 100 & 7.966 & $\begin{array}{c}7.76^{(b)} \\
(-2.58 \%)^{(0)}\end{array}$ & $\begin{array}{c}8.02^{(b)} \\
(+0.68 \%)^{(0)}\end{array}$ & -- \\
\hline ESB-CF1 & 100 & 0.118 & -- & - & $\begin{array}{c}0.108 \\
(-8.48 \%)^{(3)}\end{array}$ \\
\hline \multicolumn{6}{|c|}{$\begin{array}{l}\text { (a) Numbers in parentheses are percent deviation from delivered dose } \\
\text { equivalent rates. } \\
\text { (b) These calibration measurements were performed after the field } \\
\text { measurements were taken. }\end{array}$} \\
\hline
\end{tabular}




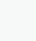

.

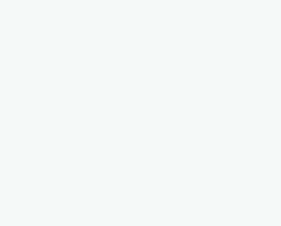

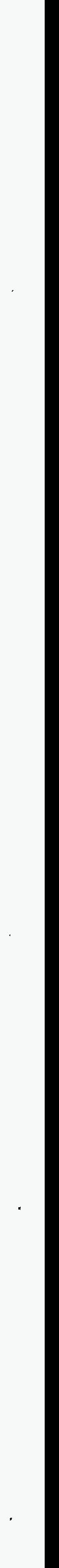




\subsection{HORKPLACE MEASUREMENTS}

This section of the report discusses the field measurements made with plutonium sources in the PFP under conditions typical of workplaces. Measure- . ments were performed in a room with concrete floors, walls, and ceiling representative of processing facilities at Hanford. Under these conditions, about half of the neutrons striking the floors will be scattered back into the room; this is typical of the "high-scatter" conditions found in the workplace. Because of their higher response to low-energy neutrons, TLD-aTbedo dosimeters will have a higher response per unit dose equivalent than under the lowscatter conditions found in calibration laboratories and, consequently, may overestimate dose equivalent. By exposing neutron dosimeters at locations where the dose equivalent has been determined using other devices (such as TEPCs or multisphere spectrometers), it is possible to determine the dosimeter response under these high-scatter conditions. This information allows field correction factors that account for spectral differences between the workplace and the calibration laboratory.

Note that the shielding and scatter conditions are sometimes of greater importance than the initial energy spectrum of neutrons emitted from the source. To be conservative, the TLD-albedo dosimeters were exposed to bare plutonium sources in air, which give a relatively low dosimeter response. per unit of dose equivalent. Measurements were also performed with acrylic plastic shielding between the dosimeters and the source. The plastic shielding generates intermediate-energy and low-energy neutrons that contribute little to the dose equivalent, but which increase the dosimeter response per unit of dose equivalent.

Information is presented here about each of the sources used for the measurements. Additional information about the plutonium sources can be found in Section 3.2 of PNL-7881 (Brackenbush, Baumgartner, and Fix 1991).

\subsection{PLUTONIUM TETRAFLUORIDE MEASUREMENTS}

Dose equivalent rate measurements and dosimeter measurements were performed on the 764-gram PuF 4 source in Room 179 of the PFP. This source is of historical significance because it was used as the calibration source for

\section{1}


neutron dosimeters at Hanford from 1958 until August 1981. The doubie encapsulated source was contained in a steel can, so it was not possible to. make exact distance measurements. However, the approximate center of gravity was determined, and distances were measured relative to this reference point.

\subsubsection{Dose Equivalent Determinations from Plutonium Tetrafluoride Source}

Measurements were performed using two TEPCS (TEPC 504 and TEPC 185). The multisphere spectrometer was used with a Harshaw ${ }^{6} \mathrm{LiI}(\mathrm{Eu}) 1.3-\mathrm{cm}$ (5-in.) diameter scintiliation crystal, number PE322, operated at +700 volts. A microrem meter (Hanford instrument number 4982) was also used to measure gamma dose. The results of the neutron measurements are shown in Table 4.1 for measurements taken at $50 \mathrm{~cm}$ (20 in.) and $100 \mathrm{~cm}$ (40 in.) from the center of gravity of the source for the bare $\mathrm{PuF}_{4}$ source and for the source shielded by various thicknesses of 40-by-40-cm (15.75-by-15.75-in.) slab shields of acrylic plastic. For the measurements on the bare $\mathrm{PuF}_{4}$ source, averages of the TEPC and multisphere spectrometer were also calculated. The uncertainties given in the table are for one standard deviation in the measured values. The TEPC data are averages of at least two measurements.

\subsubsection{MuTtisphere Spectrometer Measurements with the Plutonium Tetrafluoride} Source

A series of measurements were also performed using the multisphere spectrometer to determine the approximate energy spectra using the bare PuF $_{4}$ source and the source shielded with acrylic plastic slabs 1 to 4 in. thick. Although spectra measured by multisphere spectrometers lack the resolution of those measured with other types of spectrometers, these measurements cover the entire range of neutron energies from thermal to $20 \mathrm{MeV}$. The spectra presented have sufficient resolution to allow qualitative analys is of TLD-albedo dosimeter responses. Details of how the spectra were derived are contained in Appendix B of PNL-7881 (Brackenbush, Baumgartner, and Fix 1991) and summarized in Section 2.1 of this report. 
TABLE 4.1 Results of Neutron Measurements Performed on the PuF 4 Source at the Plutonium Finishing Plant.

\begin{tabular}{|c|c|c|c|c|c|}
\hline \multirow[b]{2}{*}{ Shielding } & \multirow[b]{2}{*}{ Detector } & \multicolumn{4}{|c|}{ Neutron Dose Equivalent Rate, $\mathrm{mSv} / \mathrm{h}^{(0)}$} \\
\hline & & & At $50 \mathrm{~cm}$ & & At $100 \mathrm{~cm}$ \\
\hline Bare PuF 4 & $\begin{array}{l}\text { Multisphere TEPC } 504 \\
\text { and } 185\end{array}$ & Average: & $\begin{array}{l}0.196 \\
0.204 \\
0.200 \pm 0.006\end{array}$ & Average: & $\begin{array}{l}0.056 \\
0.059 \\
0.058 \pm 0.002\end{array}$ \\
\hline 1-in. Acrylic Plastic & $\begin{array}{l}\text { Multisphere TEPC } 504 \\
\text { and } 185\end{array}$ & Average: & $\begin{array}{l}0.149 \\
0.151 \\
0.150 \pm 0.001\end{array}$ & Average: & $\begin{array}{l}0.042 \\
0.040 \\
0.041=0.001\end{array}$ \\
\hline 2-ín. Acrylic Plastic & $\begin{array}{l}\text { Multisphere TEPC } 504 \\
\text { and } 185\end{array}$ & Average: & $\begin{array}{l}0.095 \\
0.098 \\
0.097 \pm 0.002 \\
\end{array}$ & Average: & $\begin{array}{l}0.029 \\
0.031 \\
0.030 \pm 0.001\end{array}$ \\
\hline 3-in. Acrylic Plastic & $\begin{array}{l}\text { Multisphere TEPC } 504 \\
\text { and } 185\end{array}$ & Average: & $\begin{array}{l}0.065 \\
0.063 \\
0.064=0.001\end{array}$ & Average: & $\begin{array}{l}0.017 \\
0.021 \\
0.019 \pm 0.003\end{array}$ \\
\hline 4-in. Acrylic Plastic & $\begin{array}{l}\text { Multisphére TEPC } 504 \\
\text { and } 185\end{array}$ & Average: & $\begin{array}{l}0.038 \\
0.039 \\
0.039=0.001\end{array}$ & Average: & $\begin{array}{l}0.013 \\
0.016 \\
0.015 \pm 0.002\end{array}$ \\
\hline $\begin{array}{l}\text { (a) Uncertainties giv } \\
\text { measured values. }\end{array}$ & for one standard dev & in the & average of th & & \\
\hline
\end{tabular}

A summary of the multisphere spectrometer measurements with the PuF 4 source is given in Table 4.2. The effects of the acrylic plastic shielding are apparent from examining the table, where the increased number of lower-energy scattered neutrons produces a lower average neutron energy. A7though the total neutron flux is not greatly reduced, the neutrons that penetrate the shield are lower in energy, and there is a significant reduction in the dose equivalent rate. The table also demonstrates that there is a significant room-scatter component at $100 \mathrm{~cm}$ (40 in.) from the source. For these measurements, the slab shields were placed as close to the source as possible. Other contributing factors are materials placed in the room, or nearby rooms, which increase the relative background. 
TABLE 4.2 Summary of Multisphere Spectrometer Measurements with the $\mathrm{PuF}_{4}$ Source

\begin{tabular}{||c|c|c|c|c|c||}
\hline Shielding & Distance, cm & $\begin{array}{c}\text { Neutron Flux, } \\
\mathrm{n} / \mathrm{s}^{-\mathrm{cm}^{2}}\end{array}$ & $\begin{array}{c}\text { Average Dose } \\
\text { Equivalent Rate, } \\
\mathrm{mSv} / \mathrm{h}\end{array}$ & $\begin{array}{c}\text { Average Qual ity } \\
\text { Factor (0) }\end{array}$ & $\begin{array}{c}\text { Average Energy, } \\
\mathrm{MeV}\end{array}$ \\
\hline Bare Puf, & 50 & 184 & 0.180 & 9.6 & 1.30 \\
\hline 1-in. acrylic & 50 & 224 & 0.137 & 9.1 & 0.80 \\
\hline 2-in. acrylic & 50 & 202 & 0.093 & 8.7 & 0.55 \\
\hline 3-in. acrylic & 50 & 121 & 0.060 & 9.1 & 0.51 \\
\hline 4-in. acr.ylic & 50 & 102 & 0.035 & 7.9 & 0.43 \\
\hline Bare Puf, & 100 & 61 & 0.052 & 9.5 & 1.11 \\
\hline 1-in. acrylic & 100 & 71 & 0.039 & 9.0 & 0.70 \\
\hline 2-in. acrylic & 100 & 65 & 0.027 & 8.5 & 0.48 \\
\hline 3-in. acrylic & 100 & 40 & 0.015 & 8.3 & 0.44 \\
\hline 4-in. acrylic & 100 & 34. & 0.012 & 8.0 & 0.38 \\
\hline
\end{tabular}

The neutron flux per logarithmic energy bin determined from the multisphere measurements is given in Figure 4.1 for measurements at $50 \mathrm{~cm}(20$ in.) from the $\mathrm{PuF}_{4}$ source and in Figure 4.2 for measurements at $100 \mathrm{~cm}$ (40 in.) from the $\mathrm{PuF}_{4}$ source. At $50 \mathrm{~cm}\left(20\right.$ in.) from the $\mathrm{PuF}_{4}$ source, there are very few room-scattered neutrons in the measured spectrum from the bare source. The effect of the acrylic plastic shielding is apparent in these figures and in Table 4.2, where the PuF $_{4}$ spectrum shifts, resulting in lower average energies with increasing amounts of shielding, and the number of low-energy neutrons is significantly increased (see the Appendix, Figure A.1). The shape of the measured spectra from the multisphere measurements is quite similar to the results of Monte Carlo calculations found in Compendium of Neutron Spectra in Criticality Accident Dosimetry (Ing and Makra 1978). 


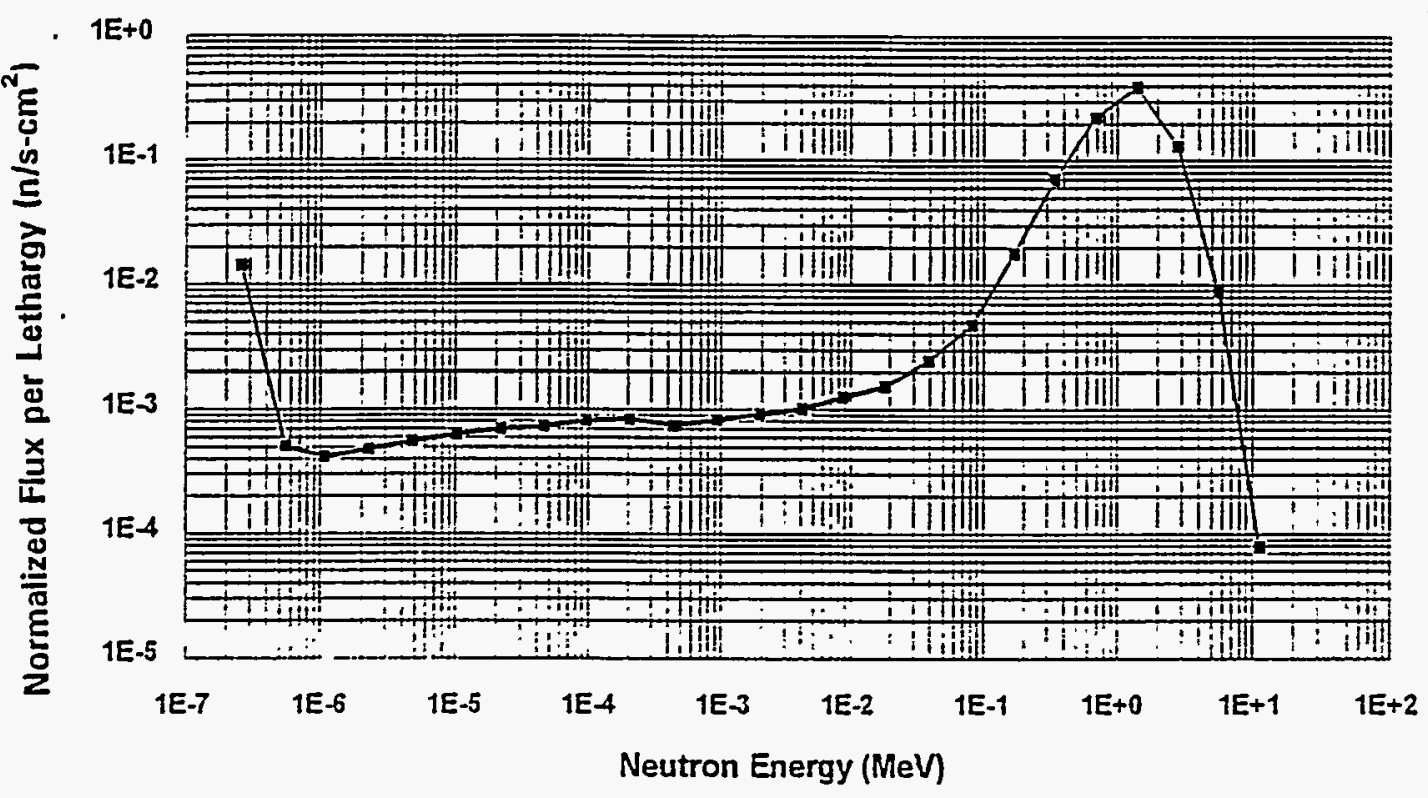

FIGURE 4.I Neutron F7ux per Unit Lethargy at $50 \mathrm{~cm}(20$ in.) from the Bare $\mathrm{PuF}_{4}$ Source Measured by the Multisphere Spectrometer

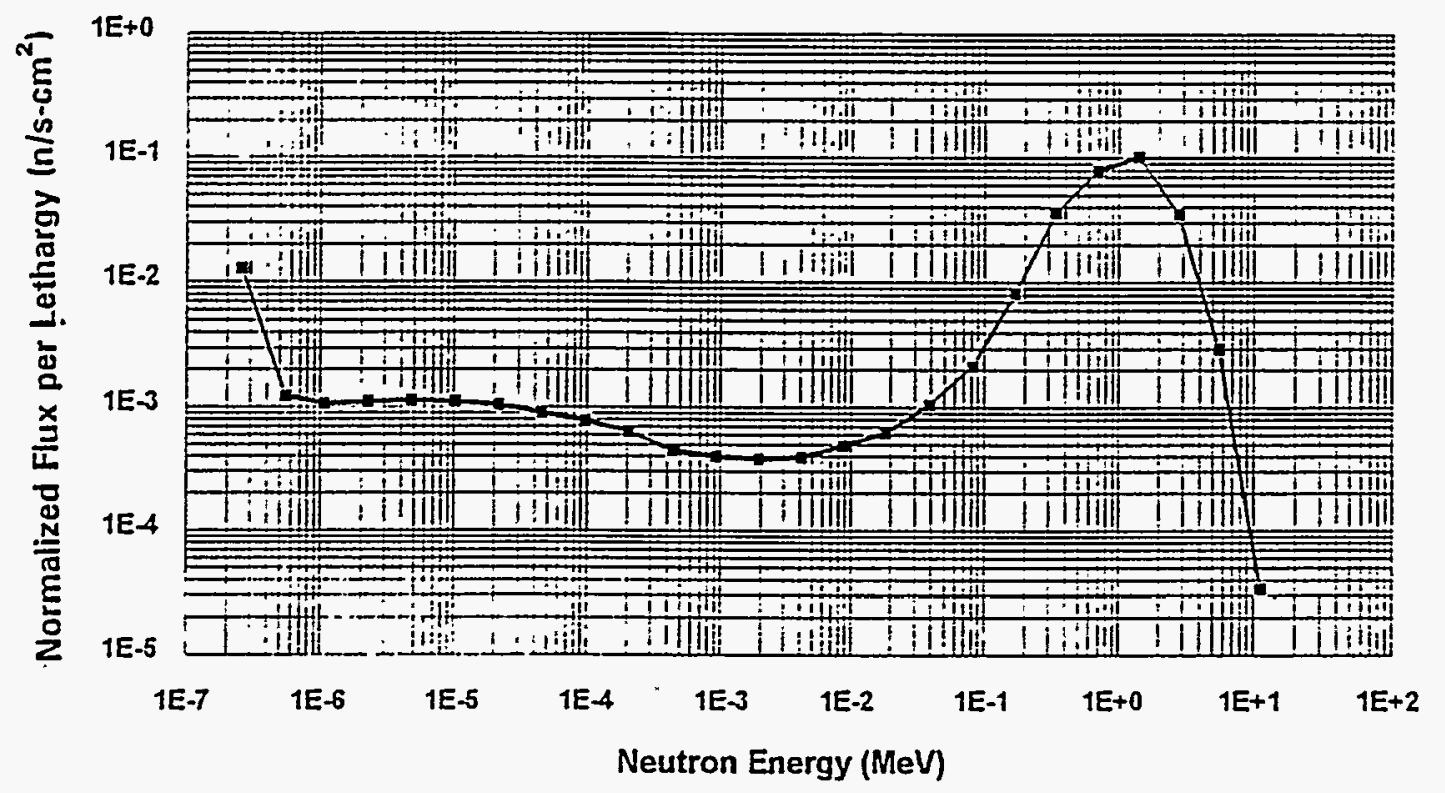

FIGURE 4.2 Neutron Flux per Unit Lethargy at $100 \mathrm{~cm}$ (40 in.) from the Bare $\mathrm{PuF}_{4}$ Source Measured by the Multisphere Spectrometer 
The measured neutron energy spectra at $100 \mathrm{~cm}$ (40 in.) show a significant number of lower-energy neutrons, presumably from room scatter. The spectrum from the bare PuF $_{4}$ source at $100 \mathrm{~cm}$ (40 in.) has essentialty the same shape as the spectrum at $50 \mathrm{~cm} 20$ in.) for energies above $1 \mathrm{keV}$. Below 1 $\mathrm{keV}$, there are significantly more neutrons, presumably from room scatter. The intermediate neutron energy spectra presented here are consistent with what one would expect. However, one should be aware that the multisphere spectrometer is not highly accurate in the intermediate energy region. The calculated fluxes in this region are dominated by measurements with the cadmium-covered detector and the cadmium-covered $7.6-\mathrm{cm}\left(3-\mathrm{in.}_{.}\right)$and $12.7-\mathrm{cm}$ (5-in.) diameter spheres. The responses of these detectors change very little with significant changes in neutron energy. More selective detectors are needed for increased energy resolution for these neutron energies.

Detailed neutron energy spectra are presented in Tables A.1 to A.10. In these tables, the differential neutron flux is the flux per energy bin. The energy bins are in logarithmic energy increments, so the fluxes are listed per unit lethargy, with dimensions of neutrons $/ \mathrm{s}-\mathrm{cm}^{2}$ per energy bin. The tables al so include the cumulative dose equivalent distribution, which gives the dose equivalent summed from the energy listed in the first column of the tables to $20 \mathrm{MeV}$.

\subsection{PLUTONIUM DIOXIDE MEASUREMENTS}

Measurements were performed on a 962 -gram $\mathrm{PuO}_{2}$ source containing 846.6 grams of plutonium. The loose $\mathrm{PuO}_{2}$.powder was $\mathrm{placed}$ in a steel can, 9-cm (3.5-in.) diameter by $9-\mathrm{cm}(3.5-$ in.) high, which in turn was sealed inside a steel can $10.5 \mathrm{~cm}$ (4.125 in.) in diameter by $18 \mathrm{~cm}$ (7 in.) high. The low-exposure plutonium contained $6.0 \mathrm{wt} \%{ }^{240} \mathrm{Pu}$ and $0.21 \mathrm{wt} \%{ }^{241} \mathrm{Pu}$, so that there was some ingrowth of ${ }^{241} \mathrm{Am}$.

The can containing the $\mathrm{PuO}_{2}$ was placed on an aluminum support stand at a height of $1 \mathrm{~m}(3.3 \mathrm{ft})$ from the floor to the bottom of the can. The center of gravity of the can was determined, and distances were measured relative to this point. The dose rates from this source were low and all of the measured dose rates had to be corrected for room background, which was about $0.001 \mathrm{mSv} / \mathrm{h}$ near the source. To minimize the effects of material in the glove 
box, the phantoms for the dosimeter exposures were positioned so that the dosimeters were shielded by the phantom or at right angles to the glove box to minimize their responses to room background.

\subsubsection{Dose Equivalent Determinations from the Plutonium Dioxide Source}

The results of the neutron measurements are summarized in Table 4.3 using the various detectors indicated in the table. The measured dose equivalent rates are low, so that there is some variation in the measurements made with the various detectors. The numbers in parentheses in the table are the percent standard deviations of the measured values. It should be noted that the dose equivalent rates shown in Table 4.3 are only four times the background dose equivalent rate.

\subsubsection{Multisphere Spectrometer Measurements with the Plutonium Dioxide Source}

A multisphere spectrometer measurement was made at $50 \mathrm{~cm}(20$ in.) from the $\mathrm{PuO}_{2}$ source with the spectrometer positioned at the same location as the large TLD phantom. A summary of the results from the multisphere spectrometer measurements is presented in Table 4.4, and details of the differential flux per logarithmic energy bin and dose equivalent distributions as a function of energy are presented in Table A.11. A plot of the differential flux, i.e., the neutron flux per logarithmic energy bin or flux per unit lethargy, is presented in Figure 4.3.

The measurement was made at $50 \mathrm{~cm}$ (20 in.) from the source to minimize errors due to varying background dose equivalent rates, but the results shown in Table 4.4 show that the average energy from the $\mathrm{PuO}_{2}$ measurement is about $1.3 \mathrm{MeV}$. Previous measurements indicate that the average energy from a bare $\mathrm{PuO}_{2}$ source should be about $2 \mathrm{MeV}$. An examination of the plot of the neutron flux as a function of energy shows that room background was influencing the measured results. It was previously thought that properly positioning the phantoms for the dosimeter exposures may reduce the influence of the room background by shielding the dosimeters from the glove-box material. While this may help the dosimeter measurements, it was determined that other neutron sources in the building were influencing the background from almost al1 directions. Furthermore, the background levels were variable as materials

\section{7}


were moved from one location to another within the building.

TABLE 4.3 Results of Neutron Measurements Taken at $50 \mathrm{~cm}$ from the $\mathrm{PuO}_{2}$ Source at the Plutonium Finishing Plant

\begin{tabular}{|l|c|}
\hline \multicolumn{1}{|c|}{ Detector } & $\begin{array}{c}\text { Corrected Dose } \\
\text { Equivalent Rate, mSv/h }\end{array}$ \\
\hline TEPC 504 and 185 & 0.0042 \\
Multisphere & 0.0041 \\
& Average: $0.0042 \pm(0.0001)$ \\
\hline
\end{tabular}

TABLE 4.4 Summary of Multisphere Spectrometer Measurements with the $\mathrm{PuO}_{2}$ Source

\begin{tabular}{||c|c|c|c|c|c||}
\hline Shieiding & Distance, cm & $\begin{array}{c}\text { Neutron } \\
\text { Flux, n/s- } \\
\mathrm{cm}^{2}\end{array}$ & $\begin{array}{c}\text { Dose } \\
\text { Equivalent Rate, mSv/h }\end{array}$ & $\begin{array}{c}\text { Average } \\
\text { Quality Factor } \\
(Q)\end{array}$ & $\begin{array}{c}\text { Average } \\
\text { Energy. MeV }\end{array}$ \\
\hline Bare $\mathrm{PuO}_{2}$ & 50 & 5.09 & 0.0037 & 8.5 & 1.3 \\
\hline
\end{tabular}

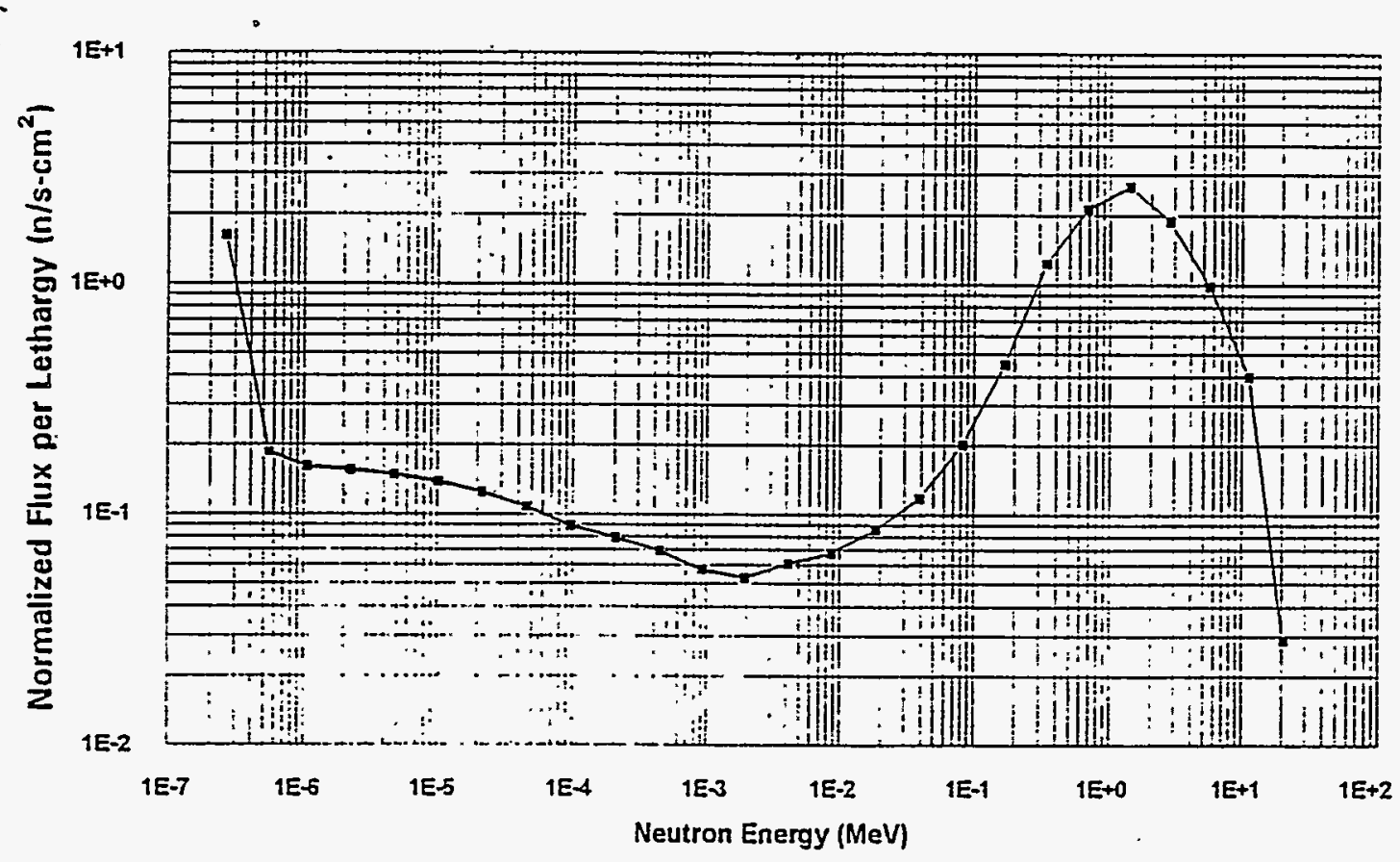

FIGURE 4.3 Neutron Flux per Unit Lethargy at $50 \mathrm{~cm}$ (20 in.) from the Bare $\mathrm{PuO}_{2}$ Source Measured by the Multisphere Spectrometer 


\subsection{PLUTONIUM METAL MEASUREMENTS}

Measurements were performed on a plutonium metal source containing 1508 grams of plutonium. Two anode heel samples were placed inside cans and sealed inside a steel can, $10.5 \mathrm{~cm}$ (4.125 in.) in diameter by $18 \mathrm{~cm}$ ( 7 in.) high. The plutonium was recently separated low-exposure plutonium containing $5.4 \mathrm{wt} \%{ }^{240} \mathrm{Pu}$ and $0.17 \mathrm{wt} \%{ }^{241} \mathrm{Pu}$. The impurities in the metal increased the neutron yield and the dose equivalent rates.

The can containing the plutonium metal source was placed on an aluminum stand at a height of $1 \mathrm{~m}(3.3 \mathrm{ft})$ from the bottom of the steel can. The center of gravity of the can was determined, and distances were measured relative to this point.

\subsubsection{Dose Equivalent Determinations from the Plutonium Metal Source}

A summary of the measured dose equivalent rates from TEPCs, and the multisphere spectrometer are presented in Table 4.5. The uncertainties in the average for the measured values are given for one standard deviation. The number in parentheses is the percent standard deviation of the measured values. The dose equivalent rate measured for this source is higher than expected, so it is suspected that the neutron emission rate may have been enhanced by impurities of low atomic number present in the anode heel samples.

TABLE 4.5 Results of Neutron Measurements Taken at $50 \mathrm{~cm}$ (20 in.) from the Plutonium Metal Source

\begin{tabular}{|l|c|}
\hline \multicolumn{1}{|c|}{ Detectors } & Corrected Dose Equivalent Rate, mSv/h \\
\hline TEPC 504 and 185 & 0.0053 \\
Multisphere & 0.0050 \\
& Average: $0.0052 \pm 0.0002(0.38)$ \\
\hline
\end{tabular}

\subsubsection{MuTtisphere Spectrometer Measurements with the Plutonium Metal Source}

A summary of the results from the multisphere spectrometer measurements is presented in Table 4.6, and detailed neutron flux and dose equivalent distributions for logarithmic energy intervals are presented in Table 4.7 . The 
multisphere measurements were performed at $50 \mathrm{~cm}$ (20 in.) for the metal measurements, so that the background would not present as much of a problem. Table 4.6 shows that the average energy is about $0.99 \mathrm{MeV}$, which is lower than the PuF $_{4}$ results. Previous measurements have demonstrated that the average neutron energy is actualiy about $2 \mathrm{MeV}$ for a bare plutonium metal source. Part of the difference in measured average energy may be ascribed to the fact that the multisphere energy bins are so wide that average energies in the MeV region are not very accurate. Also, the average depends on whether arithmetic averages or logarithmic averages are used for the midpoint energies of the bias. Furthermore, measurements show that the background dose equivalent rates increased dramatically during the oxide and metal exposures. The average energy for the metal source during the measurements made in 1991 was reported to be about $1.4 \mathrm{MeV}$ (Brackenbush, Baumgartner, and Fix 1991).

TABLE 4.6 Summary of Multisphere Spectrometer Measurements Taken at $50 \mathrm{~cm}$ (20 in.) from the Plutonium Metal Source

\begin{tabular}{|c|c|c|c|}
\hline $\begin{array}{c}\text { Neutron } \\
\text { Flux, n/s- } \\
\mathrm{cm}^{2}\end{array}$ & $\begin{array}{c}\text { Dose Equivalent } \\
\text { Rate, mSv/h }\end{array}$ & $\begin{array}{c}\text { Average Quality } \\
\text { Factor (Q) }\end{array}$ & $\begin{array}{c}\text { Average } \\
\text { Energy, MeV }\end{array}$ \\
\hline 6.26 & 0.0046 & 9.2 & 0.99 \\
\hline
\end{tabular}

The neutron flux density per logarithmic interval or the flux per unit lethargy is plotted as a function of the logarithm of the neutron energy in Figure 4.4. There is a low-energy component due to room background, and this lowered the overall average energy. These results indicate the difficulty of finding a location where the room background is low enough to allow proper measurements of plutonium metal and $\mathrm{PuO}_{2}$ sources. The low-energy component is evidenced by the background and glove-box measurments taken. Table 4.7 shows the results of these measurements where the energy was too low for the CR-39 to accurately measure the dose equivalent rate relative to TEPC, multisphere, and TLD. 
TABLE 4.7 Dose Equivalent Rates as a Function of Distance for Shielded Plutonium Sources

\begin{tabular}{|c|c|c|c|c|c|c|c|}
\hline \multirow[b]{2}{*}{$\begin{array}{c}\text { Source/ } \\
\text { Distance } \\
\end{array}$} & \multirow[b]{2}{*}{ Shielding } & \multicolumn{4}{|c|}{ Neutron, mSv/h } & \multicolumn{2}{|c|}{ Gamma. mSv/h } \\
\hline & & $\begin{array}{c}\text { Dosimeter } \\
8816 \\
\end{array}$ & TEPC & Multisphere & CR-39 & $\begin{array}{c}\text { Dosimeter } \\
8825 \\
\end{array}$ & $\begin{array}{c}\text { Rem } \\
\text { Meter }\end{array}$ \\
\hline $\mathrm{PuF}_{4} / 1 \mathrm{~m}$ & $\begin{array}{l}\text { No shield } \\
\text { 1-in. shield } \\
\text { 2-in. shield } \\
3-i n \text {. shield } \\
4-i n \text {. shield }\end{array}$ & $\begin{array}{l}0.0945 \\
0.0583 \\
N / A \\
N / A \\
\dot{H} / A \\
\end{array}$ & $\begin{array}{l}0.0593 \\
0.0404 \\
0.0311 \\
0.0214 \\
0.0161 \\
\end{array}$ & $\begin{array}{l}0.0562 \\
0.0422 \\
0.0293 \\
0.0166 \\
0.0125 \\
\end{array}$ & $\begin{array}{c}0.0646 \\
0.0416 \\
N / A \\
N / A \\
N / A\end{array}$ & $\begin{array}{c}0.0090 \\
0.0089 \\
N / A \\
N / A \\
N / A \\
\end{array}$ & $\begin{array}{l}0.0110 \\
0.0088 \\
0.0070 \\
0.0060 \\
0.0050 \\
\end{array}$ \\
\hline $\mathrm{PuF}_{4} / 50 \mathrm{~cm}$ & $\begin{array}{l}\text { No shield } \\
\text { 1-in. shield } \\
\text { 2-in. shield } \\
\text { 3-in. shield } \\
\text { 4-in. shield }\end{array}$ & $\begin{array}{l}0.354 \\
0.155 \\
0.180 \\
0.103 \\
0.109 \\
\end{array}$ & $\begin{array}{l}0.2040 \\
0.1510 \\
0.0983 \\
0.0630 \\
0.0390 \\
\end{array}$ & $\begin{array}{l}0.1960 \\
0.1490 \\
0.0946 \\
0.0650 \\
0.0383 \\
\end{array}$ & $\begin{array}{l}0.2150 \\
0.1280 \\
0.0994 \\
0.0497 \\
0.0408 \\
\end{array}$ & $\begin{array}{l}0.0310 \\
0.0290 \\
0.0280 \\
0.0222 \\
0.0212 \\
\end{array}$ & $\begin{array}{l}0.0400 \\
0.0320 \\
0.0280 \\
0.0210 \\
0.0190 \\
\end{array}$ \\
\hline $\mathrm{PuO}_{2} / 50 \mathrm{~cm}$ & No shield & 0.0045 & 0.0042 & 0.0041 & 0.0047 & 0.0183 & 0.0200 \\
\hline Metal $/ 50 \mathrm{~cm}$ & No shield & 0.0070 & 0.0053 & 0.0050 & 0.0059 & 0.0176 & 0.0220 \\
\hline $\begin{array}{l}\text { Background } \\
\text { (no source) }\end{array}$ & -- & 0.0012 & 0.0012 & 0.0013 & 0.0002 & 0.0015 & 0.0020 \\
\hline Glovebox 9 & -- & 0.0052 & 0.0052 & 0.0052 & 0.0009 & 0.0761 & 0.0365 \\
\hline
\end{tabular}

$\mathrm{N} / \mathrm{A}=$ not measured

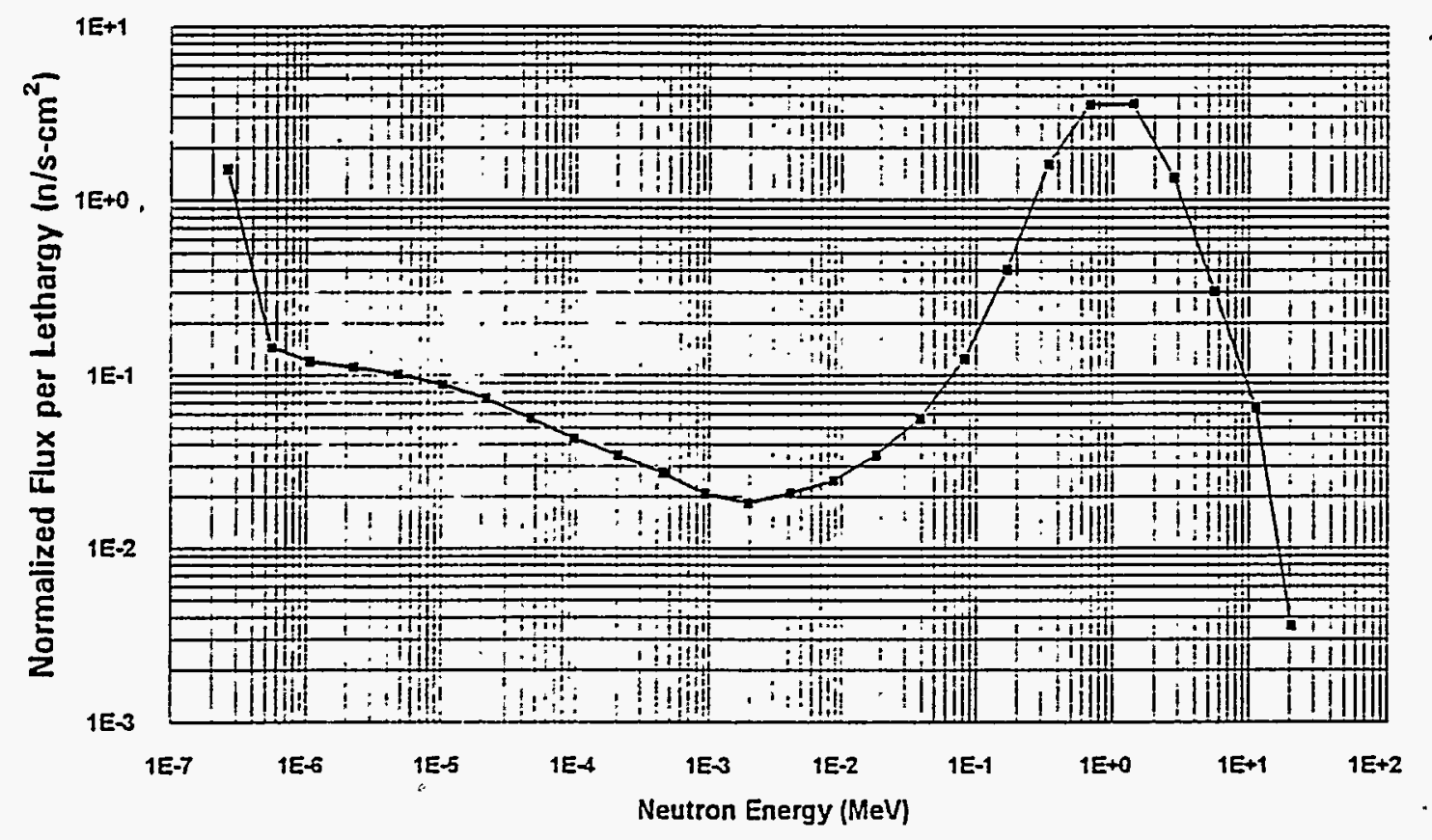

FIGURE 4.4 Neutron FTux per Unit Lethargy at $50 \mathrm{~cm}$ (20 in.) from the Bare Plutonium Metal Source Measured by the Multisphere Spectrometer 


\subsection{THERMOLUMINESCENT DOSIMETER AND CR-39 RESULTS COMPARED TO INSTRUMENTATION}

In Table 4.7, the results of the TLD and CR-39 elements of the HCND compared to TEPC and multisphere measurements show that the single-point californium calibration overestimates equivalent dose. The response per unit dose equivalent of the CR-39 is very low for the glove-box and background exposures because of the poor response in fields where the neutron energies are below $100 \mathrm{keV}$. This performance is expected. Table 4.7 shows the response of the neutron dosimeter (8816) as initially calibrated to californium. Table 4.8 shows the results after applying a site-specific correction algorithm to the 8816 results shown in Table 4.7 . Section 5.0 of this report describes the development of this site-specific algorithm.

TABLE 4.8 Dose Equivalent Rates as a Function of Distance for Shielded Plutonium Sources with New Algorithm Applied to 8816 Dosimeter

\begin{tabular}{|c|c|c|c|c|c|}
\hline \multirow{2}{*}{$\begin{array}{c}\text { Source/ } \\
\text { Distance }\end{array}$} & \multirow[b]{2}{*}{ Shielding } & \multicolumn{4}{|c|}{ Neutron. msv/h } \\
\hline & & Dosimeter 8816 & TEPC & Muitisphere & CR -39 \\
\hline $\mathrm{PuF}_{4} / 1 \mathrm{~m}$ & $\begin{array}{l}\text { No shield } \\
1 \text {-in. shield } \\
2 \text {-in. shield } \\
3 \text {-in. shield } \\
4 \text {-in. shield }\end{array}$ & $\begin{array}{c}0.0633 \\
0.0497 \\
N / A \\
N / A \\
N / A \\
\end{array}$ & $\begin{array}{l}0.0593 \\
0.0404 \\
0.0311 \\
0.0214 \\
0.0161 \\
\end{array}$ & $\begin{array}{l}0.0562 \\
0.0422 \\
0.0293 \\
0.0166 \\
0.0125 \\
\end{array}$ & $\begin{array}{l}0.0646 \\
0.0416 \\
\text { N/A } \\
\text { N/A } \\
\text { N/A } \\
\end{array}$ \\
\hline $\mathrm{PuF}_{4} / 50 \mathrm{~cm}$ & $\begin{array}{l}\text { No shield } \\
1-i n . \text { shield } \\
\text { 2-in. shield } \\
3-i n . \text { shield } \\
\text { 4-in. shield }\end{array}$ & $\begin{array}{l}0.1820 \\
0.1280 \\
0.1670 \\
0.0720 \\
0.0360 \\
\end{array}$ & $\begin{array}{l}0.2040 \\
0.1510 \\
0.0983 \\
0.0630 \\
0.0390 \\
\end{array}$ & $\begin{array}{l}0.1960 \\
0.1490 \\
0.0946 \\
0.0650 \\
0.0383 \\
\end{array}$ & $\begin{array}{l}0.2150 \\
0.1280 \\
0.0994 \\
0.0497 \\
0.0408 \\
\end{array}$ \\
\hline $\mathrm{PuO}_{2} / 50 \mathrm{~cm}$ & No shield & 0.0040 & 0.0042 & 0.0041 & 0.0047 \\
\hline Metal/50 cm & No shield & 0.0057 & 0.0053 & 0.0050 & 0.0059 \\
\hline $\begin{array}{l}\text { Background } \\
\text { (no source) }\end{array}$ & - & 0.0013 & 0.0012 & 0.0013 & 0.0002 \\
\hline Glovebox 9 & - & 0.0048 & 0.0052 & 0.0052 & 0.0009 \\
\hline
\end{tabular}

$\mathrm{N} / \mathrm{A}=$ not measured

Table 4.9 compares the dose equivalent rate determined by the HCND and the delivered dose rates, as determined by the arithmetic average of the dose equivalent rates measured by the TEPC and multisphere spectrometers for the 
various shielding configurations and plutonium sources. These are the data that were used to develop the dosimeter algorithms (presented in Section 5.0). The HCND results are presented as a percent deviation from the delivered dose equivalent rate. As shown in Table 4.9, the dose, algorithms provide reasonabiy accurate dose equivalent evaluations for a wide variety of neutron energy spectra and plutonium sources.

It is apparent from Tables 4.8 and 4.9 that the dosimeter exposures made with $5 \mathrm{~cm}(2$ in.) of acrylic plastic at $50 \mathrm{~cm}$ (20 in.) from the PuF 4 source are in error. The dosimeter-evaluated dose rates are higher with $5 \mathrm{~cm}(2 \mathrm{in}$.) of shielding than with $2.5 \mathrm{~cm}$ (lin.) of shielding. It-is believed that this was a result of large quantities of plutonium nitrate being moved into an adjacent room and increasing the neutron background during the dosimeter exposures. Unfortunately, there was not sufficient time to repeat these exposures. If we exclude this obviously erroneous data, on the average the TLD dosimeters provide dose equivalent rates that are on $1 y 1.5 \%$ higher than the dose equivalent rates from the instrument measurements, with a standard deviation of about $11 \%$.

The TED dosimeters are also surprisingly accurate, with the exception of the measurements for TED dosimeters exposed to the room background and to the glove box. In these cases, most of the neutrons are below the 100-keV energy threshold for the CR-39, and hence much of the dose is not measured.

Excluding these data, the TED dosimeters provide dose equivalent rates that, on the average, are only $2 \%$ higher than the delivered dose rate from the instrument measurements, with a standard deviation of $13 \%$.

Thus, the algorithms described in Section 5.0 can provide quite accurate dose equivalent evaluations compared with the dose equivalent measured with the instruments. These data are for a wide variety of neutron energy spectra and plutonium sources, including $\mathrm{PuF}_{4}, \mathrm{PuO}_{2}$, and plutonium metal. Average neutron energies varied between $1.3 \mathrm{MeV}$ for the bare $\mathrm{PuF}_{4}$ source and $0.4 \mathrm{MeV}$ for the highly moderated sources. However, it is possible that the dose equivalent algorithms may not provide proper evaluations for all the neutron energy spectra that may be encountered in work environments at Hanford. Additional measurements made in selected work locations at PFP are described in Section 6.0 of this report to verify proper operation of the algorithms. 
TABLE 4.9 Comparison Between Dosimeter Evaluations and Instrument Measurements

\begin{tabular}{|c|c|c|c|c|}
\hline \multirow[b]{2}{*}{ Source } & \multirow[b]{2}{*}{ - Distance } & \multirow[b]{2}{*}{ Shielding } & \multicolumn{2}{|c|}{$\begin{array}{l}\text { Percent Deviation from Delivered Dose } \\
\text { Equivalent }\end{array}$} \\
\hline & & & HCND TLD & HCND TED \\
\hline \multirow[t]{5}{*}{$\mathrm{PuF}_{6}$} & $50 \mathrm{~cm}$ & None. & -9.00 & 7.50 \\
\hline & & 1-in. acrylic & -14.7 & -14.6 \\
\hline & & 2-in. acrylic & $73.2^{(3)}$ & 3.06 \\
\hline & & 3-in. acrylic & 12.5 & -22.34 \\
\hline & & 4-in. acrylic & -6.86 & 5.56 \\
\hline \multirow[t]{2}{*}{$\mathrm{PuF}_{6}$} & $100 \mathrm{~cm}$ & None & 9.61 & 11.9 \\
\hline & & 1-in. acrylic & 20.3 & 0.73 \\
\hline $\mathrm{PuO}_{2}$ & $50 \mathrm{~cm}$ & None & -3.61 & 13.3 \\
\hline Pu Metal & $50 \mathrm{~cm}$ & None & 10.7 & 14.6 \\
\hline Background & & None & 4.00 & $-84.0^{(b)}$ \\
\hline Glove Box 9 & & None & -7.69 & $-82.7^{(0)}$ \\
\hline \multicolumn{3}{|l|}{ Average $=$} & $1.53^{(a)}$ & $2.17^{(b)}$ \\
\hline \multicolumn{3}{|c|}{ Percent Standard Deviation $=$} & $11.5^{(a)}$ & $12.7^{(b)}$ \\
\hline
\end{tabular}

(a) Excludes data for PuF, at $100 \mathrm{~cm}$ (40 in.) with $5 \mathrm{~cm}(2$ in.) acrylic plastic shielding.

${ }^{(b)}$ Excludes data for background and glovebox exposures where the majority of neutrons are below $100 \mathrm{keV}$ threshold for detection of CR-39. 


\subsection{HANFORD COMBINATION NEUTRON DOSIMETER ALGORITHM DEVELOPMENT}

To develop a dose algorithm for the 8816 neutron albedo TLD component of the HCND, smooth functions were developed that define dose conversion factors for selected chips; these formulations were based on the chip-response ratios observed when the HCND was exposed to a bare ${ }^{252} \mathrm{Cf}$ source in a low-scatter environment with varying amounts of acrylic plastic moderator placed between the source and dosimeter. The resulting algorithm was then tested under field conditions at Hanford. For both field and laboratory measurements, the TEPC results were used as the conventionally true value for neutron dose equivalent. However, as Table 4.7 shows, the algorithm developed in the calibration Taboratory with ${ }^{252} \mathrm{Cf}$ significantly overestimates neutron dose equivalent from $\mathrm{PuF}_{4}, \mathrm{PuO}_{2}$ and plutonium metal sources in high-scatter work environments. Consequently, a separate algorithm was developed for use in ' plutonium environments. This algorithm was based on measurements made at the PFP with varying amounts of acrylic plastic shielding placed between a $\mathrm{PuF}_{4}$ source and the dosimeter. The improved agreement between the TEPC-measured dose equivalent and the algorithm-calculated dose equivalent can be seen in Table 4.8. To accommodate the use of two algorithms, a code identifying the type of radiation environment in which the dosimeter was used must be provided by the user to the dosimetry laboratory for each dosimeter processed.

The need for two algorithms is not an unexpected result. For a single source, with varying degrees of moderation from hydrogenous material, there is a definable relationship between the fraction of incident neutrons which are thermal, the mean energy of the spectrum, and the dose conversion factors necessary to calculate dose equivalent. The HCND albedo dosimeter design includes cadmium filters to enable the use of these relationships. A single relationship, however, does not hold across different starting spectra with different shapes. Thus, for a single neutron source, an algorithm can be developed using the dosimeter response characteristics (i.e., chip response ratios indicating the fraction of incident and albedo neutrons which are therma 1). Such an algorithm in effect determines the degree of moderation from the unmoderated source spectrum and calculates the appropriate dose conversion factors based on empirically determined relationships. 


\subsection{ALGORITHM BASED ON ${ }^{252} \mathrm{CF}$}

The empirical data used to develop the algorithm were generated by exposing the 8816 dosimeter on a 40 by 40 by $15 \mathrm{~cm}$ ( 15.75 by 15.75 by 6 in.) acrylic plastic phantom, to ${ }^{252} \mathrm{Cf}$ in the low-scatter room at the 318 Calibration Facility. Exposures were made at $100 \mathrm{~cm}$ (40 in.) from the source to the front face of the phantom, with varying thicknesses of acrylic plastic between the bare source and the dosimeters. Exposures were made with no plastic, and with plastic of thicknesses $2.5 \mathrm{~cm}$ ( 1 in.), $5 \mathrm{~cm}(2$ in.), $7.6 \mathrm{~cm}$ (3. in.), $10 \mathrm{~cm}$ ( 4 in.), $13 \mathrm{~cm}(5$ in.) and $15 \mathrm{~cm}$ ( 6 in.). It was felt that these exposure conditions, with suitably thick shielding, could produce neutron spectra similar to current high-scatter field conditions at the PFP.

A Harshaw Model 8800 TLD card reader was employed to read the TLD cards from the 8816 dosimeter. Because this reader uses a noncontact heating system (hot nitrogen), good reproducibility is generaliy assured. The chip readings obtained from the reader are "calibrated" chip readings. Both element correction coefficients (ECCS) and reader calibration factors (RCFs) are applied by the reader to the raw light output (in nanocoulombs) to obtain calibrated chip readings $\left(X_{i}\right)$ expressed in generic units $(g U)$. For the TLD reader systems at Hanford, the $\mathrm{gU}$ is an $\mathrm{mR}$ equivalent ( $1 \mathrm{gU}=1 \mathrm{mR}$ ) because the reader is calibrated with bare cards exposed in free air to a known exposure with a ${ }^{60} \mathrm{Co}$ source. The method used by the reader to obtain calibrated chip readings $X_{i}$ is as follows:

$$
X_{i}(g U)=\text { chip reading }_{i}(n C) \times E C_{i} / \mathrm{RCF}_{i}(n C / g U)
$$

The calibrated chip readings obtained from the reader are then adjusted by subtracting background, correcting for fade, and correcting for the difference in response between bare chips exposed in free air to ${ }^{60} \mathrm{Co}$ and chips exposed in the holder on a phantom to ${ }^{137} \mathrm{Cs}$. The relationship between chip response to exposure in air and on phantom is referred to as the ${ }^{137} \mathrm{Cs}$ relative response factor (RRF) for the dosimeter and has units of $\mathrm{gU} / \mathrm{rem}$. The resulting "adjusted" chip readings thus have units of rem $\left({ }^{137} \mathrm{Cs}\right.$ rem equivalent). Each adjusted chip reading will accurately reflect the given dose when the card is exposed in a holder, on a phantom to ${ }^{137} \mathrm{Cs}$, and read 
using a reader calibrated as described above. The following equation describes the method used to obtain "adjusted" chip readings from the "calibrated" chip readings provided by the TLD reader:

$$
L_{i}=\left(X_{i}-B_{i}\right) /\left(\operatorname{RRF}_{i} * F_{i}\right)
$$

where $L_{i}=$ adjusted chip reading for chip $i\left({ }^{137}\right.$ Cs rem equivalent)

$x_{i}=$ calibrated chip reading for chip $i(g U)$

$B_{i}=$ background for position $i$ based on biank cards (gU)

$\mathrm{RRF}_{i}={ }^{137} \mathrm{Cs}$ relative response factor for position $i$ (gU/rem)

$F_{i}=$ fade factor for position $i$.

The reader should note that for the purpose of this chapter and associated appendices, units of rem shall be used rather than Systeme International (SI) units of sieverts in order to accurately represent the algorithms as used within the actual dose calculation codes.

The basic approach in developing the algorithm was to subtract the gamma signal represented by $L_{1}$ (TLD-700 chip) from the gamma + neutron signal represented by $L_{2}, L_{3}$, and $L_{4}$ (TLD-600 chips), to obtain net readings $N 2, N 3$, and $\mathrm{N} 4$, which represent the neutron dose on each chip. The net readings were then used to obtain two ratios: $N 2 / N 3$ and N4/N3. Cubic equations were then fit to the empirical data to relate the $\mathrm{N} 2 / \mathrm{N} 3$ ratio to the dose conversion factor to be applied to $\mathrm{N} 4$, and to relate the $\mathrm{N} 4 / \mathrm{N} 3$ ratio to the dose conversion factor to be applied to $\mathrm{N2}$. The basic dose calculation algorithm follows:

1. Let $L I=$ adjusted reading from chip 1

$L 2$ = adjusted reading from chip 2

$\mathrm{L} 3$ = adjusted reading from chip 3

$L 4=$ adjusted reading from chip 4

(Adjusted readings have units of ${ }^{137} \mathrm{Cs}$ rem equivalent) 
2. Calculate net signal (neutron response) on TLD-600 chips $(2,3$, and 4$)$ : $\mathrm{N} 2=\mathrm{L} 2-\mathrm{L} 1$

$\mathrm{N} 3=\mathrm{LB}-\mathrm{LI}$

$\mathrm{N} 4=\mathrm{L} 4-\mathrm{L} 1$

3. If $\mathrm{N} 2<0.005$ or $\mathrm{N} 3<0.005$ or $\mathrm{N} 4<0.005$

or $\mathrm{N} 2 / \mathrm{L} 1<0.10$ or $\mathrm{N} 4 / \mathrm{L} 1<0.10$,

Then $H_{n}=0$

go to Step 10.

4. Calculate two ratios:

$\mathrm{R} 2=\mathrm{N} 2 / \mathrm{N} 3$

$\mathrm{R} 4=\mathrm{N} 4 / \mathrm{N} 3$

If $R 2<0.9$ or $R 4<0.9$, question the dose.

5. Calculate the dose conversion factor C2 to be app7ied to N2 to obtain neutron dose equivalent:

$\mathrm{C} 2=29.2578-25.1554 * \mathrm{R} 4+8.5171 * \mathrm{R} 4^{2}-1.0618 * \mathrm{R} 4^{3}$

If $\mathrm{C2}<2$, then $\mathrm{C2}=1.0424$ (hard spectra)

If $\mathrm{C} 2>5.4314$, then $\mathrm{C} 2=5.4314$ (soft spectra)

6. Calculate neutron dose equivalent 02 from chip 2 net reading N2:

$\mathrm{D} 2=\mathrm{N} 2 / \mathrm{C} 2$

7. Calculate the dose conversion factor $\mathrm{C} 4$ to be applied to $\mathrm{N} 4$ to obtain neutron dose equivalent:

$C 4=26.0739-23.8391 * R 2+8.7743 * R 2^{2}-1.1849 * R 2^{3}$

If $\mathrm{C} 4<2.0$, then $\mathrm{C} 4=0.9737$ (hard spectra)

If $\mathrm{C} 4>8.5676$, then $\mathrm{C} 4=8.5676$ (soft spectra)

8. Calculate neutron dose equivalent $D 4$ from chip 4 net reading N4:

$\mathrm{D} 4=\mathrm{N} 4 / \mathrm{C} 4$ 
9. Calculate the 8816 albedo neutron dose equivalent result $H_{n}$ : $H_{n}=(D 2+D 4) / 2$

. If $\mathrm{D} 2 / \mathrm{D} 4<0.8$, question the dose.

If $02 / D 4>1.2$, question the dose.

10. End.

The high-end and low-end cutoffs for $\mathrm{C} 2$ and $\mathrm{C} 4$ represent the bounds of the empirical data. The dose equivalent from neutron spectra more energetic than bare ${ }^{252} \mathrm{Cf}$ will be underestimated by this model. The dose equivalent from neutron spectra softer than ${ }^{252} \mathrm{Cf}$ moderated by $15.24 \mathrm{~cm}(6 \mathrm{in}$.) of plastic wi11 be overestimated. The multiple regression model explains over $99 \%$ of the error in the data. These equations allow the evaluation of neutron doses over a range of chip ratios slightly larger than any ratio that has been measured in the field. It is expected that the computer algorithm will produce acceptable neutron dose equivalent results for point source environments and overestimate neutron dose equivalent for high-scatter environments.

\subsection{ALGORITHM BASED ON PUF}

As mentioned above, the ${ }^{252} \mathrm{Cf}$-based algorithm substantially overestimates dose in Hanford plutonium environments because in these environments the source spectra ( $\mathrm{PuF}_{4}$, plutonium metal, and $\mathrm{PuO}_{2}$ ) and facility scatter conditions differ significantly from those at the 318 Calibration Facility used in developing the ${ }^{252} \mathrm{Cf}$ algorithm. Consequently, a separate algorithm was developed for use in Hanford plutonium environments.

The data used to develop this algorithm consist of measurements made at the PFP with a PuF 4 source and various thicknesses of acrylic plastic between the source and dosimeters, which were placed on a acrylic plastic phantom, 40 by 40 by $15 \mathrm{~cm}$ ( 15.75 by 15.75 by 6 in.). The thicknesses of plastic shielding used were $2.5 \mathrm{~cm}(1$ in. $), 5 \mathrm{~cm}(2$ in. $), 7.6 \mathrm{~cm}(3$ in.), and $10 \mathrm{~cm}$ (4 in.). Details of the measurements made at the PFP with $\mathrm{PuF}_{4}, \mathrm{PuO}_{2}$, and plutonium metal sources are presented in Section 4.0. The $\mathrm{PuO}_{2}$ and plutonium metal sources did not provide a sufficient TLD neutron response compared to the moderated neutron background prevalent in the PFP to provide reproducible 
data for algorithm development purposes: Several difficulties were encountered that made data analysis difficult:

- The exposure to the different plutonium sources required long exposure times because of the low dose rates.

- For security reasons, the plutonium source had to remain in locked vaults during exposure, which contributed to the large scattered component of neutron fiux.

- During some of the exposures, there were times when plutonium materials were moved by the operating group, which resulted in dosimeter readings that were unaccounted for by instrument measurements made either before or at the end of the exposure. These changes in background and spectrum can have a significant effect on TLD response.

- The exposures were made over a six-month period and there may have been some changes unaccounted for in instrument response.

Because of these factors, no regression model could be found that explained more than $89 \%$ of the error resulting from the model fit. Ideally, a model which explained $95 \%$ or greater of the error would be considered acceptable. Also, it was not possible to separate the chip response due to 1) direct flux from the PuF $_{4}$ point. source + shielding, 2) the response due to room return from the $\mathrm{PuF}_{4}$ source, 3 ) the response due to nearby unshielded sources (e.g., from plutonium in nearby work areas), and 4 ) the response due to the ambient neutron flux. from the large inventory of plutonium stored in shielded vaults at the PFP.

The dosimeter response data were separated into three components for developing the algorithm:

- response data from bare $\mathrm{PuF}_{4}$ at $50 \mathrm{~cm}$ (20 in.) and $100 \mathrm{~cm}$ (40 in.) to represent the "unmoderated" condition

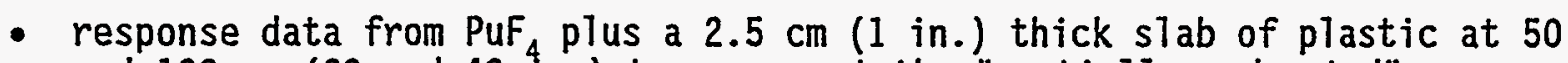
and $100 \mathrm{~cm}$ (20 and $40 \mathrm{in}$.) to represent the "partially moderated" condition

- response data from $\mathrm{PuF}_{4}$ plus $7.6 \mathrm{~cm}$ ( 3 in.) of plastic at $100 \mathrm{~cm}$ (40 in.) and $\mathrm{PuF}_{4}$ plus $10 \mathrm{~cm}$ ( 4 in.) of plastic at $100 \mathrm{~cm}$ (40 in.) to represent the "highly moderated" condition.

The chip ratios obtained from these three components encompass the chip ratios observed during the field conditions. In the discussions which follow, 
N2, N3, N4, R2, and R4 will have the same meaning as in the ${ }^{252} \mathrm{Cf}$ algorithm described in Section 5.1.

\subsubsection{Dose Calculation for the Unmoderated Condition}

Dosimeter response data from the $\mathrm{PuF}_{4}$ source $+0.0 \mathrm{~cm}$ of plastic at $50 \mathrm{~cm}$ (20 in.) and from the $\mathrm{PuF}_{4}+0.0 \mathrm{~cm}$ of plastic at $100 \mathrm{~cm}$ (40 in.) exposure geometry were used to develop expressions for fast neutron dose equivalent for the "unmoderated" condition. This condition corresponds to chip ratios R2 > 2.24 and $\mathrm{R} 4>2.4$. The dose equivalent from the unmoderated $\mathrm{PuF}_{4}$ was large compared to the dose equivalent from ambient background. The response from the $50-\mathrm{cm}\left(20-\right.$ in. $\left._{\text {. }}\right)$ distance compared to the $100-\mathrm{cm}(40-\mathrm{in}$.$) distance, however,$ showed a difference of greater than $10 \%$. Since it is not known which distance is more representative of actual personnel exposures, data for both distances were used in developing the algorithm. Dose conversion factors were obtained such that a fast neutron dose can be calculated from each of the net adjusted readings $N 2, N 3$, and $N 4$. The reported neutron dose equivalent is then the average of the three results. The derived equations are as follows:

1. Calculate N2, N3, N4, R2, and R4 as in steps 2 and 4 of the ${ }^{252} \mathrm{Cf}$-based algorithm (see Section 5.1).

If $R 2>2.24$ or $R 4>2.4$, then calculate dose equivalent as follows:

2. $\mathrm{FN}_{1}=\mathrm{N} 2 / 1.583$, where $\mathrm{FN}$ is fast neutrons.

3. $\mathrm{FN}_{2}=\mathrm{N} 3 / .505$

4. $\mathrm{FN}_{3}=\mathrm{N} 4 / 1.536$

5. $H n=\left(F N_{1}+F N_{2}+F N_{3}\right) / 3$, where $H n$ is the neutron dose equivalent.

The above equations were used to calculate neutron dose equivalent from the dosimeter response data collected from exposures to plutonium metal, $\mathrm{PuO}_{2}$, and $\mathrm{PuF}_{4}$ at $50 \mathrm{~cm}$ (20 in.) and $\mathrm{PuF}_{4}$ at $100 \mathrm{~cm}$ (40 in.) as well as the glove- 
box exposures. The results for all exposure conditions agreed within a factor of $\pm 10 \%$.

\subsubsection{Dose Calculation for the Partial7y Moderated Condition .}

Dosimeter response data from the $\mathrm{PuF}_{4}$ source $+2.54 \mathrm{~cm}$ ( 1 in.) of plastic at $50 \mathrm{~cm}$ (20 in.) and from the $\mathrm{PuF}_{4}+2.54 \mathrm{~cm}$ ( 1 in.) of plastic at $100-\mathrm{cm}$ (40 in.) exposure geometry were used to develop expressions for fast and slow neutron dose equivalent for the "partially moderated" condition. This condition generally corresponds to chip ratios R2 between 1.6 and 2.24, and R4 between 1.8 and 2.4. The dosimeter response data were influenced by a change in the background during the exposure of the $\mathrm{PuF}_{4}$ source $+2.54-\mathrm{cm}(1-\mathrm{in}$. plastic slab at $100 \mathrm{~cm}$ (40 in.). For this condition, dose equivalent is modeled as having two components, one due to fast neutrons (FN) and one due to slow neutrons (SN):

1. Calculate N2, N3, N4, R2, and R4 as in steps 2 and 4 of the ${ }^{252} \mathrm{Cf}$-based algorithm (see Section 5.1).

If $1.60<R 2 \leq 2.24$ and $1.80<R 4 \leq 2.40$, then calculate dose equivalent as follows:

2. $S N=0.0605 * N 3-0.00946 * N 2-0.0114 * N 4$

3. $F N=0.733 * N 2-2.68 * N 3+0.845 * N 4$

4. $H n=F N+S N$

\subsubsection{Dose Calculation for the Highly Moderated Condition}

Dosimeter response data from the $\mathrm{PuF}_{4}$ source with $7.62-\mathrm{cm}(3-\mathrm{in}$.$) of$ plastic at $50 \mathrm{~cm}(20 \mathrm{in.})$ and the PuF $_{4}$ source with $10.16-\mathrm{cm}\left(4-\mathrm{in}_{\text {. }}\right)$ of plastic at $50 \mathrm{~cm}$ (20 in.) were used to develop expressions for fast neutron dose equivalent and slow neutron dose equivalent. The "highly moderated" condition general7y corresponds to chip ratios $\mathrm{R} 2<1.5$ and $\mathrm{R} 4<1.8$. The derived equations and methodology are as follows: 
1. Calcuiate $\mathrm{N} 2, \mathrm{~N} 3, \mathrm{~N} 4, \mathrm{R} 2$ and $\mathrm{R} 4$ as in steps 2 and 4 of the ${ }^{252} \mathrm{Cf}$-based algorithm (see Section 5.1)

If $R 2<1.5$ or $R 4<1.8$, then calculate dose as follows:

2. Calculate the slow neutron dose equivalent:

SN $=-0.00102 * N 2+0.00697 * N 3-0.00138 * N 4$

3. Calculate the fast neutron dose equivalent components:

3a. $\mathrm{FN}_{1}=+0.810 * \mathrm{~N} 2-1.22 * \mathrm{~N} 3+0.241 * \mathrm{~N}_{4}$

If $\mathrm{FN}_{1}<0, \mathrm{FN}_{1}=0$

3b. $\mathrm{FN}_{2}=+0.535 * \mathrm{~N} 2-1.67 * \mathrm{~N} 3+0.722 * \mathrm{~N}_{4}$

If $\mathrm{FN}_{2}<0, \mathrm{FN}_{2}=0$

3c. $\mathrm{FN}_{3}=+0.267 * \mathrm{~N} 2-1.83 * \mathrm{~N} 3+1.01 * \mathrm{~N} 4$

If $\mathrm{FN}_{3}<0, \mathrm{FN}_{3}=0$

4. Calculate fast neutron dose equivalent:

$\mathrm{FN}=\left(\mathrm{FN}_{1}+\mathrm{FN}_{2}+\mathrm{FN}_{3}\right) / 3$

5. Calculate total neutron dose equivalent:

$\mathrm{Hn}=\mathrm{SN}+\mathrm{FN}$

Exposures which generated $R 2$ and $R 4$ values within the applicable range for this branch of the algorithm include the PFP background measurements, $\mathrm{PuF}_{4}$ source plus $5.08 \mathrm{~cm}$ ( 2 in.) of plastic at $50 \mathrm{~cm}$ (20 in.), PuF ${ }_{4}$ source plus $7.62 \mathrm{~cm}\left(3\right.$ in.) of plastic at $50 \mathrm{~cm}\left(20\right.$ in.), and $P_{4} F_{4}$ source plus $10.16 \mathrm{~cm}$ (4 in.) of plastic at $50 \mathrm{~cm}$. The error for the two values-Puf ${ }_{4}$ plus $7.62 \mathrm{~cm}$ ( 3 in.) of plastic at $50 \mathrm{~cm}\left(20\right.$ in.) and $\mathrm{PuF}_{4}$ plus $10.16 \mathrm{~cm}(4$ in.) of plastic was less than $20 \%$.

The data from the PuF 4 source plus $5.08 \mathrm{~cm}$ (2 in.) of plastic at $50 \mathrm{~cm}$ (20 in.) was high by $60 \%$. This high result is an anomaly and resolution can be obtained only by further field measurements. At this time, no field 
location has been measured with these spectra; however, it is very possible that field measurements may reveal a limited number of locations with low dose rates and a spectrum similar to the spectrum for the $P_{4 F_{4}}$ source plus $5.08 \mathrm{~cm}$ (2 in.) of plastic at $50 \mathrm{~cm}(20$ in.). If some locations have this type of spectrum, a facility calibration factor will likely be necessary for those locations.

As a check of the algorithm using the $\mathrm{PuF}_{4}$ source, a smal7 study of several vault locations was made. Section 6.2 discusses the vault study results.

\subsection{CR-39 TRACK-ETCH DOSIMETER ALGORITHM}

Two foils in each batch are exposed to bare ${ }^{252} \mathrm{Cf}$ and used to determine a batch calibration factor which relates mrem to track count; the calibration factor will have units of $\mathrm{mrem} / \mathrm{tracks} / \mathrm{cm}^{2}$. The two blank foils are used to determine a batch background factor having units of tracks $/ \mathrm{cm}^{2}$. Within the dose range $0-1000 \mathrm{mrem}$, the number of track counts is directly proportional to neutron dose equivalent received. The neutron dose equivalent in mrem is then calculated by averaging the two foil track counts, subtracting the background factor, and multiplying that result by the calibration factor, as follows:

$$
H_{n}=\left[\left(T_{1}+T_{2}\right) / 2-B\right] * C
$$

where $\quad H_{n}=$ neutron dose equivalent

$T_{1}=$ foil 1 track count in tracks $/ \mathrm{cm}^{2}$

$T_{2}=$ foil 2 track count in tracks $/ \mathrm{cm}^{2}$

$B=$ batch background factor in tracks $/ \mathrm{cm}^{2}$

C = batch calibration factor in $\mathrm{mrem} / \mathrm{tracks} / \mathrm{cm}^{2}$

The lower energy threshold of CR-39 response to neutrons is approximately $100 \mathrm{keV}$. For this reason, care must be exercised. when using CR-39 in highly scattered neutron fields where lower-energy neutrons may be a significant component of the personnel dose. The PNNL measurements in the PFP work environments have shown significant under-response for TEDs in highly moderated neutron fields. Based on these measurements, a range of acceptable 
values for each of the albedo TLD chip ratios $R 2$ and $R 4$ has been determined, which indicates sufficient hardness in the neutron spectrum for energyindependent dose measurement with $\mathrm{CR}-39$. If $\mathrm{R} 2<1.6$ or $\mathrm{R} 4<1.8$, then the neutron spectrum is too moderated and significant under-response of the CR-39 is likely. Under these circumstances, the CR-39 foil is typically not processed. 



\subsection{SUPPLEMENTAL HORKPLACE MEASUREMENTS}

To assure proper performance of the HCND algorithms, additional measurements were performed to observe dosimeter performance exposed to realistic neutron energy spectra encountered in the workplace. This was accomplished by selecting several locations for study. At each location, the neutron energy spectra were measured using the multisphere spectrometer and determining dose equivalent rates from the multisphere and tissue equivalent proportional counters, as described in Section 2.0. Then, dosimeters were exposed on acrylic plastic phantoms 30 by 30 by $15 \mathrm{~cm}$ ( 12 by 12 by 6 in.) at these locations, so that the evaluated dose equivalent from the dosimeter could be directly compared with the measured dose equivalent. This section describes these field measurements.

Most of the neutron exposures at Hanford occur at the PFP, where large quantities of plutonium are stored. Although plutonium is no longer being produced, the amount of plutonium is expected to increase as inventories are consolidated and material is moved to the PFP to be placed under international safeguard controls. There are wide variations in the neutron energy spectra encountered at the PFP because of great variations in shielding and types of material present, which includes $\mathrm{PuO}_{2}$, plutonium metal, $\mathrm{PuF}_{4}$, and mixed oxide fuel rods that contain plutonium. Exposure conditions range from essentially no neutron shielding when the plutonium is physically handled to massive neutron shielding with several feet of concrete and iron. The neutron energy spectra encountered range from "hard" spectra, which are essentially fission spectra from the unshielded plutonium, to "soft" low-energy spectra, encountered behind the massive shields in the storage vaults, behind water walls, and behind other neutron shields which have been installed to reduce the dose to workers.

It is possible that exposure situations could occur where the dose algorithms used in evaluating the dosimeter response could produce erroneous dose equivalent estimates. Therefore, dosimeter exposures were performed at a wide variety of locations, where dose equivalent rates were measured and neutron energy spectra characterized. The results of these measurements 
demonstrated that the dose equivalents determined by the HCND were within acceptable error limits for the wide variety of spectra encountered at the PFP.

Because of limited resources, it was not possible to perform spectral measurements at every location where there were differences in the neutron energy spectrum. In low-dose-rate areas, the spectral measurements would require several days to obtain statistical accuracy, and dosimeter exposures would require weeks. A method was devised by which a few short measurements could be used as a spectral indicator for selecting locations for more detailed measurements. These locations included office areas on the "frontside," control rooms, plutonium storage vaults, and plutonium process areas.

\subsection{SPECTRAL SURVEY}

Because of 7 imited resources, it was thought that a simple method could be developed to relate the ratio of count rates from the $20-\mathrm{cm}(8-\mathrm{in}$.$) and$ $8-\mathrm{cm}\left(3-i n_{.}\right)$diameter multispheres to the average neutron energy. This method had been proposed before as a method of "field calibrating" TLD-albedo dosimeters, but had mixed success. For very low-energy neutrons, the $20-\mathrm{cm}$ (8-in.) diameter sphere will absorb most of the neutrons, and very long counting times may be required to obtain statistical counting accuracy. Data were assembled from previous multisphere measurements of bare $\mathrm{PuF}_{4}$ and ${ }^{252} \mathrm{Cf}$ sources, and sources shielded by up to $10 \mathrm{~cm}$ (4 in.) of acrylic plastic under well-defined scattering conditions. Multisphere measurements were also included for workplace spectra in front of a plutonium glove box, as well as low-energy spectra from neutrons scattered through several concrete walls at the PFP. Figure 6.1 shows a plot of the ratio of count rate from the $20-\mathrm{cm}$ (8-in.) to $8-\mathrm{cm}(3-i n$.$) diameter spheres, as a function of average energy$ calculated by the computer code SPUNIT (Brackenbush and Scherpelz 1984). The data can be fitted to a straight line with an standard deviation of $19 \%$, which is indicated by the dashed 7 ines in Figure 6.1. Thus, it appears that a reasonable estimate of the average neutron energy can be obtained from just the ratio of counts from two spherical moderators placed over the ${ }^{6} \mathrm{LiI}$ scintillator detector. 


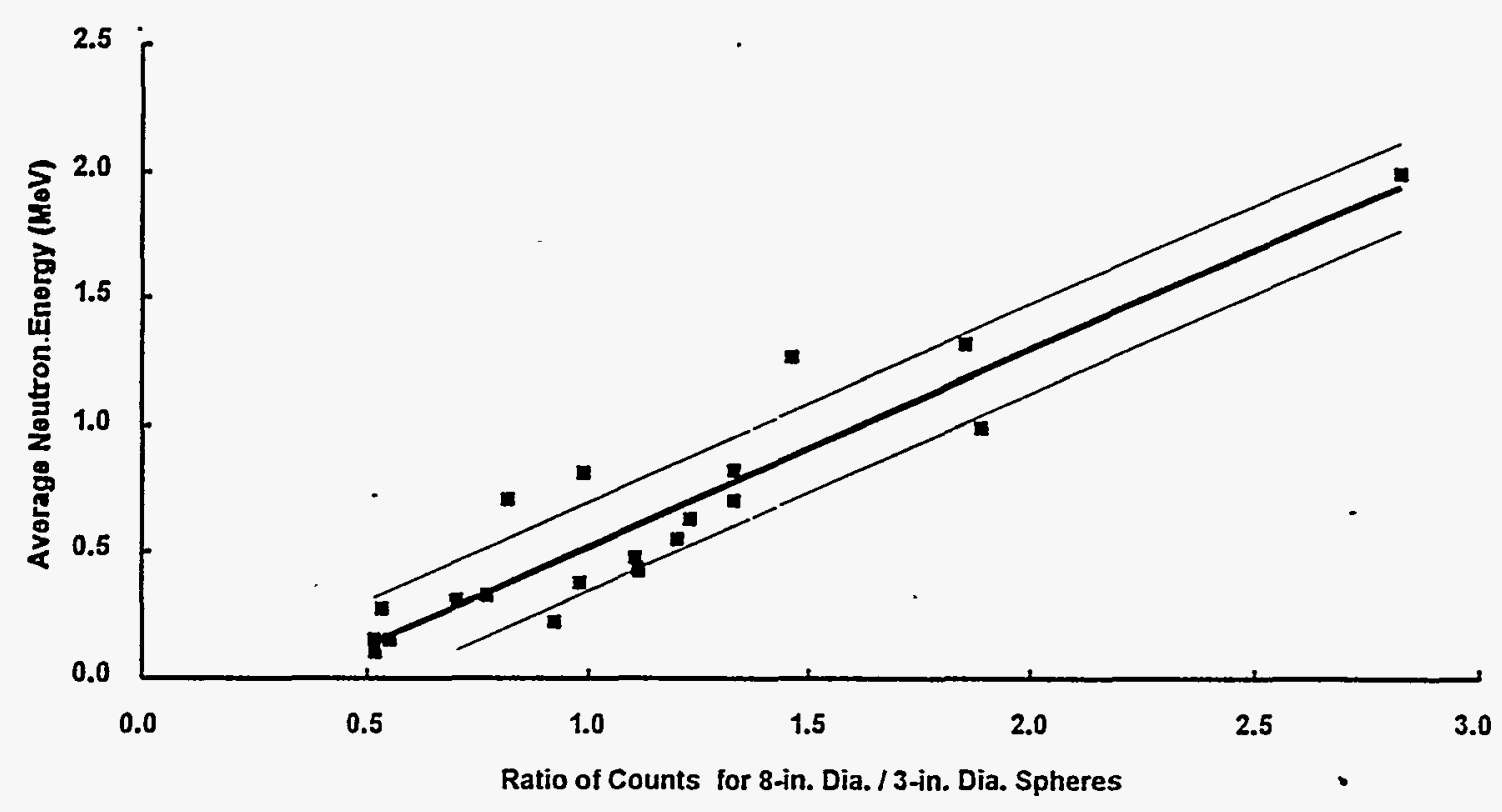

FIGURE 6.1. Correlation Between the Average Neutron Energy Determined from Multisphere Spectrometer Measurements and the Ratio of the Count Rates from the $20-\mathrm{cm}\left(8-\mathrm{in}_{.}\right)$and $8-\mathrm{cm}(3-i n$.$) Diameter$ Spheres

As shown in Figure 6.2, it appears that the ratio of bal1 counts can also be used to "calibrate" the $20-\mathrm{cm}$ (8-in.) spherical detector as a rem meter. Again, a straight line can be fitted to the calibration factor (i.e., the $\mu S v /$ hour per count/second from the $20-\mathrm{cm}$ [8-in.] sphere) with a $14 \%$ standard deviation, which is shown by the dashed lines in Figure 6.2. The dose equivalent rate was determined by multisphere and TEPC measurements using the methods outlined in Section 2.0 of this report. The dose equivalent rate can simply be found from the product of the count rate from the $20-\mathrm{cm}(8-\mathrm{in}$.) diameter sphere multiplied by the calibration constant derived from Figure 6.2. This is a simple method to obtain reasonably accurate dose equivalent rates from quick measurements made with the $20-\mathrm{cm}(8-i n$.$) and 8-\mathrm{cm}\left(3-\mathrm{in.}_{.}\right)$ diameter spheres. For low- energy, highly scattered neutrons, this method appears to be more accurate than measurements made with a Snoopy with a single calibration factor. But experience from measurements in nuclear power reactors has shown that this method may fail for very low-energy neutrons with 
average energies in the $\mathrm{keV}$ region. In that case, the count rate from the 20-cm (8-in.) diameter ball can be dominated by only a few higher-energy neutrons because almost al1 of the lower-energy neutrons are absorbed before reaching the LiI scintillator detector.

The methods described in the previous paragraphs were used to perform a survey of the entire 234-5 Building, including the "frontside" offices, maintenance shops, ventilation ducts on Level 2 where workers are exposed changing high-efficiency particulate air (HEPA) filters, and piutoniumhandling areas. This preliminary survey was used to find the extremes of neutron energies found in the plant, so that dosimeters could be exposed to verify proper operation at these selected locations where the dose rate was high enough to perform measurements in a reasonable time. This greatly reduced the number of measurements required. The results of this preliminary survey are presented in Table 6.1.

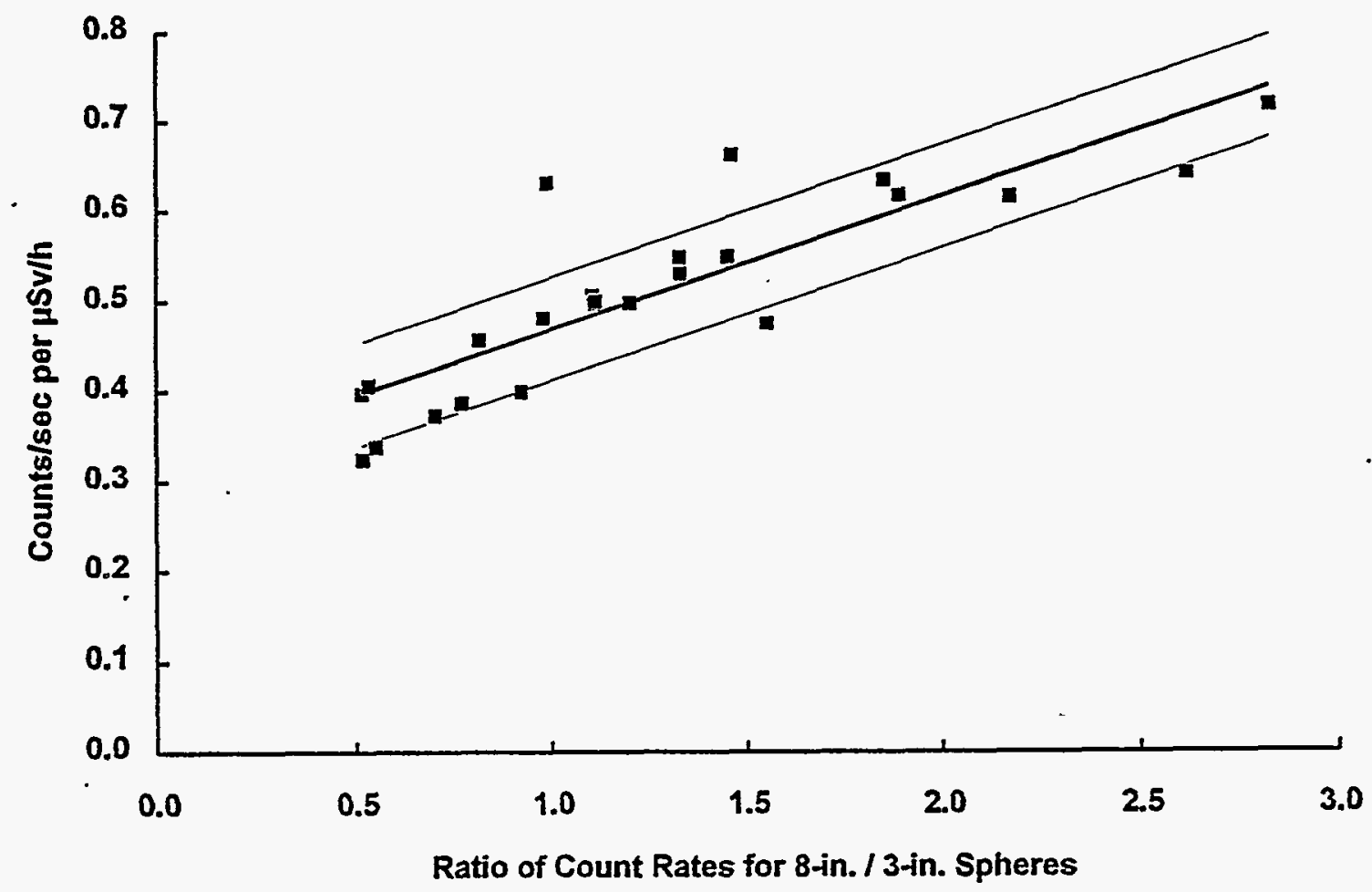

FIGURE 6.2. Correlation Between the Dose Equivalent Calibration Constant and the Ratio of the Count Rates from the 20-cm (8-in.) and 8-cm (3-in.) Diameter Spheres 
TABLE 6.1. Summary of Neutron Survey Measurements at the Plutonium Finishing Plant to Determine the Range of Neutron Energies at Locations Where Workers are Exposed

Location

"Frontside" or Office Areas-

Office, Loc. A

Office, Loc. B

Office, Loc. C

Office, Loc. D

New Office, Entry, Loc. E

New Office, Loc. F

in Front Side Duct Leve1, Loc. G

Upstairs Office, Loc. H

Upstairs Equipment Room, Loc I

Upstairs Control Room, Loc. J

Upstairs Office, Loc. K

Upstairs Electrical Shop, Loc. L

Upstairs Electrical Shop, Loc. M

Upstairs Rest Room, Loc. N

Upstairs Rest Room, Loc. 0

Upstairs Rest Room, Loc. P

Upstairs Storeroom, Loc. Q

- Upstairs Lunch Room, Loc. R

Upstairs Lunch Room, Loc. P
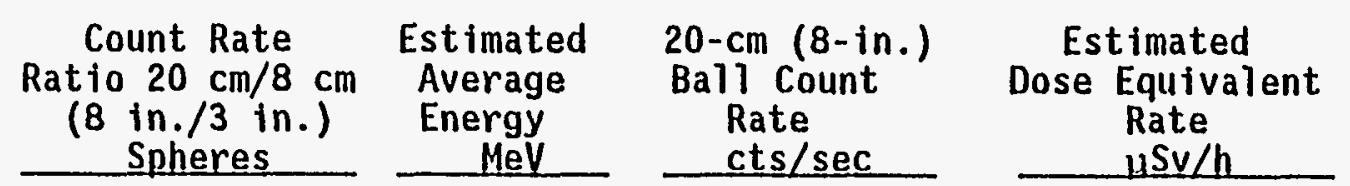

0.49

0.52

0.61

0.50

0.79

0.58

0.49

0.51

0.57

0.53

0.58

0.52

0.54

0.56

0.56

0.65

0.69

0.72

0.57

0.12

0.14

0.21

0.13

0.36

0.19

0.13

0.14

0.19

0.15

0.19

0.14

0.16

0.18

0.17

0.25

0.27

0.30

0.19

0.61

0.46

0.33

0.39

0.04

0.04

1.40

2.28

4.86

0.76

0.77

0.65

1.53

4.10

4.60

7.53

12.92

$0.09^{\circ}$

0.06

0.24

0.17

0.13

$0: 15$

0.02

0.02

0.55

0.91

1.96

0.30

0.31

0.26

0.61

1.65

1.85

3.10

5.38

0.04

0.02 . 
TABLE 6.1. Cont'd

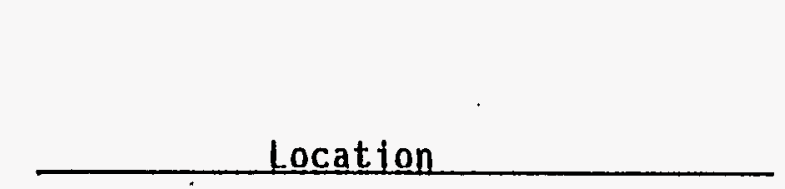

"Backside" or Process Areas-

Office Room, Loc. Q

Office Room, Loc. R

Near Fluorinator Box, Loc. S

Control Room, Loc. T

Glove Box, Loc. U

Fluorinator Glove Box, Loc.

Water Wa11, Loc. W

$a$

Duct Leve1 2, HEPA Filter, Loc. X Duct Level 2, HEPA Filter, Loc. $Y$
Count Rate Ratio $20 \mathrm{~cm} / 8 \mathrm{~cm}$

( 8 in. $/ 3$ in.)

Spheres

0.52
0.59
0.93
0.72
0.85
1.19
0.68
1.22
0.96
Estimated

Average

Energy

$\mathrm{MeV}$

0.15

0.20

0.47

0.31

0.40

0.67

0.27

0.69

0.49 20-cm (8-in.) Ball Count Rate cts/sec

\subsection{9}

1.75

75.94

6.45

3.31

229.65

2.16

72.25

80.43 .
Estimated

Dose Equivalent Rate 11Sv/h
0.15
0.71
33.6
2.7
1.43
0.89 109.

34.5
35.8 


\subsection{Z-VAULT MEASUREMENTS}

This section provides details of the field measurements in the 2736-ZB vaults. The vaults contain unique neutron energy spectra that pose a severe test of the new dosimetry system being implemented at Hanford. These measurements are also important because of the potential of large neutron exposures to personnel involved in placing several metric tons of plutonium under surveillance by the International Atomic Energy Agency '(IAEA).

Measurements were performed at five different locations within the storage vault complex. A "Snoopy" neutron survey instrument was used to determine approximate dose equivalent rates to select the locations, then six dosimeters were placed on acrylic plastic phantoms, 30 by 30 by $15 \mathrm{~cm}$ ( 12 by 12 by 6 in.) positioned approximately 1 meter $(3.3 \mathrm{ft})$ above the floor. The plastic phantoms were positioned in aisles with the back side of the phantom near the concrete walls of the storage vaults. This was necessary to minimize disruption of work within the vaults. After the dosimeter exposures were completed, the neutron energy spectra were measured using the multisphere spectrometer; then, dose measurements were performed using two $12.7-\mathrm{cm}$ (5-in.) diameter spherical TEPCS.

The results of the instrument measurements are presented in Table 6.2. Note that it was not possible to perform TEPC measurements in Vault 3 and the hallway because equipment placed at these positions would have interfered with normal vault operations. There seems to be reasonable agreement between a11 of the dose equivalent measurements, which have a standard deviation of $10 \%$ or less at each location.

The neutron energy spectra measured by the multisphere spectrometer at each of the five locations is presented in Figures 6.3 through 6.7, which present the neutron flux density per unit lethargy plotted as a function of the logarithm of the neutron energy. In these plots, equal areas represent equal neutron fluxes. The neutron flux has been normalized to a unit dose equivalent, so that differences in the spectra can be readily seen. There are dramatic differences in the neutron energies in the vault areas.

\section{7}


TABLE 6.2. Dose Equivalent Rates from Multisphere and Tissue Equivalent Proportional Counter Measurements in the 2736-ZB Vaults

Measured Neutron Dose Equivalent Rates, uSv/h

Multishpere

Location

Vault 1

Vault 2

Vault 3

Vault 4

Ha77way
48

327 4.9 105 24 .
Snoopy Spectromenter IEPC 185

40
400
11
120
20

340

102
TEPC 504

38
372
-
122
-

Standard

Average Deviation

42.8

346

$4.9^{\circ}$

110

24

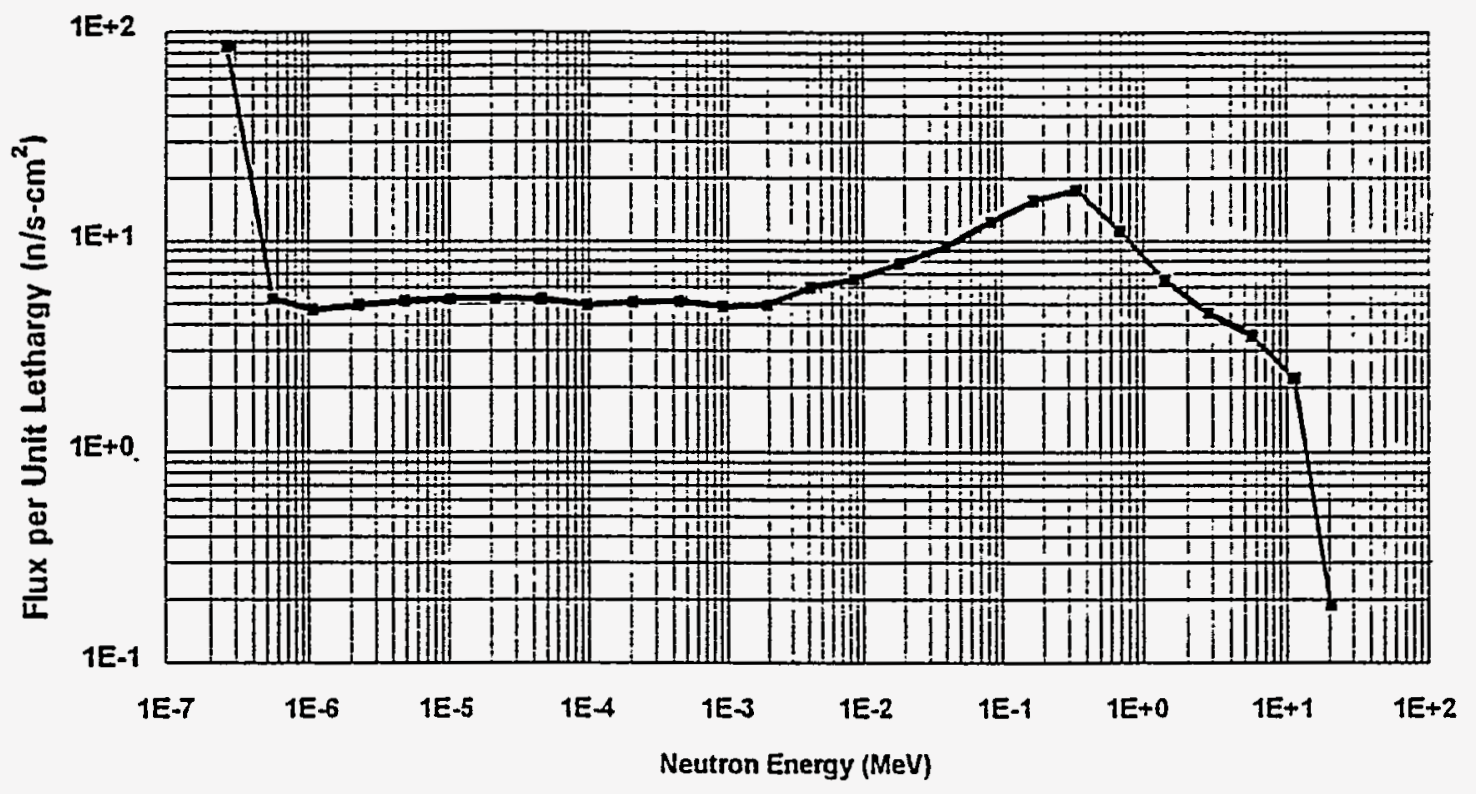

FIGURE 6.3. Neutron Energy Spectrum Measured by the Multisphere Spectrometer in Vault 1 of the 2736-ZB Building - The neutron flux density is normalized to unit dose equivalent. 


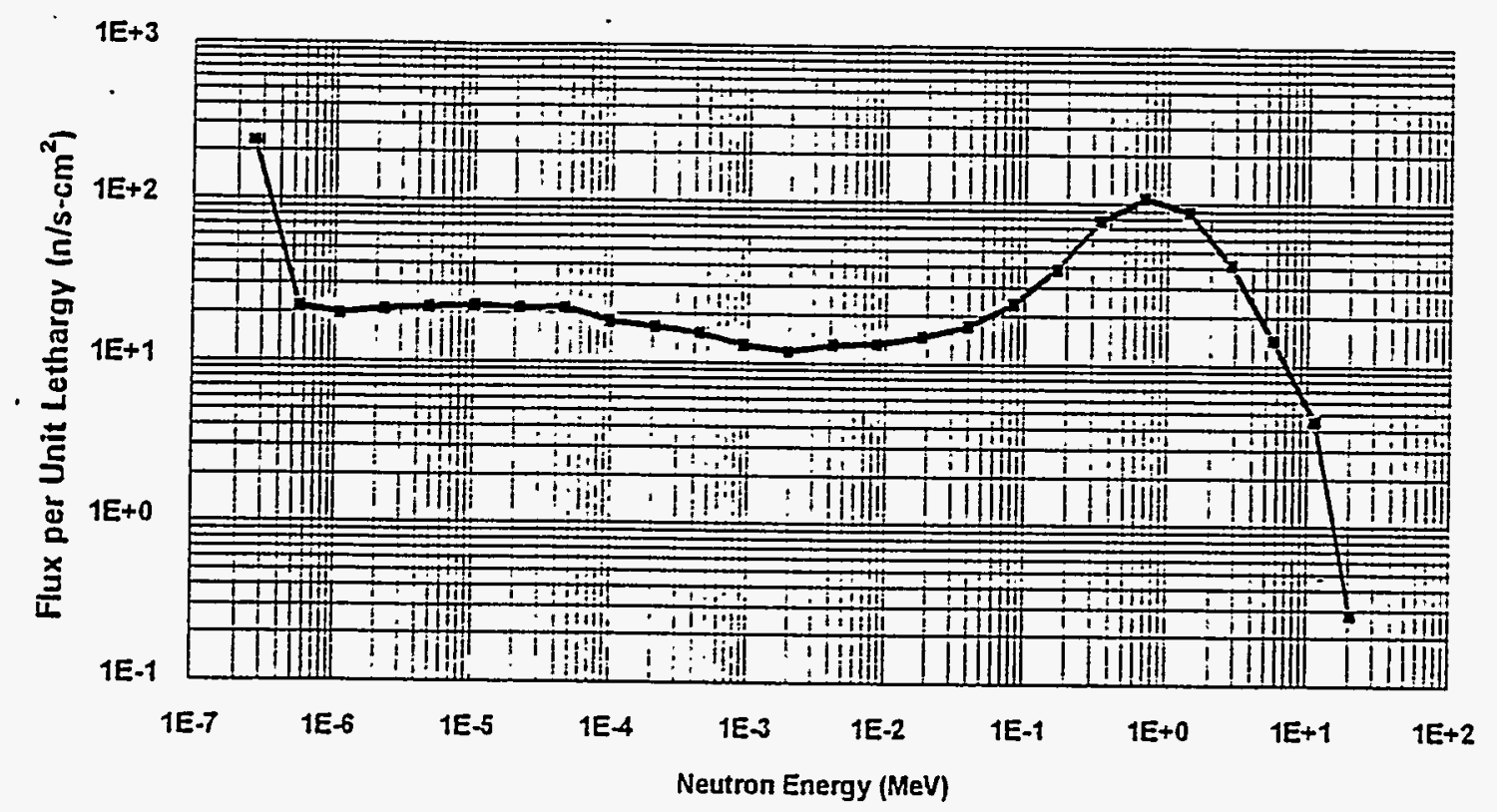

FIGURE 6.4. Neutron Energy Spectrum Measured by the Multisphere Spectrometer in Vault 2 of the 2736-ZB Building - The neutron flux density is normalized to unit dose equivalent.

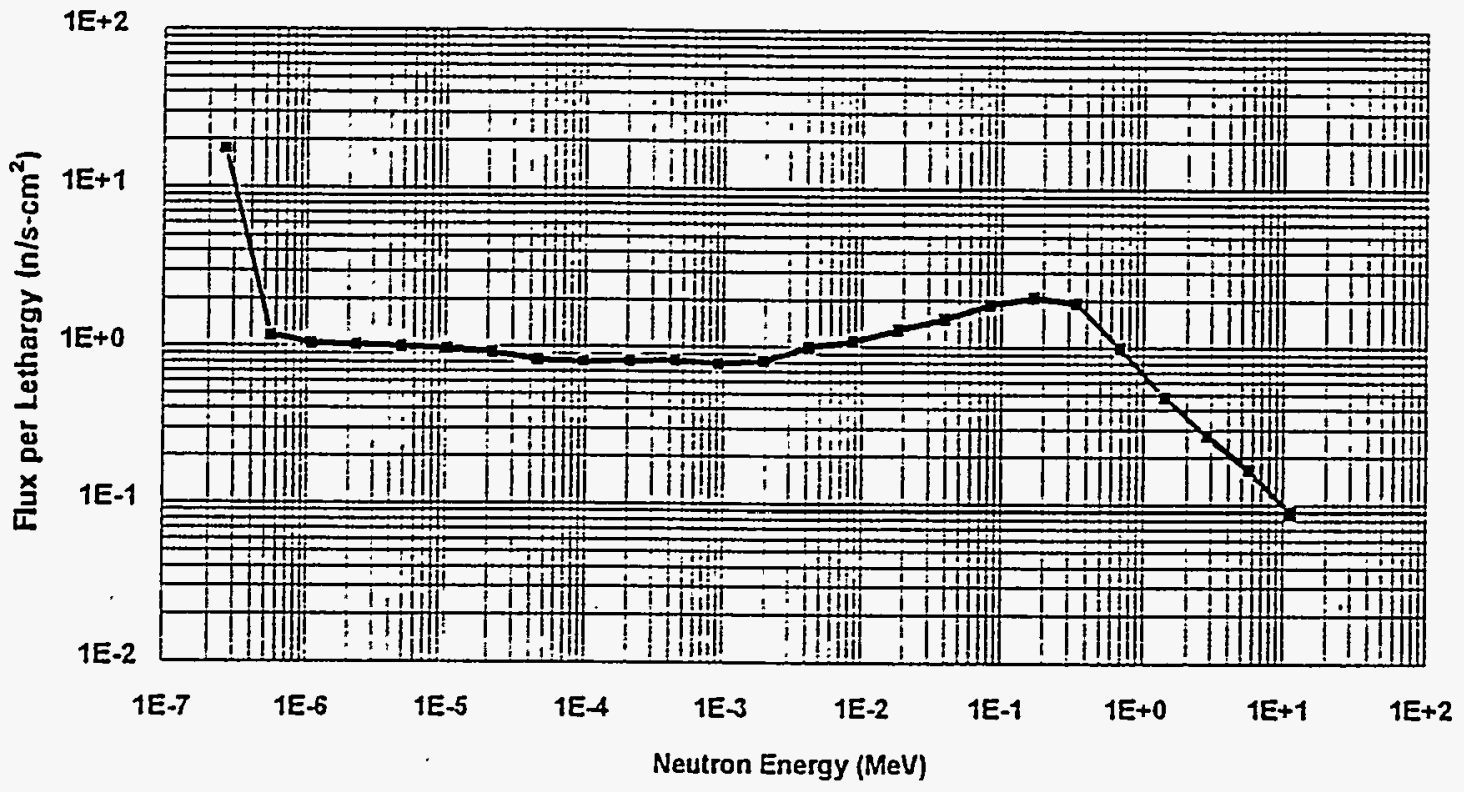

FIGURE 6.5. Neutron Energy Spectrum Measured by the MuTtisphere Spectrometer in Vault 3 of the 2736-ZB Building - The neutron flux density is normalized to unit dose equivalent. 


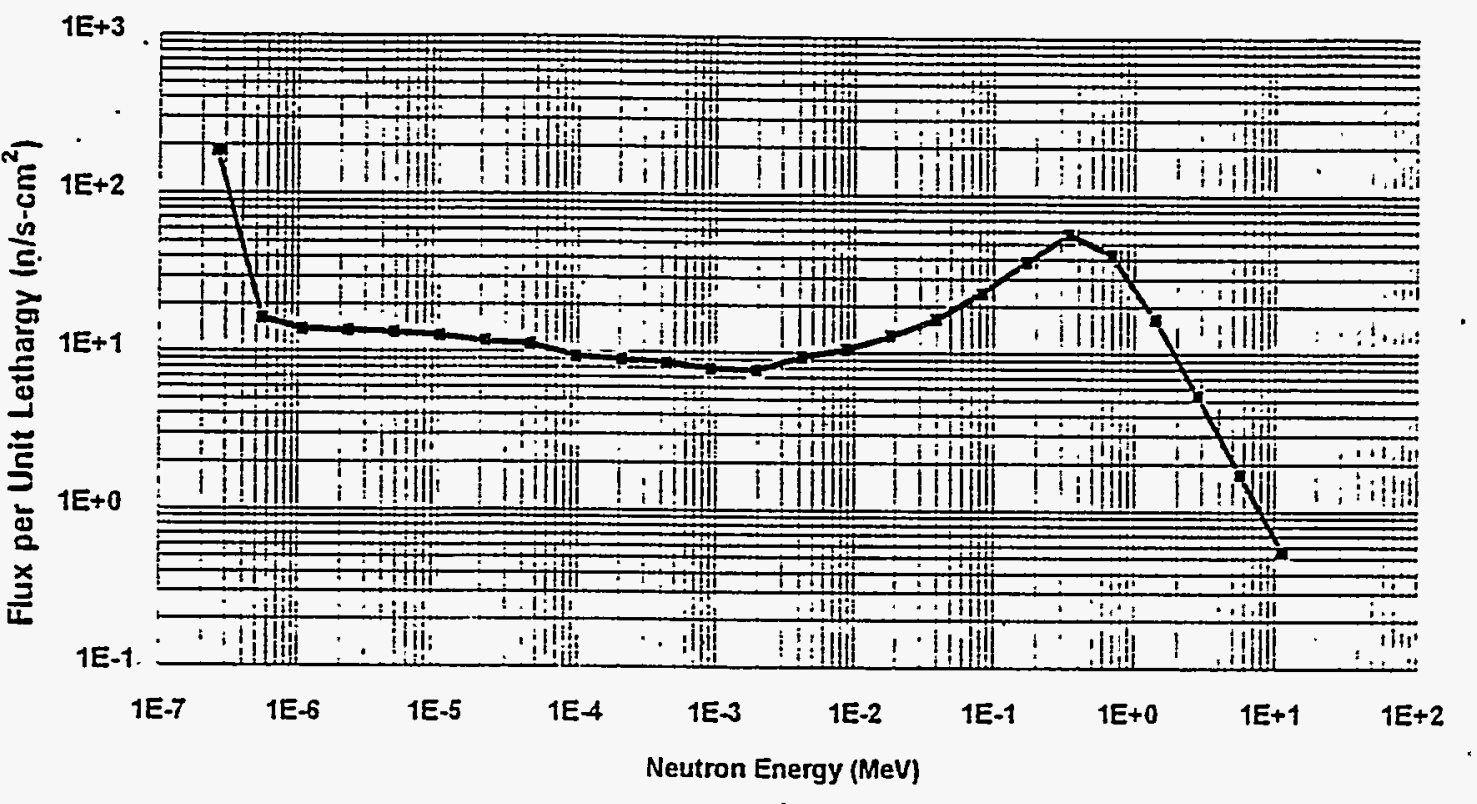

FIGURE 6.6. Neutron Energy Spectrum Measured by the Multisphere Spectrometer in Vault 4 of the 2736-ZB Building - The neutron flux density is normalized to unit dose equivalent.

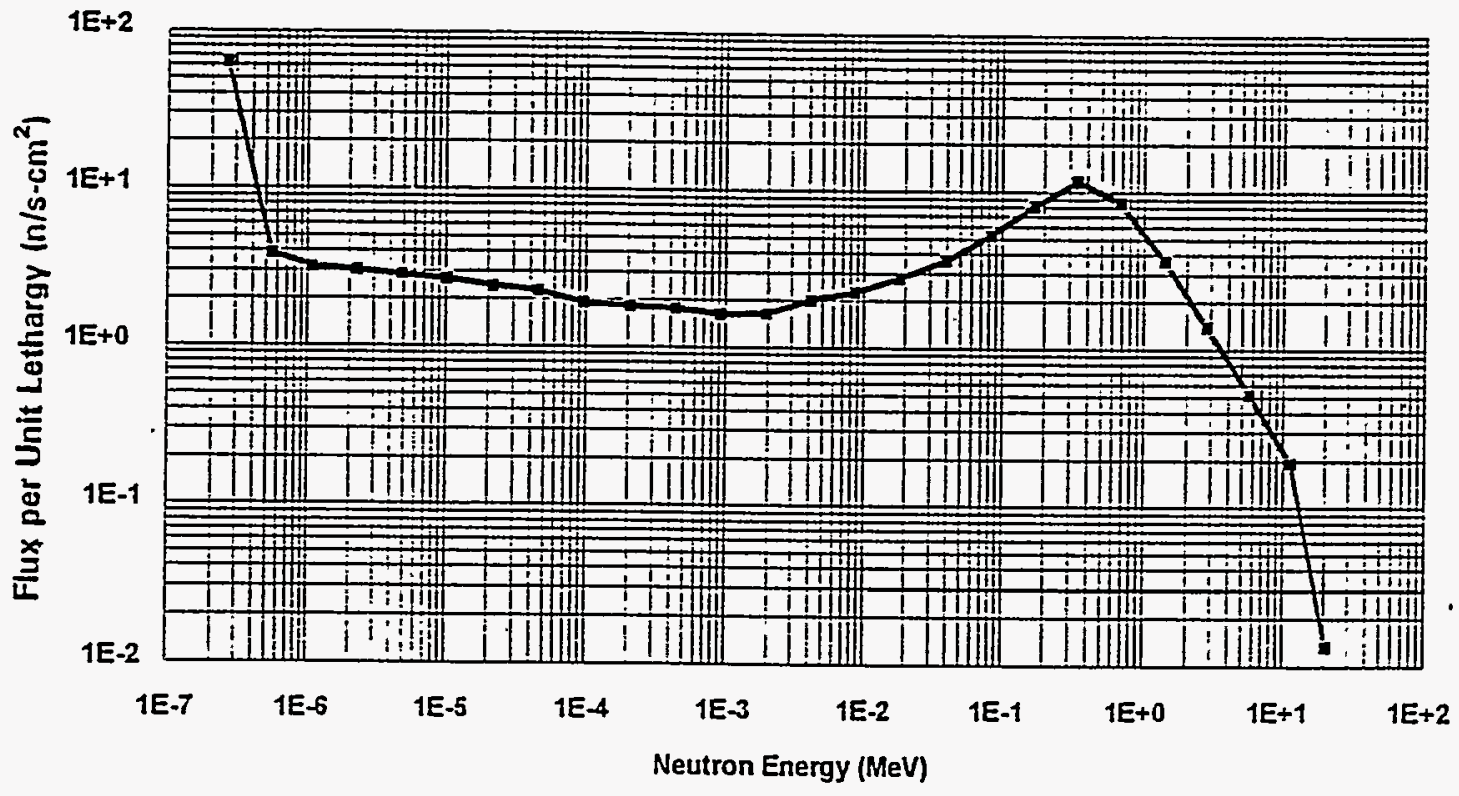

FIGURE 6.7. Neutron Energy Spectrum Measured by the MuItisphere Spectrometer in the Hallway Outside of the Vaults the 2736-ZB Building - The neutron flux density is normalized to unit dose equivalent. 
The "hardest" spectra are found in Vault 2, which contained hundreds of kilograms of $\mathrm{PuO}_{2}$ in storage and shipping containers with little additional neutron shielding. Consequently, the spectrum from Vault 2 presented in Figure 6.4 has a distinct peak at about $1 \mathrm{MeV}$ with fewer low-energy scattered neutrons, but a large thermal component from neutrons reflected from the floor and walls.

Vautts 1,3 , and 4 have large quantities of $\mathrm{PuO}_{2}$ stored behind thick steel shielding, which can be as much as 4-in. thick. As expected, Vaults 1 and 4 have very similar spectra, with peak energies of $300 \mathrm{keV}$ to $400 \mathrm{keV}$. But Vault 3, which contains the least amount of plutonium, has a slightly lower peak energy at about $200 \mathrm{keV}$, a greater number of intermediate-energy neutrons, and the largest thermal component. These spectra are much "softer" or lower in energy than any of the other measurements performed at the PFP. It is believed that these spectra are the result of low-energy neutrons passing through the "windows" or antiresonances in the absorption crosssection of iron at $26 \mathrm{keV}$ and $51 \mathrm{keV}$. Similar "soft" spectra have been measured by the authors using spectrometers with better resolution in the containment of commercial nuclear power plants, where neutrons pass through the thick steel pressure vessel of the reactor.

Measurements were also performed in the hallway outside the storage vaults, as shown in Figure 6.7. This spectrum a7so has a peak energy of about $300 \mathrm{keV}$, a large intermediate-energy component, and a large thermal neutron component similar to that found in Vaults 1 and 4. All the spectra in the 2736-ZB vault storage areas contain a great number of neutrons with intermediate and thermal energies and pose a difficult test for the dose equivalent algorithm used to evaluate the TLD-albedo dosimeter in the HCND. From the spectral data, one would expect that the TLD-albedo dosimeter will overestimate the neutron dose equivalent and the TED would seriously underestimate dose equivalent. Most of the neutrons have energies below the energy threshold for detection by the TED. The results of dosimeter measurements at these locations using the plutonium-based algorithm are presented in Table 6.3. As expected, the TLD-aTbedo component overestimated the delivered dose by factors of 1.5 to 1.8 for Vaults 1,3 , and 4 . For the harder spectrum in Vault 2, the TLD-albedo dosimeter underestimated the 
delivered dose equivalent by $16 \%$. Surprisingly, in the hal7way the HCND was within $4 \%$ of the delivered dose equivalent estimated from spectrometer. measurements.

TABLE 6.3. Results of the Dosimeter Exposures in the 2736-ZB Vaults

Indicated Dose Equivalent Rate From Dosiemter ${ }_{\mathrm{SSV}} / \mathrm{h}$

Location

Vault 1 .

Vault 2

Vault 3

Vault 4

Hallway
New TLD-Albedo

$63(+46 \%)^{(a)}$

$297(-16 \%)$

$8(+63 \%)$

$198(+80 \%)$

$25(+4 \%)$
Track-Etch Dosimeter

$13(-70 \%)^{(a)}$

$46(-87 \%)$

$1(-80 \%)$

$33(-70 \%)$

$5(-80 \%)$
Detivered Dose Equivalent Rate Calculated from Spectrometer, $\mu \mathrm{Sv} / \mathrm{h}$

(a) Number in parentheses is the percent deviation from the delivered dose equivalent rate.

\section{3 "FRONTSIDE" MEASUREMENTS}

In the past few years, water walls and additional neutron shielding have been added to the plutonium-processing areas to reduce the dose to operating personne1. But neutrons are still able to scatter over the shields and pass through the concrete walls into the "frontside" offices. TLD-albedo dosimeters are quite sensitive to these highly scattered neutrons, and a measurable signal can be recorded on the TLD-600 chips in the HSD and the HCND. However, it is expected that the dose evaluation algorithm in the HCND will provide more accurate dose equivalent evaluations than the Hanford Multipurpose Dosimeter used previous7y. As indicated in Table 6.1, almost al1 of the spectra encountered on the "frontside" of the 234-5 Building are reasonably similar and have about the same average energy. From the preliminary survey made with the ratio method described in Section 6.1, the average neutron energy varies between $120 \mathrm{keV}$ and $300 \mathrm{keV}$. 
Two Tocations with higher dose rates were selected for detailed spectral measurements. These locations were close to the positions measured previous7y in the initial survey discussed in Section 6.1. Location $Q$, the storeroom on the third floor, was chosen because it had the highest dose rates and had a neutron energy spectrum similar to a nearby complex of offices. Location B was selected because it had a neutron energy spectrum similar to that found in nearby maintenance and electrical shops and the in control room on the third floor. No exposures were performed on the office areas on the first floor because the dose equivalent rates were too low to obtain statistical1y significant data, even with exposures of several weeks duration. But the spectral survey indicated that the spectra in the offices on the first floor are similar to those measured on the third floor.

The neutron energy spectrum at Location $Q$, the storeroom on the third floor, is presented in Figure 6.8. This graph presents the neutron flux per unit lethargy normalized to unit dose equivalent, so that it can be compared with the neutron energy spectra discussed in previous sections. This is a relatively "soft" or low-energy spectrum typical of the degraded neutrons scattered around the shields and through the concrete walls. The spectrum has a large number of thermal and intermediate neutrons. The peak energy is about $400 \mathrm{keV}$, and the flux-weighted average energy calculated from the multisphere spectrometer is $460 \mathrm{keV}$.

Figure 6.9 shows the neutron energy spectrum measured by the multisphere spectrometer on the third floor at Location I near the shops and control room. The shape of the spectrum is similar to that of Figure 6.8, except the neutrons have slightly lower energies. The fast neutron peak occurs at about $300 \mathrm{keV}$, and the flux-weighted average neutron energy is about $200 \mathrm{keV}$ due to a greater number of intermediate neutrons. The dose equivalent rates were calculated from the neutron energy spectra using the conversion coefficients from NCRP Report 38 (NCRP 1971), which are identical to the values given in Title 10, Part 835 of the Code of Federal Regulations. The calculated dose rates are presented in Table 6.4. 


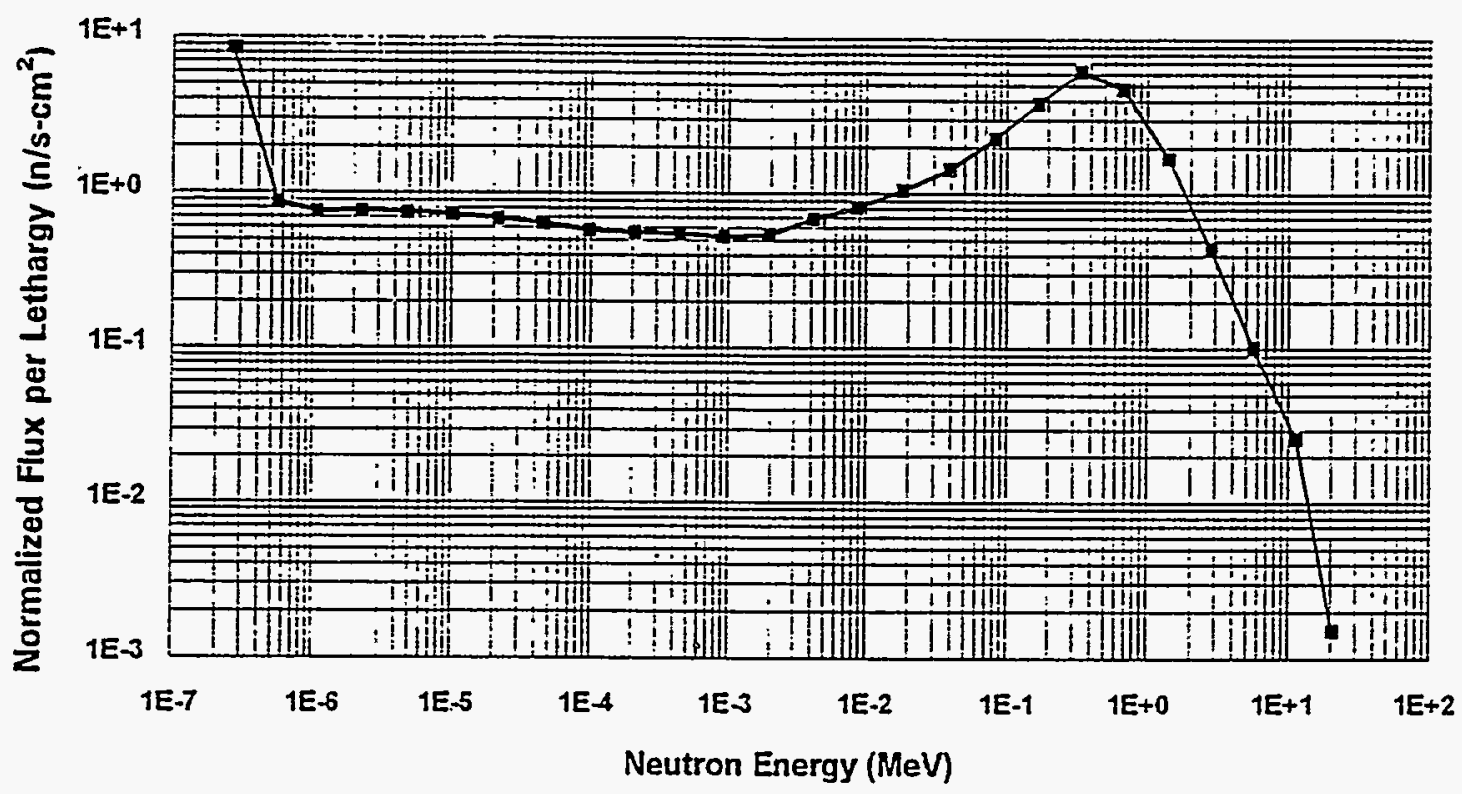

FIGURE 6.8. Neutron Energy Spectrum Measured by the Multisphere Spectrometer at Location $Q$ in the Storeroom Near the Office Areas on the Third Floor on the "Frontside" of the 234-5 Building - The neutron flux density is normalized to unit dose equivalent.

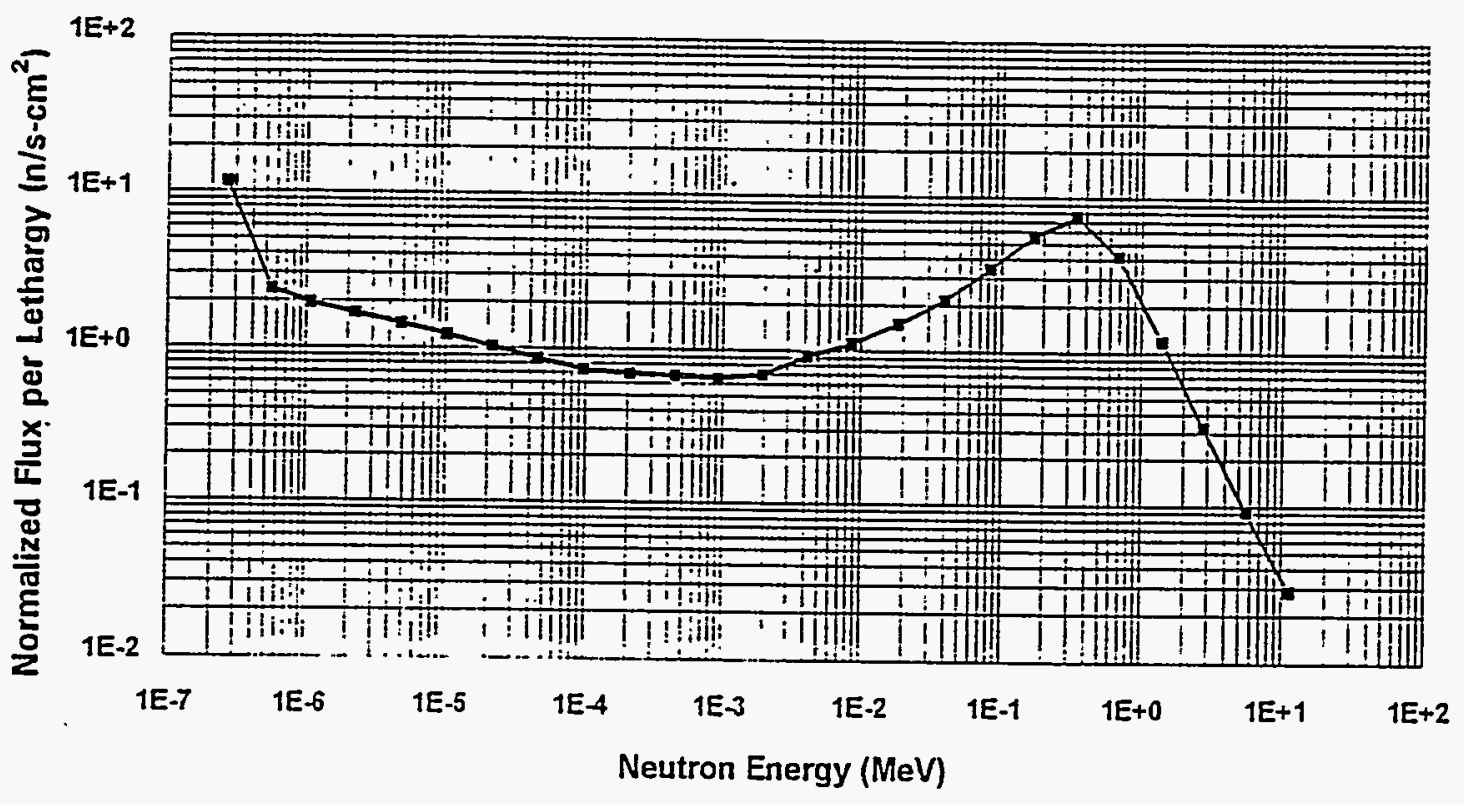

FIGURE 6.9. Neutron Energy Spectrum Measured by the Multisphere Spectrometer At Location I Near the Shops and Control Room on the Third Floor of the "Frontside" of the 234-5 Building - The neutron f7ux density is normalized to unit dose equivalent. 
TABLE 6.4. Results of the Dosimeter Exposures on the "Frontside" of the 234-5 Building

Indicated Dose Equivalent Rate from Dosimeter, $\mu \mathrm{Sv} / \mathrm{h}$

Location

Location Q

Storeroom

Location I

near shops
New TLD-ATbedo Track-Etch Dosimeter

$5.7 \quad(+13 \%)^{(a)} \quad 1.0 \quad(-83 \%)^{(a)}$

$1.5(+66 \%)^{(a)} \quad$ Not Evaluated
Delivered Dose Equivalent Rate Calculated from Spectrometer, uSv/h

5.06

0.897

(a) Numbers in parentheses are the percent deviation from the delivered dose equivalent rate.

After the spectral measurements were completed, HCNDs were placed on both sides of acrylic plastic phantoms, 30 by 30 by $15 \mathrm{~cm}$ ( 12 by 12 by 6 in.) and the phantoms were placed at the same positions used for the spectral measurements. The evaluated dose equivalent rates from the HCNDs are presented in Table 6.4. The numbers in parentheses are the percent deviation from the delivered dose rate, determined from the multisphere spectrometer measurements. As expected, the TED underestimated the dose equivalent because most of the neutrons have energies below the detection threshold for CR-39. The TLD-albedo dosimeter overestimated the dose equivalent because of the "soft" spectra. The large number of intermediate energy neutrons at Location I, as shown in Figure 6.8 , is probably responsible for the $+66 \%$ error.

\section{4 "BACKS IDE" MEASUREMENTS}

A series of spectral measurements and dosimeter exposures were also performed on the "backside" or process area on the first floor of the 234-5 Building. The first measurements were made with the multisphere spectrometer near the fluorinator hoods along two separate process 7 ines, and the results are presented in Figures 6.10 and 6.11. The spectra are very similar in general shape, as one would expect. The spectrum at Location $S$ shown in 
Figure 6.10 has a peak energy of $500 . \mathrm{keV}$ and a flux-weighted average energy of $400 \mathrm{keV}$; it is "softer" or has lower-energy neutrons than the spectrum at Location $V$. The spectrum at Location $V$ in Figure 6.11 has a fast neutron peak at about $700 \mathrm{keV}$ and a flux-weighted average energy of $600 \mathrm{keV}$.

The dose equivalent rates calculated from the spectral data are. presented in Table 6.5, with the results from HCND dosimeters exposed on acrylic plastic slab phantoms where the multisphere measurements were performed. Because the neutron field is highty anisotropic near the fluorinator boxes, only data from the dosimeters directly exposed to the fluorinator glove boxes are presented in Table 6.5: As expected, the TED dosimeters record only about half of the neutron dose. The TLD-albedo dosimeters provide better dose estimates. But the results are somewhat unexpected; the dosimeters exposed to the "softer" spectrum overestimate the delivered dose by $29 \%$, while the dosimeters exposed to the "harder" or higher energy spectrum underestimated the delivered dose by $26 \%$. Apparently, the algorithm used to calculate dose equivalent is quite sensitive to spectral shifts in this energy region.

TABLE 6.5. Results of the Hanford Combination Neutron Dosimeter Exposures on the "Backside" of the 234-5 Building

Dose

Delivered

Indicated Dose Equivalent Rate from Dosimeter $\mu \mathrm{Sv} / \mathrm{h}$

Equivalent Rate

Calculated from

Spectrometer

Location

New TLD-ATbedo

Track-Etch Dosimeter

$\mu \mathrm{SV} / \mathrm{h}$

Location $S$

Fluorinator

$59.9(+29 \%)^{(a)}$

$24.5(-60 \%)^{(a)}$

46.6

Location $V$

Fluorinator

$85.0(-26 \%)^{(a)}$

$40.6(-49)^{(a)}$

115.5

(a) Numbers in parentheses are the percent deviation from the delivered dose equivalent rate. 


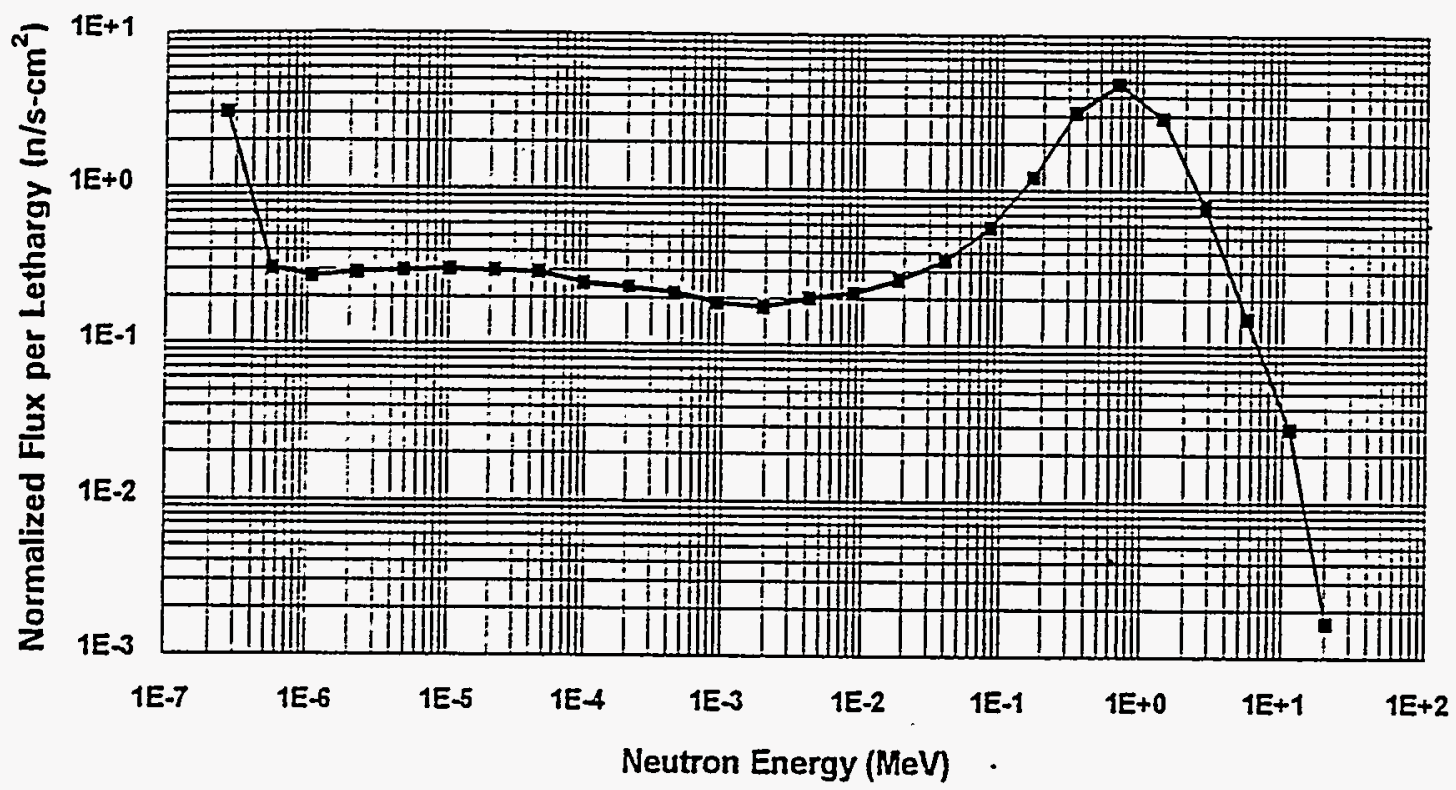

FIGURE 6.10. Neutron Energy Spectrum Measured by the Multisphere Spectrometer at Location S Near the Fluorinator on the "Backside" of the 234-5 Building - The neutron flux density is normalized to unit dose equivalent.

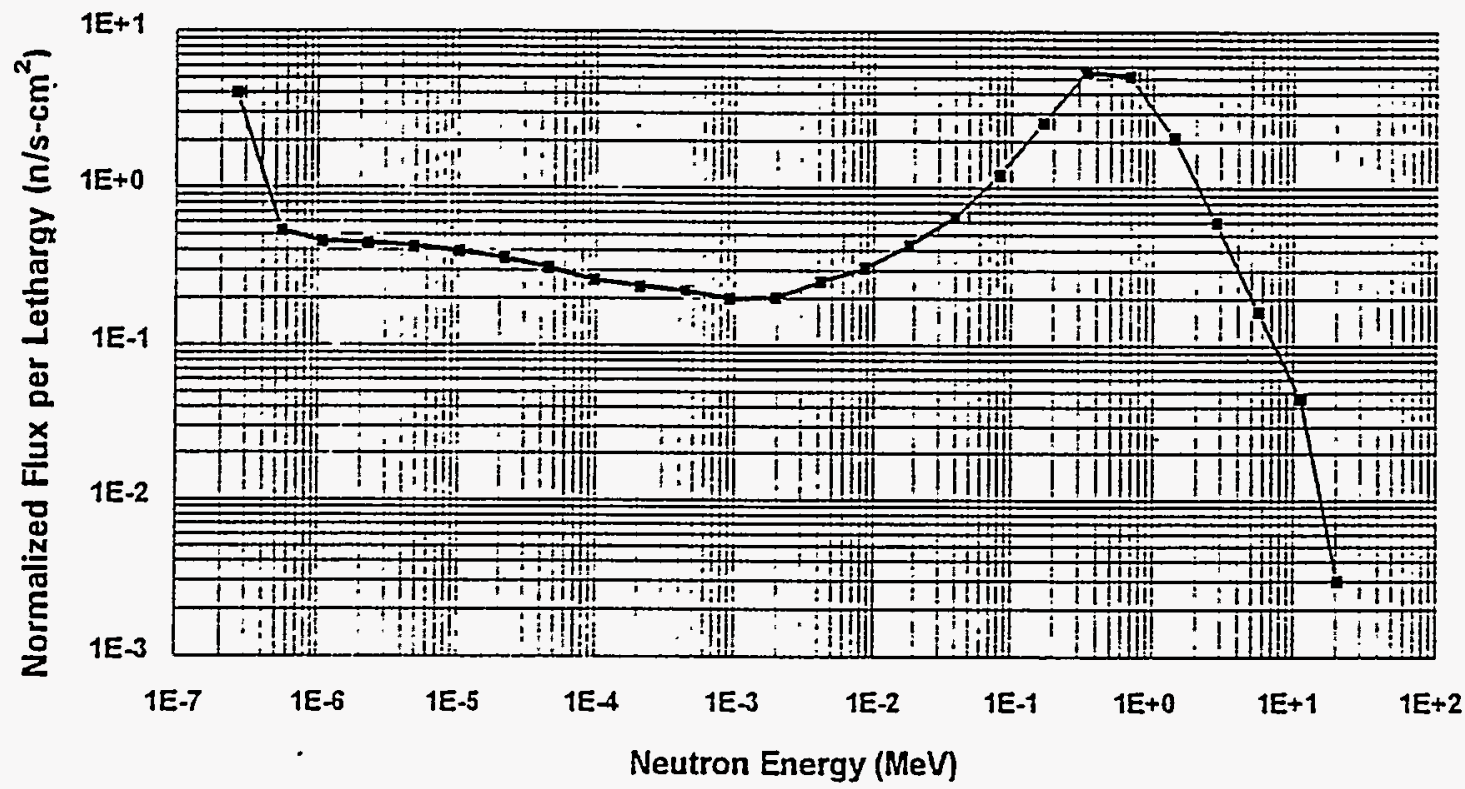

FIGURE 6.11. Neutron Energy Spectrum Measured by the Multisphere Spectrometer At Location V near the Fluorinator on the "Backside" or Process Area of the 234-5 Building - The neutron flux density is normalized to unit dose equivalent.

\subsection{7}





\subsection{CONCLUSION}

Neutron field measurements of the HCND within the PFP conducted for this report are different from earlier measurements performed while plutonium finishing was conducted. The addition of massive neutron shields to selected working areas within the PFP to reduce the dose equivalence to workers has produced some unexpected effects on HCND response.

\subsection{PLUTONIUM FINISHING PLANT NEUTRON FIELDS}

Neutron doses to workers protected by the neutron shielding have been greatly reduced, as expected. However, the water walls and polyethylene shielding do not extend from the floor to the ceiling, and some neutrons scatter around the shielding. This has caused an increase in the low-energy neutron flux in many locations and in the office areas. These very low-energy neutrons, resulting from multiple scattering interactions, provide a severe test for any available passive neutron dosimeter system. Attempts have been. made during the past year to develop dose equivalent algorithms used with the HCND, containing both TLD-aTbedo and TED components, to accurately calculate dose under these conditions at the PFP.

\subsection{THERMOLUMINESCENT DOSIMETER - ALBEDO RESPONSE CHARACTERISTICS}

The TLD-a1bedo component of the HCND consists of two cards: 1) an 8816 four-element card containing three ${ }^{6}$ LiF and one ${ }^{7}$ LiF chips for neutron dose determination and 2) an 8825 four-element card containing a 11 'LiF chips for shaliow, eye, and deep dose estimation. This component has several advantages:

- highly automated system

- good anguiar response

- demonstrated performance for beta and photon dose determination

- gamma-corrected neutron response using combinations of ${ }^{6} \mathrm{LiF}$ and ${ }^{7} \mathrm{LiF}$ chips

- Tong history of use at Hanford. 
This component a7so has some disadvantages:

- energy dependent neutron response

- neutron response dependent secondary interaction (i.e., albedo effect based on neutrons backscattered from the body), which is dependent upon material composition, size, placement, etc.

- dosimeter el ement response to beta, photon, and, in the case of ${ }^{6}$ LiF chips, neutron radiation

- relatively complex algorithm, particularly with the design of the HCND using two separate parameters (based on chip response) to estimate the incident neutron spectra.

The neutron response of the HCND 8816 TLD-albedo component is based on the use of ${ }^{6}$ LiF TLD chips that have a neutron absorption cross-section inversely proportional to the velocity of the neutron. As such, the response of the chips is dependent on the energy of the incident neutrons being very sensitive to low-energy neutrons.

If exposed to monoenergetic neutrons only, the response of the LiF chips changes by a.7most three orders of magnitude for neutrons with energies between thermal and $10 \mathrm{MeV}$. The dosimeter response is also geometry-dependent (i.e., different responses are observed depending on whether the incident neutron radiation is anterior-posterior, isotropic, etc.). Low-energy neutrons and highty scattered fields in the current environment at the PFP require that dosimeters be worn in the proper orientation, close to the chest or torso. It is very difficult to accurately measure neutron dose equivalence in this environment.

Results from measurements at the PFP reported in this document and in PNL-7881 (Brackenbush, Bumgartner, and Fix 1991) show that Hanford TLD-albedo dosimeters perform we11 in the work environment, compared to the measured dose with TEPCs, as long as care is taken to properly calibrate the dosimeter for the characteristics of the neutron field. The energy compensation algorithms developed for the TLD-albedo component of the HCND, based on two separate variables describing dosimeter response characteristics, compare well with TEPC measurements of the actual dose equivalent in al1 measured work locations. The possible exception is the very highly scattered neutron fields in the office locations, where the HCND tends to overestimate the dose 
equivalent. This is likely attributable to significant dosimeter response from neutrons incident upon the dosimeter for very large angles (i.e., the highly scattered neutron fields in the office locations are essentialiy - isotropic) and the associated disproportionate response of the ${ }^{6}$ LiF chips to the Tower-energy neutrons.

\subsection{TRACK-ETCH DOSIMETER RESPONSE CHARACTERISTICS}

The TED component of the HCND consists of two CR-39 foils located within the TLD holder containing the 8816 card. This component has several important response characteristics. Relative advantages of this component include:

- direct interaction with incident neutrons

- relatively flat neutron energy response above the $100-\mathrm{kel}$ energy threshold

- no response to photon radiation

- simple algorithm to calculate dose equivalent.

Relative disadvantages include:

- intensive and time-consuming manual processing

- electrochemical etching conducted in groups of 24 foils with the foil response dependent upon the etch cycle

- poor anguTar response characteristics

- for optimum dose interpretations, etching cycle that needs to be modified depending upon the dose level

- Tittle response below energy threshold of about $100 \mathrm{keV}$.

The TED component (i.e., CR-39 foils) of the HCND is routinely processed only when the TLD-albedo neutron component exceeds a specified dose equivalent threshold level and the response characteristics of the TLD-albedo indicate a neutron spectra of predominantly higher energies. Parameters describing the response characteristics of the TLD-aTbedo dosimeter which must be met prior to processing the TED were derived from field measurements at the PFP (i.e., determined from analysis of TLD, TED, and TEPC data at each measurement location). The significance of the lower level energy threshold of about 
$100 \mathrm{keV}$ for CR-39 neutron response was evident in the PFP measurements. At some locations, there simply were too many neutrons of lower energy for accurate dose assessment with the CR-39 foiTs without introduction of fieldspecific calibration factors. In addition, the CR-39 response becomes nonlinear at some point beyond $10 \mathrm{mSv}$ with the routine readout protocol.

The CR-39 dosimeter has the potential for use as an extremity dosimeter because of its small size and direct interaction with the neutron radiation. The PFP measurements showed very good performance of the TED in spectra where the average energy is above $100 \mathrm{keV}$. For example, TED measurements of sources of plutonium, even with significant shielding material, were very acceptable. However, the TED under-responded to the actual neutron dose equivalent by as much as a factor of six in the office locations where low-energy, highly scattered neutron fields were observed.

\subsection{OVERALL RESPONSE OF HANFORD COMBINATION NEUTRON DOSIMETER}

Based on the measurements conducted at the PFP, both the TLD-albedo and TED components of the HCND satisfactorily calculated dose equivalence for work locations involving actual sources of plutonium metal, $\mathrm{PuO}_{2}$, or $\mathrm{PuF}_{4}$ compared to TEPC measurements of the actual dose equivalent. In the PFP, work

locations where highly scattered, low-energy neutron fields were observed, the TLD-aTbedo dosimeter is expected to overestimate the dose equivalent, and the TED is expected to underestimate dose equivalent. In general, the results indicate that the energy-compensating algorithm developed for the TLD-aTbedo component is functioning properly, even for the wide variety of "hard" and "soft" spectra encountered at the PFP. When an error is made in dose evaluation, the error is generally conservative, i.e., the dosimeter will overestimate dose equivalent and will not miss dose. The worst case observed occurred in the unique, very low-energy spectra found in the 2736-ZB vaults, where the TLD-albedo component overestimated the dose equivalent by $80 \%$ and the TED component underestimated the dose by a factor of six.

It is possible to introduce field-specific calibration factors to be used with either or both dosimeter components to improve the dose estimates; however, this would entail significant risk of inaccurately calculating dose when changes in the work environment occur, such as. changes in plutonium 
inventory, location, etc. As such, routine dependence on the TLD-albedo component appears to be the best alternative.

In reviewing the data presented in this report, a reader may have the impression that the HCND has consistently large errors. This is not the case. The locations selected for this study were cases specifically selected to test the extreme limits for the respective TLD-albedo and TED components and the respective dose algorithms. For many workplace exposures, one or both of the HCND TLD-a7bedo or TED components worked very acceptably. For example, in the hal7way in the $2736-\mathrm{ZD}$ vaults, the dose equivalent evaluated by the TLD-albedo component agreed within $4 \%$ of that determined from spectrometric measurements. In the storeroom and general office areas on the third floor of the 234-5 Building, the TLD-albedo component agreed within $15 \%$ of the dose equivalent rate determined by the spectrometers. Even in the anisotropic fields near the flourinator boxes in the plutonium-processing areas, the TLD-albedo component agreed within $30 \%$ of the dose equivalent rate determined from spectrometers. For almost all of the plutonium metal, $\mathrm{PuO}_{2}$ and $\mathrm{PuF}_{4}$ source measurements, with selected shielding materials, the TED component results were very acceptable.. However, as noted in this report, the TED component routinely underestimated dose equivalent in the currently observed high-scatter work environments at the PFP because the majority of neutrons had energies below the CR-39 threshold for detection.

There is concern that future changes in the neutron spectra at the PFP might result in cases in which the energy compensating algorithm used to calculate dose in the TLD-albedo component might fail and produce erroneous dose results. As such, validation of the performance of the HCND is recommended whenever any significant changes in the work environment occur. Certainly, the HCND performance should be evaluated every few years to assure that no changes have occurred. If direct handling of plutonium becomes a predominant exposure mode in the future, consideration should be given to using the TED component because of its energy-independent response for higherenergy neutrons. In addition, TED dosimetry has the potential for use as a neutron extremity dosimeter which is currentiy not available. 



\subsection{REFERENCES}

10 CFR 835. December 14, 1993. "Occupational Radiation Protection; Final RuTe." Federal Register.

52 CFR 2822-2834. January 27, 1987. "Federal Radiation Protection Guidance to.Federal Agencies for Occupational Exposure; Approval of the Environmental Protection Agency Recommendations." Federal Register.

American National Standards Institute (ANSI). 1993. American National Standard for Dosimetry, Personnel Dosimetry Performance - Criteria for Testing. ANSI N13.11, New York, New York. Rev. 1993.

Brackenbush, L. H., G. H. R. Endres, J. M. Selby, and E. J. Vallario. 1980. Personnel Neutron Dosimetry at Department of Eneray Facilities. PNL-3213, Pacific Northwest Laboratory, Richland, Washington.

Brackenbush, L. H., H. V. Baumgartner, and J. J. Fix. 1991. Response of TLDA7bedo and Nuclear Track Dosimeters Exposed to Plutonium Sources. PNL-7881, Pacific Northwest Laboratory, Richland, Washington.

Brackenbush, L. H., and R. I. Scherpelz. 1984. "SPUNIT, A Code for Multisphere Unfolding." In Computer Applications in Health Physics, R. L. Kathren, D. P. Higby, and M. A. McKinney, eds., pp 4.1-4.6. Proceedings of the Seventh Midyear Topical Symposium of the Health Physics Society, Columbia Chapter of the Health Physics Society Richland, Hashington.

Brackenbush, L. H., and L. G. Faust. 1970. Neutron Spectra of Plutonium Compounds, Part 1: ${ }^{3} \mathrm{He}$ and ${ }^{6} \mathrm{Li}$ Spectrometer Measurements. BNW-1262, Pacific Northwest Laboratory, Richland, Washington.

Bramblett, R. L., R. I. Ewing, and T. H. Bonner. 1960. "A New Type of Neutron Spectrometer." Nuclear Instruments and Methods 9:1-12.

Doroshenko, J. J., S. N. Kraitor, T. V. Kuznetsova, K. K. Kushnereva, and E. S. Lonov. 1977. "New Methods for Measuring Neutron Spectra with Energy from $0.4 \mathrm{eV}$ to $10 \mathrm{MeV}$ by Track and Activation Detectors." Nuclear Technology $33: 296-304$.

Hankins, D. E., S. G. Homann, and J. Hestermark. 1989. Personnel Neutron Dosimetry Using Electrochemically Etched CR-39 Foils. UCRL-53833, Rev.1, Lawrence Livermore National Laboratory, Livermore, Califọnia.

Ing, H., and S. Makra. 1978. Compendium of Neutron Spectra in Criticality Accident Dosimetry. Technical Report Series No. 180, International Atomic Energy Agency, Vienna.

International Commission on Radiological Protection (ICRP). 1991.1990 Recommendations of the International Commission on Radiological Protection. ICRP Publication 60, Pergamon Press, 0xford, England. 
International Commission on Radiological Protection (ICRP). 1987. Data for Use in Protection Against External Radiation. ICRP Publication 51, Pergamon Press, Oxford, England.

International Commission on Radiological Protection (ICRP). 1977. Recommendations of the International Commission on Radiological Protection. ICRP Publication 26, Pergamon Press, 0xford, England.

International Commission on Radiation Units and Measurements (ICRU). 1983. Microdosimetry. ICRU Report No. 36, ICRU Publications, Bethesda, Maryland.

Johnson, T. L., and S. G. Gorbics. 1981. "An Iterative Perturbation Method for Unfolding Neutron Spectra from Bonner Sphere Data." Health Physics $41(6): 859$.

Kellerer, A. M. 1969. "Analysis of Patterns of Energy Deposition." In Proceedings of the Second Symposium on Microdosimetry, Stresa, Italy, pp. 107-134. Office for Official Publications of the European Community, Luxembourg.

National Council on Radiation Protection and Measurements (NCRP). 1971. Protection Against Neutron Radiation. NCRP Report No. 38, Bethesda, Maryland.

Piesch, E., and B. Burgkhardt: 1978. "The Role of an Analyzer Type Albedo Dosimeter in Routine Monitoring and the Current Situation for the Calibration Technique." In Seventh DOE Workshop on Personne1 Neutron Dosimetry, pp. 25-37. PNL-2807, Pacific Northwest Laboratory, Richland, Washington.

Routi, T. J., and J. V. Sandberg. 1978. General Purpose Unfolding Program LOUH178 with Linear and Non-7inear Regularization. Report TKK-/A359, He $s$ sinki University of Technology, Department of Technical Physics, Otaneimi, Finland.

Schwartz, R. B., and C. M. Eisenhauer. . 1982. Procedures for Calibrating Neutron Personnel Dosimeters. NBS Special Publication No. 633, U.S. National Bureau of Standards, Washington, D.C.

U:S. Department of Energy (DOE). 1994. U.S. Department of Energy Radiological Control Manual. DOE/EH-0256T, Revision 1, Washington, D.C. 


\section{APPENDIX}

MULTISPHERE SPECTROMETER DATA 
.

\section{.}




\section{MULTISPHERE SPECTROMETER DATA}

This appendix contains the results of the multisphere spectrometer measurements on the plutonium tetrafluoride $\left(\mathrm{PuF}_{4}\right)$, plutonium dioxide $\left(\mathrm{PuO}_{2}\right)$, and plutonium metal sources. The multisphere spectrometer is described in Section 2.1. Details of the measurements are described in Section 5.1.2 for the $\mathrm{PuF}_{4}$ source, in Section 5.2.2 for the $\mathrm{PuO}_{2}$ source, and in Section 5.3.2 for the plutonium-gallium metal source.

The results of the SPUNIT spectrum unfolding code are presented in Tables A.1 to A.12. The tables contain differential energy spectra and cumulative spectra in terms of the flux density. per unit lethargy. The differential and cumulative dose equivalent distributions are also presented for the same logarithmic energy bins. Differential neutron energy spectra are often presented as a function of flux density per unit lethargy, so that lowenergy neutron spectra are more apparent. This is especially important when comparing spectra measured behind neutron shielding. If the neutron flux density per unit lethargy is plotted on a linear scale, and the neutron energy is plotted on a logarithmic scale, then equal areas represent equal flux densities.

Tables A.I through A.5 present the measured spectra at $50 \mathrm{~cm}$ (20 in.) from the PuF $_{4}$ source with no shielding and with $2.54 \mathrm{~cm}(1$ in. $), 5.04 \mathrm{~cm}(2$ in.), $7.62 \mathrm{~cm}$ ( 3 in.) and $10.2 \mathrm{~cm}$ ( 4 in.) of acrylic plastic shielding. Tables A.6 through A.10 give the measured spectra at $100 \mathrm{~cm}$ (40 in.) for the same shield configurations. Tables $A .11$ and $A .12$ give the measured spectra at $50 \mathrm{~cm}$ (20 in.) from the $\mathrm{PuO}_{2}$ and plutonium metal sources without any shielding.

The results are displayed in Figures A.I through A.3. Figure A.I shows the changes in the neutron energy spectra produced by shielding the PuF source. The neutron flux densities per unit lethargy were measured at a distance of $50 \mathrm{~cm}\left(20 \mathrm{in.}\right.$ ) from the $\mathrm{PuF}_{4}$ source, and the results have been normalized so that a1] of the spectra fit onto the graph. As expected, the bare $\mathrm{PuF}_{4}$ source shows a prominent peak at $1.3 \mathrm{MeV}$ from the fluorine(alphaneutron) reaction and few room scattered neutrons. With $2.54 \mathrm{~cm}$ ( 1 in.) of

\section{A.1}


acrylic plastic shielding, the spectrum exhibits a broader peak with a slightly lower average energy, and increased intermediate and slow. neutron components. ${ }^{a}$ With $10.2 \mathrm{~cm}$ (4 in.) of acrylic plastic shielding, the fast neutron peak is even broader and has a lower average energy. The intermediate and slow neutron components are significantly increased compared to the fast neutron component. Data for the 5.04- $\mathrm{cm}\left(2-\right.$ in. $\left._{0}\right)$ and $7.6-\mathrm{cm}\left(3-\right.$ in. $_{\text {. }}$ slab shields of acrylic plastic were not included on the graph for.clarity, but these data are presented in Tables A.3 and A.4.

Figure A.2 demonstrates the effects of room scatter on the measured spectra at distances of $50 \mathrm{~cm}\left(20\right.$ in.) and $100 \mathrm{~cm}$ (40 in.) from the bare $\mathrm{PuF}_{4}$ source without any shielding. These spectra have been normalized to accent the differences in the shape of the spectra. The fast neutron peak at $1.3 \mathrm{MeV}$ is about the same for both spectra. However, neutrons scattered from the concrete walls and floor of the room produce much larger intermediate and slow neutron components for the spectrum measured at $100 \mathrm{~cm}$ (40 in.).

Final7y, Figure A.3 demonstrates the differences in the spectral measurements for the $\mathrm{PuF}_{4}, \mathrm{PuO}_{2}$, and plutonium-gallium metal alloy sources. The $\mathrm{PuF}_{4}$ source shows a distinct peak at $1.3 \mathrm{MeV}$ from the fluorine (alphaneutron) reaction with few intermediate and thermal neutrons. Both the metal and $\mathrm{PuO}_{2}$ sources show a broader fast neutron peak, with $\mathrm{PuO}_{2}$ having the broadest peak due to fast neutrons produced by the oxygen (alpha-neutron) reaction. The metal and $\mathrm{PuO}_{2}$ sources emit about 1000 times fewer neutrons than the $\mathrm{PuF}_{4}$ source. As a result, room backgrounds are more pronounced and, relative to the fast neutron peak, there are larger intermediate and slow neutron components for the $\mathrm{PuO}_{2}$ and metal spectra. $\mathrm{keV}$; slow neutrons have energies below $0.1 \mathrm{eV}$. 


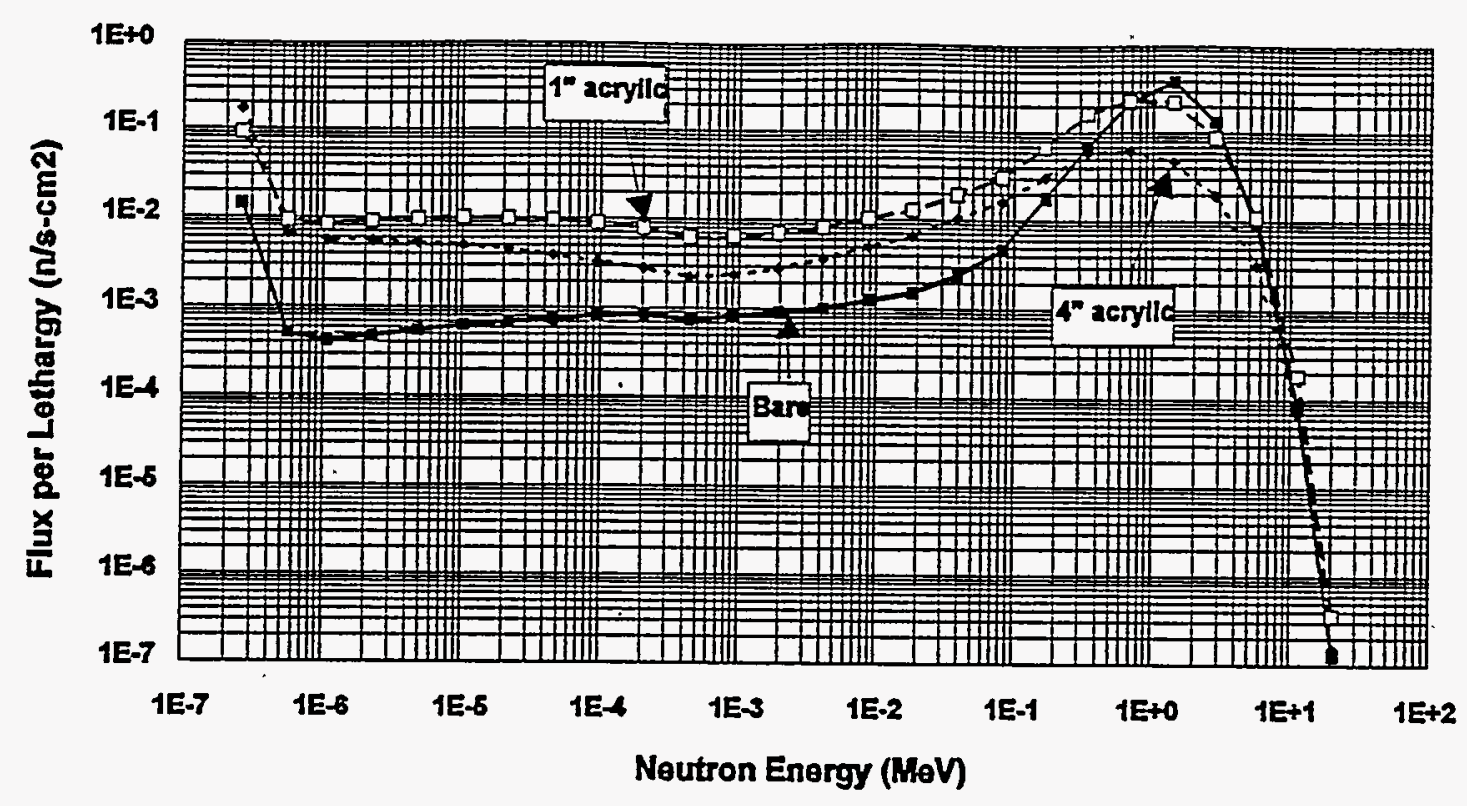

FIGURE A.1. Neutron Flux Density per Unit Lethargy Measured by the Multisphere Spectrometer at $50 \mathrm{~cm}(20$ in.) from the PuF 4 Source with Acrylic Plastic Shields

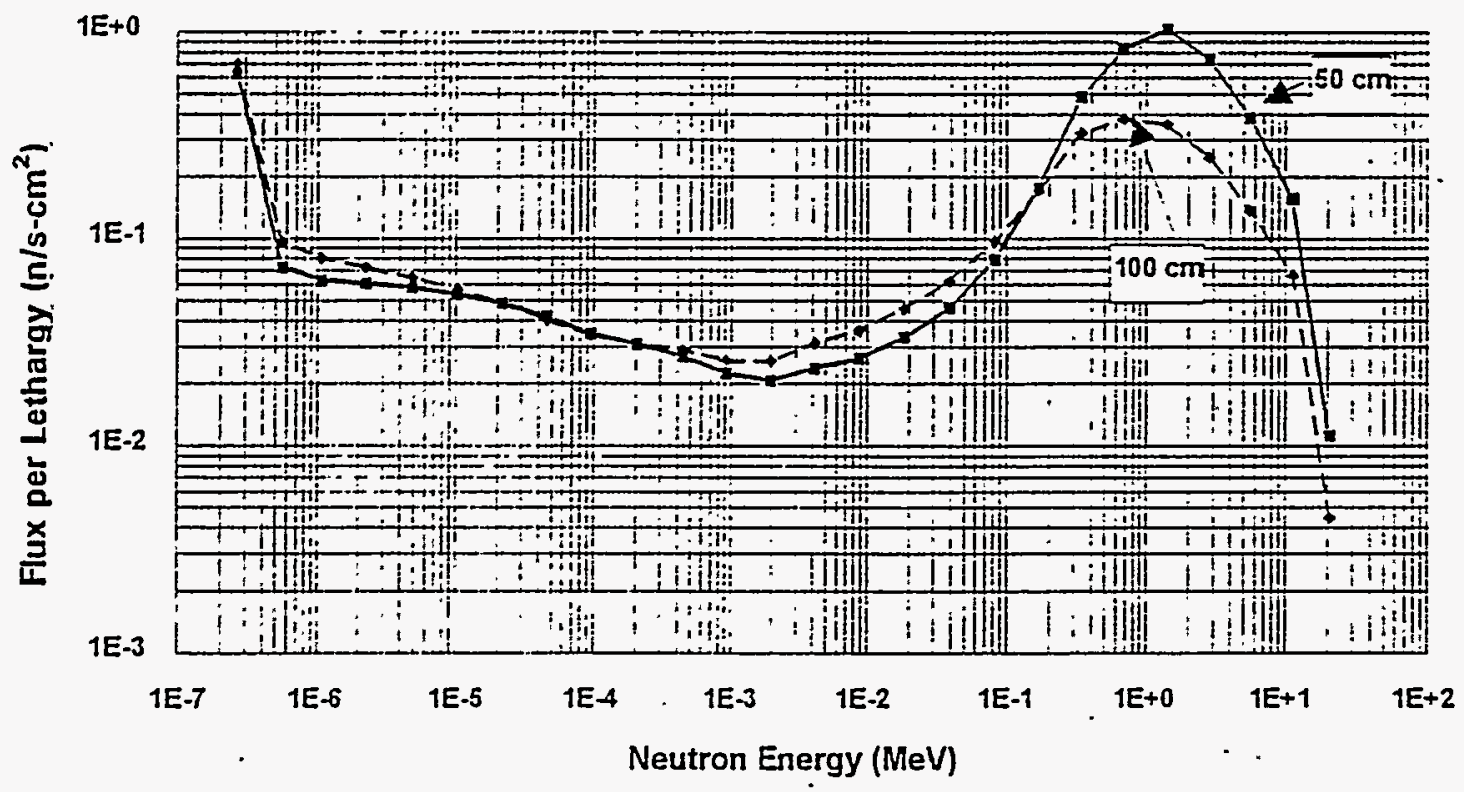

FIGURE A.2. Neutron Flux per Unit Lethargy Measured by the Multisphere Spectrometer at $50 \mathrm{~cm}(20 \mathrm{in.})$ and $100 \mathrm{~cm}(40 \mathrm{in.})$ from the Unshielded $\mathrm{PuF}_{4}$ Source 


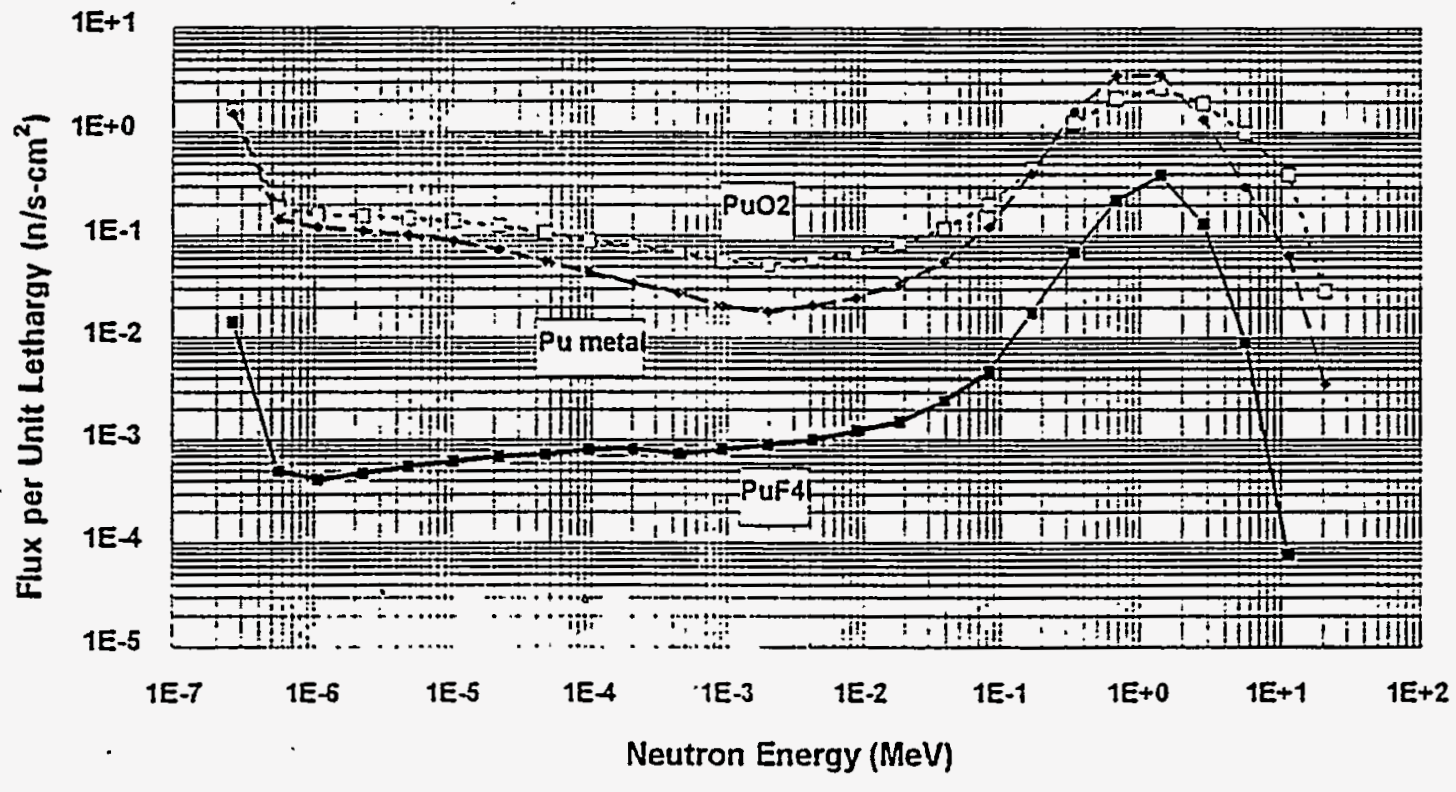

FIGURE A.3. Neutron Flux Density Measured by the Multisphere Spectrometer at $50 \mathrm{~cm}\left(20\right.$ in.) from the $\mathrm{PuF}_{4}, \mathrm{PuO}_{2}$, and Plutonium Metal Sources - The fluxes have been normatized for clarity. 
TABLE A.1. Neutron Flux, Absorbed Dose, and Dose Equivalent Distributions Detèmined from Multisphere Spectrometer Measurements at $50 \mathrm{~cm}$ (20 in.) from the Bare PuF 4 Source

\begin{tabular}{|c|c|c|c|c|c|c|}
\hline \multirow[b]{2}{*}{$\begin{array}{c}\text { Bin } \\
\text { Number }\end{array}$} & \multirow[b]{2}{*}{$\begin{array}{l}\text { Energy, } \\
\mathrm{MeV}\end{array}$} & \multirow[b]{2}{*}{$\begin{array}{c}\text { Flux, } \\
\mathrm{N} / \mathrm{S}-\mathrm{cm}^{2}\end{array}$} & \multicolumn{2}{|c|}{ Differential } & \multicolumn{2}{|c|}{ Cumulative } \\
\hline & & & $\begin{array}{l}\text { Dose, } \\
\mathrm{mGy} / \mathrm{h}\end{array}$ & $\begin{array}{l}\text { Dose } \\
\text { Equivalent, } \\
\mathrm{mSv} / \mathrm{h} \\
\end{array}$ & $\begin{array}{c}\text { Dose } \\
\text { Distribution, } \\
\mathrm{mGy} / \mathrm{h} \\
\end{array}$ & $\begin{array}{c}\text { Dose } \\
\text { Equivalent } \\
\text { Distribution, } \\
\mathrm{mSv} / \mathrm{h} \\
\end{array}$ \\
\hline $\begin{array}{l}1 \\
2 \\
3 \\
4 \\
5 \\
6 \\
7 \\
8 \\
9 \\
10 \\
11 \\
12 \\
13 \\
14 \\
15 \\
16 \\
17 \\
18 \\
19 \\
20 \\
21 \\
22 \\
23 \\
24 \\
25 \\
26 \\
\text { Total }\end{array}$ & $\begin{array}{l}2.57 \mathrm{E}-07 \\
5.48 \mathrm{E}-07 \\
1.06 \mathrm{E}-06 \\
2.25 \mathrm{E}-06 \\
4.77 \mathrm{E}-06 \\
1.01 \mathrm{E}-05 \\
2.14 \mathrm{E}-05 \\
4.52 \mathrm{E}-05 \\
9.58 \mathrm{E}-05 \\
2.03 \mathrm{E}-04 \\
4.34 \mathrm{E}-04 \\
9.13 \mathrm{E}-04 \\
1.92 \mathrm{E}-03 \\
4.07 \mathrm{E}-03 \\
8.62 \mathrm{E}-03 \\
1.82 \mathrm{E}-02 \\
3.86 \mathrm{E}-02 \\
8.18 \mathrm{E}-02 \\
1.67 \mathrm{E}-01 \\
3.37 \mathrm{E}-01 \\
6.79 \mathrm{E}-01 \\
1.39 \mathrm{E}+00 \\
2.78 \mathrm{E}+00 \\
5.54 \mathrm{E}+00 \\
1.12 \mathrm{E}+01 \\
2.04 \mathrm{E}+01\end{array}$ & $\begin{array}{l}3.02 \mathrm{E}+00 \\
1.06 \mathrm{E}-01 \\
8.76 \mathrm{E}-02 \\
1.01 \mathrm{E}-01 \\
1.17 \mathrm{E}-01 \\
1.32 \mathrm{E}-01 \\
1.46 \mathrm{E}-01 \\
1.54 \mathrm{E}-01 \\
1.71 \mathrm{E}-01 \\
1.75 \mathrm{E}-01 \\
1.56 \mathrm{E}-01 \\
1.72 \mathrm{E}-01 \\
1.92 \mathrm{E}-01 \\
2.13 \mathrm{E}-01 \\
2.64 \mathrm{E}-01 \\
3.25 \mathrm{E}-01 \\
5.17 \mathrm{E}-01 \\
9.98 \mathrm{E}-01 \\
3.75 \mathrm{E}+00 \\
1.47 \mathrm{E}+01 \\
4.69 \mathrm{E}+01 \\
8.24 \mathrm{E}+01 \\
2.77 \mathrm{E}+01 \\
1.89 \mathrm{E}+00 \\
1.66 \mathrm{E}-02 \\
2.65 \mathrm{E}-05 \\
1.84 \mathrm{E}+05\end{array}$ & $\begin{array}{l}5.72 \mathrm{E}-05 \\
2.32 \mathrm{E}-06 \\
1.95 \mathrm{E}-06 \\
2.24 \mathrm{E}-06 \\
2.55 \mathrm{E}-06 \\
2.85 \mathrm{E}-06 \\
3.14 \mathrm{E}-06 \\
3.29 \mathrm{E}-06 \\
3.63 \mathrm{E}-06 \\
3.59 \mathrm{E}-06 \\
3.08 \mathrm{E}-06 \\
3.25 \mathrm{E}-06 \\
3.56 \mathrm{E}-06 \\
3.91 \mathrm{E}-06 \\
4.79 \mathrm{E}-06 \\
6.59 \mathrm{E}-06 \\
1.24 \mathrm{E}-05 \\
2.82 \mathrm{E}-05 \\
1.40 \mathrm{E}-04 \\
7.71 \mathrm{E}-05 \\
3.79 \mathrm{E}-03 \\
1.01 \mathrm{E}-02 \\
4.20 \mathrm{E}-03 \\
3.93 \mathrm{E}-04 \\
3.97 \mathrm{E}-06 \\
8.67 \mathrm{E}-09 \\
2.09 \mathrm{E}-03\end{array}$ & $\begin{array}{l}1.33 E-04 \\
4.85 E-06 \\
4.09 E-06 \\
4.75 E-06 \\
5.45 E-06 \\
6.15 E-06 \\
6.66 E-06 \\
6.85 E-06 \\
7.41 E-06 \\
7.30 E-06 \\
6.23 E-06 \\
6.57 E-06 \\
7.17 E-06 \\
7.85 E-06 \\
9.69 E-06 \\
1.82 E-05 \\
5.27 E-05 \\
1.85 E-04 \\
1.19 E-03 \\
7.74 E-04 \\
4.12 E-02 \\
9.95 E-02 \\
3.42 E-02 \\
2.75 E-03 \\
2.74 E-05 \\
6.00 E-08 \\
1.80 E-03\end{array}$ & $\begin{array}{l}1.89 \mathrm{E}-02 \\
1.88 \mathrm{E}-02 \\
1.88 \mathrm{E}-02 \\
1.88 \mathrm{E}-02 \\
1.88 \mathrm{E}-02 \\
1.88 \mathrm{E}-02 \\
1.88 \mathrm{E}-02 \\
1.88 \mathrm{E}-02 \\
1.88 \mathrm{E}-02 \\
1.88 \mathrm{E}-02 \\
1.88 \mathrm{E}-02 \\
1.88 \mathrm{E}-02 \\
1.88 \mathrm{E}-02 \\
1.88 \mathrm{E}-02 \\
1.88 \mathrm{E}-02 \\
1.88 \mathrm{E}-02 \\
1.87 \mathrm{E}-02 \\
1.87 \mathrm{E}-02 \\
1.87 \mathrm{E}-02 \\
1.86 \mathrm{E}-02 \\
1.85 \mathrm{E}-02 \\
1.47 \mathrm{E}-02 \\
4.60 \mathrm{E}-03 \\
3.97 \mathrm{E}-04 \\
3.98 \mathrm{E}-06 \\
6.89 \mathrm{E}-09\end{array}$ & $\begin{array}{l}1.80 E-01 \\
1.80 E-01 \\
1.80 E-01 \\
1.80 E-01 \\
1.80 E-01 \\
1.80 E-01 \\
1.80 E-01 \\
1.80 E-01 \\
1.80 E-01 \\
1.80 E-01 \\
1.80 E-01 \\
1.80 E-01 \\
1.80 E-01 \\
1.80 E-01 \\
1.80 E-01 \\
1.80 E-01 \\
1.80 E-01 \\
1.80 E-01 \\
1.80 E-01 \\
1.79 E-01 \\
1.78 E-01 \\
1.37 E-01 \\
3.70 E-02 \\
2.78 E-03 \\
2.75 E-05 \\
8.39 E-07\end{array}$ \\
\hline
\end{tabular}


TABLE A.2. Neutron Flux, Absorbed Dose, and Dose Equivalent Distributions Determined from Mult isphere Spectrometer Measurements at $50 \mathrm{~cm}$ (20 in.) from the PuF 4 Source with 2.54-cm (1-in.) Acrylic Plastic Shield

\begin{tabular}{|c|c|c|c|c|c|c|}
\hline \multirow[b]{2}{*}{$\begin{array}{l}\text { Bin } \\
\text { Number }\end{array}$} & \multirow[b]{2}{*}{$\begin{array}{l}\text { Energy, } \\
\text { MeV }\end{array}$} & \multirow[b]{2}{*}{$\begin{array}{c}\text { Flux, } \\
\mathrm{N} / \mathrm{S}-\mathrm{cm}^{2}\end{array}$} & \multicolumn{2}{|c|}{ Differential } & \multicolumn{2}{|c|}{ Cumulative } \\
\hline & & & $\begin{array}{l}\text { Dose, } \\
\mathrm{mGy} / \mathrm{h}\end{array}$ & $\begin{array}{c}\text { Dose } \\
\text { Equivalent, } \\
\text { mSv/h } \\
\end{array}$ & $\begin{array}{c}\text { Dose } \\
\text { Distribution, } \\
\text { mGy/h } \\
\end{array}$ & $\begin{array}{c}\text { Dose } \\
\text { Equivalent } \\
\text { Distribution, } \\
\text { mSv/h } \\
\end{array}$ \\
\hline $\begin{array}{l}1 \\
2 \\
3 \\
4 \\
5 \\
6 \\
7 \\
8 \\
9 \\
10 \\
11 \\
12 \\
13 \\
14 \\
15 \\
16 \\
17 \\
18 \\
19 \\
20 \\
21 \\
22 \\
23 \\
24 \\
25 \\
26 \\
\text { Total }\end{array}$ & $\begin{array}{l}2.57 \mathrm{E}-07 \\
5.48 \mathrm{E}-07 \\
1.06 \mathrm{E}-06 \\
2.25 \mathrm{E}-06 \\
4.77 \mathrm{E}-06 \\
1.01 \mathrm{E}-05 \\
2.14 \mathrm{E}-05 \\
4.52 \mathrm{E}-05 \\
9.58 \mathrm{E}-05 \\
2.03 \mathrm{E}-04 \\
4.34 \mathrm{E}-04 \\
9.13 \mathrm{E}-04 \\
1.92 \mathrm{E}-03 \\
4.07 \mathrm{E}-03 \\
8.62 \mathrm{E}-03 \\
1.82 \mathrm{E}-02 \\
3.86 \mathrm{E}-02 \\
8.18 \mathrm{E}-02 \\
1.67 \mathrm{E}-01 \\
3.37 \mathrm{E}-01 \\
6.79 \mathrm{E}-01 \\
1.39 \mathrm{E}+00 \\
2.78 \mathrm{E}+00 \\
5.54 \mathrm{E}+00 \\
1.12 \mathrm{E}+01 \\
2.04 \mathrm{E}+01\end{array}$ & $\begin{array}{l}1.93 E+01 \\
1.95 E+00 \\
1.76 E+00 \\
1.92 E+00 \\
2.04 E+00 \\
2.11 E+00 \\
2.08 E+00 \\
1.98 E+00 \\
1.84 E+00 \\
1.64 E+00 \\
1.30 E+00 \\
1.33 E+00 \\
1.48 E+00 \\
1.71 E+00 \\
2.18 E+00 \\
2.71 E+00 \\
4.09 E+00 \\
6.50 E+00 \\
1.41 E+01 \\
3.49 E+01 \\
4.90 E+01 \\
4.73 E+01 \\
1.84 E+01 \\
2.33 E+00 \\
3.86 E-02 \\
7.59 E-05 \\
2.24 E+05\end{array}$ & $\begin{array}{l}3.66 \mathrm{E}-04 \\
4.28 \mathrm{E}-05 \\
3.92 \mathrm{E}-05 \\
4.24 \mathrm{E}-05 \\
4.46 \mathrm{E}-05 \\
4.56 \mathrm{E}-05 \\
4.47 \mathrm{E}-05 \\
4.24 \mathrm{E}-05 \\
3.90 \mathrm{E}-05 \\
3.36 \mathrm{E}-05 \\
2.55 \mathrm{E}-05 \\
2.52 \mathrm{E}-05 \\
2.74 \mathrm{E}-05 \\
3.13 \mathrm{E}-05 \\
3.95 \mathrm{E}-05 \\
5.48 \mathrm{E}-05 \\
9.78 \mathrm{E}-05 \\
1.84 \mathrm{E}-04 \\
5.28 \mathrm{E}-04 \\
1.83 \mathrm{E}-04 \\
3.96 \mathrm{E}-03 \\
5.80 \mathrm{E}-03 \\
2.80 \mathrm{E}-03 \\
4.84 \mathrm{E}-04 \\
9.19 \mathrm{E}-06 \\
2.49 \mathrm{E}-08 \\
1.66 \mathrm{E}-03\end{array}$ & $\begin{array}{l}8.50 E-04 \\
8.95 E-05 \\
8.23 E-05 \\
8.99 E-05 \\
9.56 E-05 \\
9.84 E-05 \\
9.51 E-05 \\
8.84 E-05 \\
7.96 E-05 \\
6.81 E-05 \\
5.17 E-05 \\
5.09 E-05 \\
5.51 E-05 \\
6.30 E-05 \\
7.98 E-05 \\
1.51 E-04 \\
4.17 E-04 \\
1.21 E-03 \\
4.49 E-03 \\
1.84 E-03 \\
4.31 E-02 \\
5.71 E-02 \\
2.28 E-02 \\
3.39 E-03 \\
6.35 E-05 \\
1.72 E-07 \\
1.37 E-01\end{array}$ & $\begin{array}{l}1.50 \mathrm{E}-02 \\
1.46 \mathrm{E}-02 \\
1.46 \mathrm{E}-02 \\
1.45 \mathrm{E}-02 \\
1.45 \mathrm{E}-02 \\
1.45 \mathrm{E}-02 \\
1.44 \mathrm{E}-02 \\
1.44 \mathrm{E}-02 \\
1.43 \mathrm{E}-02 \\
1.43 \mathrm{E}-02 \\
1.42 \mathrm{E}-02 \\
1.42 \mathrm{E}-02 \\
1.42 \mathrm{E}-02 \\
1.42 \mathrm{E}-02 \\
1.41 \mathrm{E}-02 \\
1.41 \mathrm{E}-02 \\
1.40 \mathrm{E}-02 \\
1.39 \mathrm{E}-02 \\
1.38 \mathrm{E}-02 \\
1.32 \mathrm{E}-02 \\
1.31 \mathrm{E}-02 \\
9.09 \mathrm{E}-03 \\
3.30 \mathrm{E}-03 \\
4.93 \mathrm{E}-04 \\
9.22 \mathrm{E}-06 \\
2.37 \mathrm{E}-08\end{array}$ & $\begin{array}{l}1.37 \mathrm{E}-01 \\
1.36 \mathrm{E}-01 \\
1.36 \mathrm{E}-01 \\
1.36 \mathrm{E}-01 \\
1.35 \mathrm{E}-01 \\
1.35 \mathrm{E}-01 \\
1.35 \mathrm{E}-01 \\
1.35 \mathrm{E}-01 \\
1.35 \mathrm{E}-01 \\
1.35 \mathrm{E}-01 \\
1.35 \mathrm{E}-01 \\
1.35 \mathrm{E}-01 \\
1.35 \mathrm{E}-01 \\
1.35 \mathrm{E}-01 \\
1.35 \mathrm{E}-01 \\
1.35 \mathrm{E}-01 \\
1.34 \mathrm{E}-01 \\
1.34 \mathrm{E}-01 \\
1.33 \mathrm{E}-01 \\
1.28 \mathrm{E}-01 \\
1.26 \mathrm{E}-01 \\
8.34 \mathrm{E}-02 \\
2.63 \mathrm{E}-02 \\
3.45 \mathrm{E}-03 \\
6.36 \mathrm{E}-05 \\
1.53 \mathrm{E}-07\end{array}$ \\
\hline
\end{tabular}


TABLE A.3. Neutron Flux, Absorbed Dose, and Dose Equivalent Distributions Determined from Multisphere Spectrometer Measurements at $50 \mathrm{~cm}$ (20 in.) from the PuF ${ }_{4}$ Source with 5-cm (2-in.) Acrylic Plastic Shield

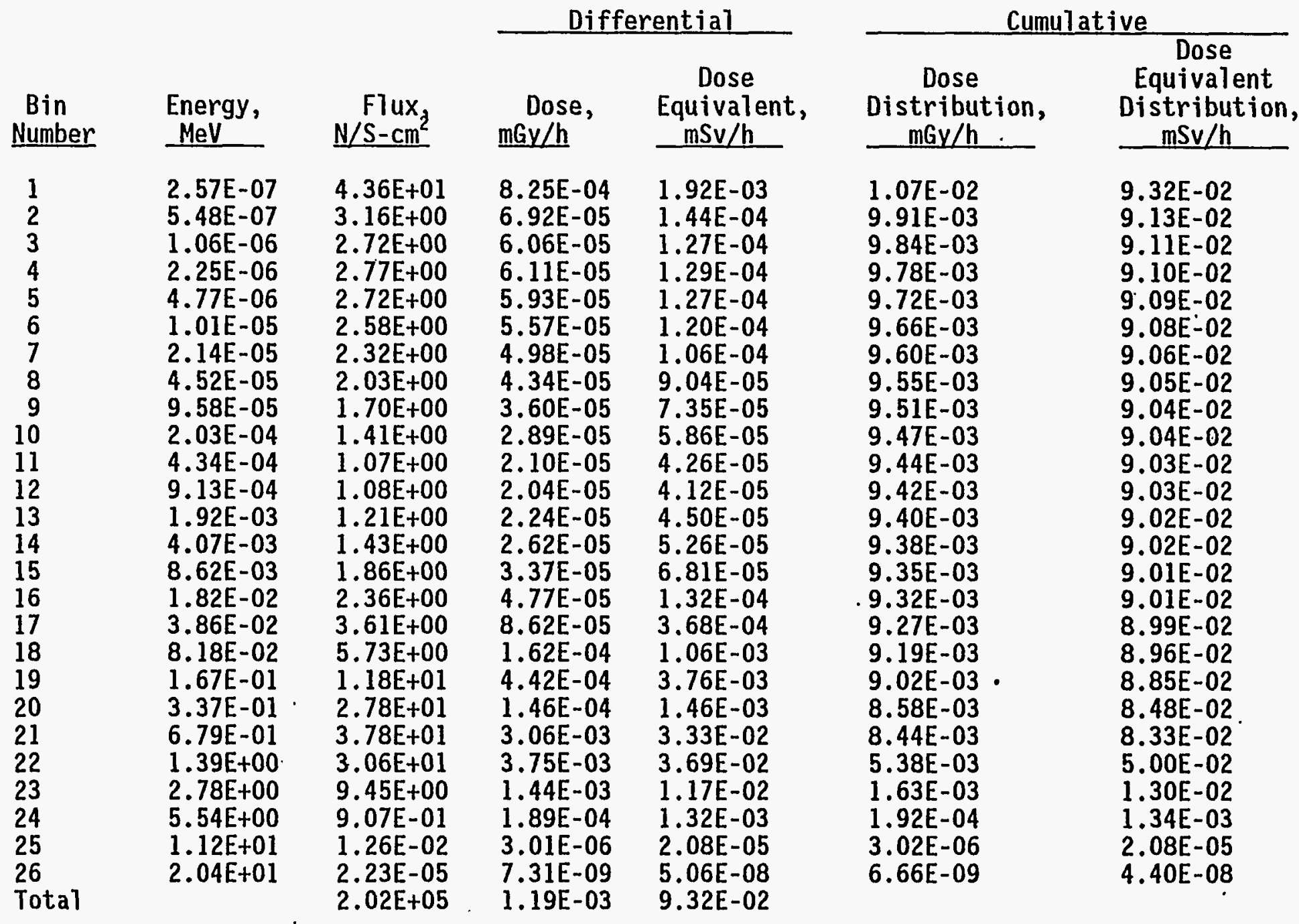


TABLE A.4. Neutron Flux, Absorbed Dose, and Dose Equivalent Distributions Determined from Multisphere Spectrometer Measurements at $50 \mathrm{~cm}\left(20\right.$ in.) from the PuF ${ }_{4}$ Source with 7.6-cm (3-in.) Acrylic Plastic Shield

\begin{tabular}{|c|c|c|c|c|c|c|}
\hline \multirow[b]{2}{*}{$\begin{array}{l}\text { Bin } \\
\text { Number }\end{array}$} & \multirow[b]{2}{*}{$\begin{array}{l}\text { Energy, } \\
\mathrm{MeV}\end{array}$} & \multirow[b]{2}{*}{$\begin{array}{r}\text { Flux } \\
\mathrm{N} / \mathrm{S}-\mathrm{cm}^{2}\end{array}$} & \multicolumn{2}{|c|}{ Differential } & \multicolumn{2}{|c|}{ Cumulative } \\
\hline & & & $\begin{array}{l}\text { Dose, } \\
\mathrm{mGy} / \mathrm{h}\end{array}$ & $\begin{array}{c}\text { Dose } \\
\text { Equivalent, } \\
\mathrm{mSv} / \mathrm{h} \\
\end{array}$ & $\begin{array}{c}\text { Dose } \\
\text { Distribution, } \\
\mathrm{mGy} / \mathrm{h} \\
\end{array}$ & $\begin{array}{c}\text { Dose } \\
\text { Equivalent } \\
\text { Distribution, } \\
\mathrm{mSv} / \mathrm{h} \\
\end{array}$ \\
\hline $\begin{array}{l}1 \\
2 \\
3 \\
4 \\
5 \\
6 \\
7 \\
8 \\
9 \\
10 \\
11 \\
12 \\
13 \\
14 \\
15 \\
16 \\
17 \\
18 \\
19 \\
20 \\
21 \\
22 \\
23 \\
24 \\
25 \\
26 \\
\text { Total }\end{array}$ & $\begin{array}{l}2.57 \mathrm{E}-07 \\
5.48 \mathrm{E}-07 \\
1.06 \mathrm{E}-06 \\
2.25 \mathrm{E}-06 \\
4.77 \mathrm{E}-06 \\
1.01 \mathrm{E}-05 \\
2.14 \mathrm{E}-05 \\
4.52 \mathrm{E}-05 \\
9.58 \mathrm{E}-05 \\
2.03 \mathrm{E}-04 \\
4.34 \mathrm{E}-04 \\
9.13 \mathrm{E}-04 \\
1.92 \mathrm{E}-03 \\
4.07 \mathrm{E}-03 \\
8.62 \mathrm{E}-03 \\
1.82 \mathrm{E}-02 \\
3.86 \mathrm{E}-02 \\
8.18 \mathrm{E}-02 \\
1.67 \mathrm{E}-01 \\
3.37 \mathrm{E}-01 \\
6.79 \mathrm{E}-01 \\
1.39 \mathrm{E}+00 \\
2.78 \mathrm{E}+00 \\
5.54 \mathrm{E}+00 \\
1.12 \mathrm{E}+01 \\
2.04 \mathrm{E}+01\end{array}$ & $\begin{array}{l}2.96 \mathrm{E}+01 \\
1.91 \mathrm{E}+00 \\
1.58 \mathrm{E}+00 \\
1.57 \mathrm{E}+00 \\
1.50 \mathrm{E}+00 \\
1.38 \mathrm{E}+00 \\
1.18 \mathrm{E}+00 \\
1.08 \mathrm{E}+00 \\
7.43 \mathrm{E}-01 \\
5.52 \mathrm{E}-01 \\
3.71 \mathrm{E}-01 \\
3.31 \mathrm{E}-01 \\
3.26 \mathrm{E}-01 \\
3.50 \mathrm{E}-01 \\
4.19 \mathrm{E}-01 \\
5.03 \mathrm{E}-01 \\
7.73 \mathrm{E}-01 \\
1.37 \mathrm{E}+00 \\
3.96 \mathrm{E}+00 \\
1.63 \mathrm{E}+01 \\
3.41 \mathrm{E}+01 \\
1.86 \mathrm{E}+01 \\
2.19 \mathrm{E}+00 \\
7.20 \mathrm{E}-02 \\
3.74 \mathrm{E}-04 \\
6.18 \mathrm{E}-07 \\
1.21 \mathrm{E}+05\end{array}$ & $\begin{array}{l}5.60 \mathrm{E}-04 \\
4.18 \mathrm{E}-05 \\
3.51 \mathrm{E}-05 \\
3.47 \mathrm{E}-05 \\
3.28 \mathrm{E}-05 \\
2.99 \mathrm{E}-05 \\
2.54 \mathrm{E}-05 \\
2.32 \mathrm{E}-05 \\
1.58 \mathrm{E}-05 \\
1.13 \mathrm{E}-05 \\
7.29 \mathrm{E}-06 \\
6.26 \mathrm{E}-06 \\
.6 .05 \mathrm{E}-06 \\
6.41 \mathrm{E}-06 \\
7.61 \mathrm{E}-06 \\
1.02 \mathrm{E}-05 \\
1.85 \mathrm{E}-05 \\
3.88 \mathrm{E}-05 \\
1.48 \mathrm{E}-04 \\
8.55 \mathrm{E}-05 \\
2.76 \mathrm{E}-03 \\
2.28 \mathrm{E}-03 \\
3.32 \mathrm{E}-04 \\
1.50 \mathrm{E}-05 \\
8.92 \mathrm{E}-08 \\
2.02 \mathrm{E}-10 \\
7.24 \mathrm{E}-04\end{array}$ & $\begin{array}{l}1.30 \mathrm{E}-03 \\
8.74 \mathrm{E}-05 \\
7.37 \mathrm{E}-05 \\
7.36 \mathrm{E}-05 \\
7.02 \mathrm{E}-05 \\
6.45 \mathrm{E}-05 \\
5.41 \mathrm{E}-05 \\
4.83 \mathrm{E}-05 \\
3.22 \mathrm{E}-05 \\
2.30 \mathrm{E}-05 \\
1.48 \mathrm{E}-05 \\
1.27 \mathrm{E}-05 \\
1.22 \mathrm{E}-05 \\
1.29 \mathrm{E}-05 \\
1.54 \mathrm{E}-05 \\
2.82 \mathrm{E}-05 \\
7.88 \mathrm{E}-05 \\
2.55 \mathrm{E}-04 \\
1.26 \mathrm{E}-03 \\
8.58 \mathrm{E}-04 \\
.3 .00 \mathrm{E}-02 \\
2.24 \mathrm{E}-02 \\
2.71 \mathrm{E}-03 \\
1.05 \mathrm{E}-04 \\
6.16 \mathrm{E}-07 \\
1.40 \mathrm{E}-09 \\
5.96 \mathrm{E}-02\end{array}$ & $\begin{array}{l}6.53 \mathrm{E}-03 \\
5.97 \mathrm{E}-03 \\
5.92 \mathrm{E}-03 \\
5.89 \mathrm{E}-03 \\
5.85 \mathrm{E}-03 \\
5.82 \mathrm{E}-03 \\
5.79 \mathrm{E}-03 \\
5.77 \mathrm{E}-03 \\
5.74 \mathrm{E}-03 \\
5.73 \mathrm{E}-03 \\
5.72 \mathrm{E}-03 \\
5.71 \mathrm{E}-03 \\
5.70 \mathrm{E}-03 \\
5.70 \mathrm{E}-03 \\
5.69 \mathrm{E}-03 \\
5.68 \mathrm{E}-03 \\
5.67 \mathrm{E}-03 \\
5.65 \mathrm{E}-03 \\
5.62 \mathrm{E}-03 \\
5.47 \mathrm{E}-03 \\
5.38 \mathrm{E}-03 \\
2.63 \mathrm{E}-03 \\
3.47 \mathrm{E}-04 \\
1.51 \mathrm{E}-05 \\
8.94 \mathrm{E}-07 \\
2.01 \mathrm{E}-10\end{array}$ & $\begin{array}{l}5.96 \mathrm{E}-02 \\
5.83 \mathrm{E}-02 \\
5.83 \mathrm{E}-02 \\
5.82 \mathrm{E}-02 \\
5.81 \mathrm{E}-02 \\
5.80 \mathrm{E}-02 \\
5.80 \mathrm{E}-02 \\
5.79 \mathrm{E}-02 \\
5.79 \mathrm{E}-02 \\
5.78 \mathrm{E}-02 \\
5.78 \mathrm{E}-02 \\
5.78 \mathrm{E}-02 \\
5.78 \mathrm{E}-02 \\
5.78 \mathrm{E}-02 \\
5.78 \mathrm{E}-02 \\
5.77 \mathrm{E}-02 \\
5.77 \mathrm{E}-02 \\
5.76 \mathrm{E}-02 \\
5.74 \mathrm{E}-02 \\
5.61 \mathrm{E}-02 \\
5.53 \mathrm{E}-02 \\
2.52 \mathrm{E}-02 \\
2.81 \mathrm{E}-03 \\
1.05 \mathrm{E}-04 \\
6.18 \mathrm{E}-07 \\
1.85 \mathrm{E}-09\end{array}$ \\
\hline
\end{tabular}


TABLE A.5. Neutron F.7ux, Absorbed Dose, and Dose Equivalent Distributions Determined from Multisphere Spectrometer Measurements at $50 \mathrm{~cm}$ (20 in.) from the PuF 4 Source with 10-cm (4-in.) Acrylic Plastic Shield

\begin{tabular}{|c|c|c|c|c|c|c|}
\hline \multirow[b]{2}{*}{$\begin{array}{l}\text { Bin } \\
\text { Number }\end{array}$} & \multirow[b]{2}{*}{$\begin{array}{l}\text { Energy, } \\
\mathrm{MeV}\end{array}$} & \multirow[b]{2}{*}{$\begin{array}{l}\text { Flux, } \\
\mathbb{N} / S-\mathrm{cm}^{2} \\
\end{array}$} & \multicolumn{2}{|c|}{ Differential } & \multicolumn{2}{|c|}{ Cumulative } \\
\hline & & & $\begin{array}{l}\text { Dose, } \\
\mathrm{mGy} / \mathrm{h}\end{array}$ & $\begin{array}{c}\text { Dose } \\
\text { Equivalent, } \\
\mathrm{mSv} / \mathrm{h}\end{array}$ & $\begin{array}{c}\text { Dose } \\
\text { Distribution, } \\
\text { mGy/h } \\
\end{array}$ & $\begin{array}{c}\text { Dose } \\
\text { Equivalent } \\
\text { Distribution, } \\
\mathrm{mSv} / \mathrm{h} \\
\end{array}$ \\
\hline $\begin{array}{l}1 \\
2 \\
3 \\
4 \\
5 \\
6 \\
7 \\
8 \\
9 \\
10 \\
11 \\
12 \\
13 \\
14 \\
15 \\
16 \\
17 \\
18 \\
19 \\
20 \\
21 \\
22 \\
23 \\
24 \\
25 \\
26 \\
\text { Total }\end{array}$ & $\begin{array}{l}2.57 \mathrm{E}-07 \\
5.48 \mathrm{E}-07 \\
1.06 \mathrm{E}-06 \\
2.25 \mathrm{E}-06 \\
4.77 \mathrm{E}-06 \\
1.01 \mathrm{E}-05 \\
2.14 \mathrm{E}-05 \\
4.52 \mathrm{E}-05 \\
9.58 \mathrm{E}-05 \\
2.03 \mathrm{E}-04 \\
4.34 \mathrm{E}-04 \\
9.13 \mathrm{E}-04 \\
1.92 \mathrm{E}-03 \\
4.07 \mathrm{E}-03 \\
8.62 \mathrm{E}-03 \\
1.82 \mathrm{E}-02 \\
3.86 \mathrm{E}-02 \\
8.18 \mathrm{E}-02 \\
1.67 \mathrm{E}-01 \\
3.37 \mathrm{E}-01 \\
6.79 \mathrm{E}-01 \\
1.39 \mathrm{E}+00 \\
2.78 \mathrm{E}+00 \\
5.54 \mathrm{E}+00 \\
1.12 \mathrm{E}+01 \\
2.04 \mathrm{E}+01\end{array}$ & $\begin{array}{l}3.62 \mathrm{E}+01 \\
1.39 \mathrm{E}+00 \\
1.17 \mathrm{E}+00 \\
1.15 \mathrm{E}+00 \\
1.11 \mathrm{E}+00 \\
1.04 \mathrm{E}+00 \\
9.29 \mathrm{E}-01 \\
8.08 \mathrm{E}-01 \\
6.94 \mathrm{E}-01 \\
5.95 \mathrm{E}-01 \\
4.74 \mathrm{E}-01 \\
5.08 \mathrm{E}-01 \\
6.04 \mathrm{E}-01 \\
7.62 \mathrm{E}-01 \\
1.04 \mathrm{E}+00 \\
1.38 \mathrm{E}+00 \\
2.18 \mathrm{E}+00 \\
3.46 \mathrm{E}+00 \\
6.53 \mathrm{E}+00 \\
1.24 \mathrm{E}+01 \\
1.30 \mathrm{E}+01 \\
9.79 \mathrm{E}+00 \\
4.10 \mathrm{E}+00 \\
6.76 \mathrm{E}-01 \\
1.46 \mathrm{E}-02 \\
3.18 \mathrm{E}-05 \\
1.02 \mathrm{E}+05\end{array}$ & $\begin{array}{l}6.86 \mathrm{E}-04 \\
3.04 \mathrm{E}-05 \\
2.59 \mathrm{E}-05 \\
2.55 \mathrm{E}-05 \\
2.43 \mathrm{E}-05 \\
2.25 \mathrm{E}-05 \\
2.00 \mathrm{E}-05 \\
1.73 \mathrm{E}-05 \\
1.47 \mathrm{E}-05 \\
1.22 \mathrm{E}-05 \\
9.32 \mathrm{E}-06 \\
9.60 \mathrm{E}-06 \\
1.12 \mathrm{E}-05 \\
1.39 \mathrm{E}-05 \\
1.88 \mathrm{E}-05 \\
2.79 \mathrm{E}-05 \\
5.20 \mathrm{E}-05 \\
9.78 \mathrm{E}-05 \\
2.44 \mathrm{E}-04 \\
6.47 \mathrm{E}-05 \\
1.05 \mathrm{E}-03 \\
1.20 \mathrm{E}-03 \\
6.23 \mathrm{E}-04 \\
1.41 \mathrm{E}-04 \\
3.49 \mathrm{E}-06 \\
1.04 \mathrm{E}-08 \\
4.94 \mathrm{E}-04\end{array}$ & $\begin{array}{l}1.59 \mathrm{E}-03 \\
6.36 \mathrm{E}-05 \\
5.44 \mathrm{E}-05 \\
5.40 \mathrm{E}-05 \\
5.21 \mathrm{E}-05 \\
4.86 \mathrm{E}-05 \\
4.24 \mathrm{E}-05 \\
3.60 \mathrm{E}-05 \\
3.00 \mathrm{E}-05 \\
2.48 \mathrm{E}-05 \\
1.89 \mathrm{E}-05 \\
1.94 \mathrm{E}-05 \\
2.26 \mathrm{E}-05 \\
2.80 \mathrm{E}-05 \\
3.81 \mathrm{E}-05 \\
7.71 \mathrm{E}-05 \\
2.22 \mathrm{E}-04 \\
6.42 \mathrm{E}-04 \\
2.07 \mathrm{E}-03 \\
6.49 \mathrm{E}-04 \\
1.14 \mathrm{E}-02 \\
1.18 \mathrm{E}-02 \\
5.07 \mathrm{E}-03 \\
9.83 \mathrm{E}-04 \\
2.41 \mathrm{E}-05 \\
7.21 \mathrm{E}-07 \\
3.51 \mathrm{E}-02\end{array}$ & $\begin{array}{l}4.45 \mathrm{E}-03 \\
3.76 \mathrm{E}-03 \\
3.73 \mathrm{E}-03 \\
3.70 \mathrm{E}-03 \\
3.68 \mathrm{E}-03 \\
3.65 \mathrm{E}-03 \\
3.63 \mathrm{E}-03 \\
3.61 \mathrm{E}-03 \\
3.59 \mathrm{E}-03 \\
3.58 \mathrm{E}-03 \\
3.57 \mathrm{E}-03 \\
3.56 \mathrm{E}-03 \\
3.55 \mathrm{E}-03 \\
3.54 \mathrm{E}-03 \\
3.52 \mathrm{E}-03 \\
3.50 \mathrm{E}-03 \\
3.48 \mathrm{E}-03 \\
3.42 \mathrm{E}-03 \\
3.33 \mathrm{E}-03 \\
3.08 \mathrm{E}-03 \\
3.02 \mathrm{E}-03 \\
1.97 \mathrm{E}-03 \\
7.67 \mathrm{E}-04 \\
1.44 \mathrm{E}-04 \\
3.50 \mathrm{E}-06 \\
1.06 \mathrm{E}-08\end{array}$ & $\begin{array}{l}3.51 \mathrm{E}-02 \\
3.35 \mathrm{E}-02 \\
3.35 \mathrm{E}-02 \\
3.34 \mathrm{E}-02 \\
3.34 \mathrm{E}-02 \\
3.33 \mathrm{E}-02 \\
3.33 \mathrm{E}-02 \\
3.32 \mathrm{E}-02 \\
3.32 \mathrm{E}-02 \\
3.32 \mathrm{E}-02 \\
3.31 \mathrm{E}-02 \\
3.31 \mathrm{E}-02 \\
3.31 \mathrm{E}-02 \\
3.31 \mathrm{E}-02 \\
3.31 \mathrm{E}-02 \\
3.30 \mathrm{E}-02 \\
3.29 \mathrm{E}-02 \\
3.27 \mathrm{E}-02 \\
3.21 \mathrm{E}-02 \\
3.00 \mathrm{E}-02 \\
2.94 \mathrm{E}-02 \\
1.79 \mathrm{E}-02 \\
6.08 \mathrm{E}-03 \\
1.01 \mathrm{E}-03 \\
2.41 \mathrm{E}-05 \\
7.06 \mathrm{E}-08\end{array}$ \\
\hline
\end{tabular}


TABLE A.6. Neutron Flux, Absorbed Dose, and Dose Equivalent Distributions Determined from Multisphere Spectrometer Measurements at $100 \mathrm{~cm}$ (40 in.) from the Bare PuF ${ }_{4}$ Source

\begin{tabular}{|c|c|c|c|c|c|c|}
\hline \multirow[b]{2}{*}{$\begin{array}{l}\text { Bin } \\
\text { Number }\end{array}$} & \multirow[b]{2}{*}{$\begin{array}{l}\text { Energy, } \\
\mathrm{MeV}\end{array}$} & \multirow[b]{2}{*}{$\begin{array}{r}\text { Flux } \\
N / S-\mathrm{Cm}^{2}\end{array}$} & \multicolumn{2}{|c|}{ Differential } & \multicolumn{2}{|c|}{ Cumulative } \\
\hline & & & $\begin{array}{l}\text { Dose, } \\
\mathrm{mGy} / \mathrm{h}\end{array}$ & $\begin{array}{l}\text { Dose } \\
\text { Equivalent, } \\
\mathrm{mSv} / \mathrm{h} \\
\end{array}$ & $\begin{array}{c}\text { Dose } \\
\text { Distribution, } \\
\text { mGy/h }\end{array}$ & $\begin{array}{c}\text { Dose } \\
\text { Equivalent } \\
\text { Distribution, } \\
\mathrm{mSv} / \mathrm{h} \\
\end{array}$ \\
\hline $\begin{array}{l}1 \\
2 \\
3 \\
4 \\
5 \\
6 \\
7 \\
8 \\
9 \\
10 \\
11 \\
12 \\
13 \\
14 \\
15 \\
16 \\
17 \\
18 \\
19 \\
20 \\
21 \\
22 \\
23 \\
24 \\
25 \\
26 \\
\text { Total }\end{array}$ & $\begin{array}{l}2.57 \mathrm{E}-07 \\
5.48 \mathrm{E}-07 \\
1.06 \mathrm{E}-06 \\
2.25 \mathrm{E}-06 \\
4.77 \mathrm{E}-06 \\
1.01 \mathrm{E}-05 \\
2.14 \mathrm{E}-05 \\
4.52 \mathrm{E}-05 \\
9.58 \mathrm{E}-05 \\
2.03 \mathrm{E}-04 \\
4.34 \mathrm{E}-04 \\
9.13 \mathrm{E}-04 \\
1.92 \mathrm{E}-03 \\
4.07 \mathrm{E}-03 \\
8.62 \mathrm{E}-03 \\
1.82 \mathrm{E}-02 \\
3.86 \mathrm{E}-02 \\
8.18 \mathrm{E}-02 \\
1.67 \mathrm{E}-01 \\
3.37 \mathrm{E}-01 \\
6.79 \mathrm{E}-01 \\
1.39 \mathrm{E}+00 \\
2.78 \mathrm{E}+00 \\
5.54 \mathrm{E}+00 \\
1.12 \mathrm{E}+01 \\
2.04 \mathrm{E}+01\end{array}$ & $\begin{array}{l}2.69 \mathrm{E}+00 \\
2.59 \mathrm{E}-01 \\
2.24 \mathrm{E}-01 \\
2.34 \mathrm{E}-01 \\
2.38 \mathrm{E}-01 \\
2.34 \mathrm{E}-01 \\
2.19 \mathrm{E}-01 \\
1.90 \mathrm{E}-01 \\
1.65 \mathrm{E}-01 \\
1.33 \mathrm{E}-01 \\
9.35 \mathrm{E}-02 \\
8.28 \mathrm{E}-02 \\
7.95 \mathrm{E}-02 \\
8.24 \mathrm{E}-02 \\
1.02 \mathrm{E}-01 \\
1.31 \mathrm{E}-01 \\
2.22 \mathrm{E}-01 \\
4.53 \mathrm{E}-01 \\
1.70 \mathrm{E}+00 \\
7.52 \mathrm{E}+00 \\
1.63 \mathrm{E}+01 \\
2.16 \mathrm{E}+01 \\
7.30 \mathrm{E}+00 \\
6.25 \mathrm{E}-01 \\
7.16 \mathrm{E}-03 \\
1.25 \mathrm{E}-05 \\
6.09 \mathrm{E}+04\end{array}$ & $\begin{array}{l}5.09 \mathrm{E}-05 \\
5.67 \mathrm{E}-06 \\
4.99 \mathrm{E}-06 \\
5.17 \mathrm{E}-06 \\
5.20 \mathrm{E}-06 \\
5.07 \mathrm{E}-06 \\
4.71 \mathrm{E}-06 \\
4.06 \mathrm{E}-06 \\
3.51 \mathrm{E}-06 \\
2.73 \mathrm{E}-06 \\
1.84 \mathrm{E}-06 \\
1.57 \mathrm{E}-06 \\
1.47 \mathrm{E}-06 \\
1.51 \mathrm{E}-06 \\
1.85 \mathrm{E}-06 \\
2.65 \mathrm{E}-06 \\
5.30 \mathrm{E}-06 \\
1.28 \mathrm{E}-05 \\
6.36 \mathrm{E}-05 \\
3.94 \mathrm{E}-05 \\
1.32 \mathrm{E}-03 \\
2.64 \mathrm{E}-03 \\
1.11 \mathrm{E}-03 \\
1.30 \mathrm{E}-04 \\
1.71 \mathrm{E}-06 \\
4.09 \mathrm{E}-09 \\
6.02 \mathrm{E}-04\end{array}$ & $\begin{array}{l}1.18 \mathrm{E}-04 \\
1.18 \mathrm{E}-05 \\
1.05 \mathrm{E}-05 \\
1.09 \mathrm{E}-05 \\
1.11 \mathrm{E}-05 \\
1.09 \mathrm{E}-05 \\
1.00 \mathrm{E}-05 \\
8.45 \mathrm{E}-06 \\
7.17 \mathrm{E}-06 \\
5.54 \mathrm{E}-06 \\
3.73 \mathrm{E}-06 \\
3.16 \mathrm{E}-06 \\
2.97 \mathrm{E}-06 \\
3.03 \mathrm{E}-06 \\
3.75 \mathrm{E}-06 \\
7.32 \mathrm{E}-06 \\
2.26 \mathrm{E}-05 \\
.8 .39 \mathrm{E}-05 \\
5.41 \mathrm{E}-04 \\
3.95 \mathrm{E}-04 \\
1.44 \mathrm{E}-02 \\
2.60 \mathrm{E}-02 \\
9.04 \mathrm{E}-03 \\
9.09 \mathrm{E}-04 \\
1.18 \mathrm{E}-05 \\
2.83 \mathrm{E}-08 \\
5.16 \mathrm{E}-02\end{array}$ & $\begin{array}{l}5.43 E-03 \\
5.38 E-03 \\
5.37 E-03 \\
5.37 E-03 \\
5.36 E-03 \\
5.36 E-03 \\
5.35 E-03 \\
5.35 E-03 \\
5.34 E-03 \\
5.34 E-03 \\
5.33 E-03 \\
5.33 E-03 \\
5.33 E-03 \\
5.33 E-03 \\
5.33 E-03 \\
5.33 E-03 \\
5.32 E-03 \\
5.32 E-03 \\
5.31 E-03 \\
5.24 E-03 \\
5.20 E-03 \\
3.88 E-03 \\
1.24 E-03 \\
1.32 E-04 \\
1.71 E-06 \\
3.02 E-09\end{array}$ & $\begin{array}{l}5.16 \mathrm{E}-02 \\
5.15 \mathrm{E}-02 \\
5.15 \mathrm{E}-02 \\
5.15 \mathrm{E}-02 \\
5.15 \mathrm{E}-02 \\
5.15 \mathrm{E}-02 \\
5.15 \mathrm{E}-02 \\
5.14 \mathrm{E}-02 \\
5.14 \mathrm{E}-02 \\
5.14 \mathrm{E}-02 \\
5.14 \mathrm{E}-02 \\
5.14 \mathrm{E}-02 \\
5.14 \mathrm{E}-02 \\
5.14 \mathrm{E}-02 \\
5.14 \mathrm{E}-02 \\
5.14 \mathrm{E}-02 \\
5.14 \mathrm{E}-02 \\
5.14 \mathrm{E}-02 \\
5.13 \mathrm{E}-02 \\
5.07 \mathrm{E}-02 \\
5.04 \mathrm{E}-02 \\
3.60 \mathrm{E}-02 \\
9.96 \mathrm{E}-03 \\
9.20 \mathrm{E}-04 \\
1.18 \mathrm{E}-05 \\
2.21 \mathrm{E}-08\end{array}$ \\
\hline
\end{tabular}


TABLE A.7. Neutron Flux, Absorbed Dose, and Dose Equivalent Distributions Determined from Multisphere Spectrometer Measurements at $100 \mathrm{~cm}$ (40 in.) from the PuF ${ }_{4}$ Source with 2.54-cm (1-in.) Acrylic Plastic Shield

\begin{tabular}{|c|c|c|c|c|c|c|}
\hline \multirow[b]{2}{*}{$\begin{array}{l}\text { Bin } \\
\text { Number }\end{array}$} & \multirow[b]{2}{*}{$\begin{array}{l}\text { Energy, } \\
\mathrm{MeV}\end{array}$} & \multirow[b]{2}{*}{$\begin{array}{c}\text { Flux, } \\
\mathrm{N} / \mathrm{S}-\mathrm{cm}^{2}\end{array}$} & \multicolumn{2}{|c|}{ Differential } & \multicolumn{2}{|c|}{ Cumulative } \\
\hline & & & $\begin{array}{l}\text { Dose, } \\
\mathrm{mGy} / \mathrm{h}\end{array}$ & $\begin{array}{l}\text { Dose } \\
\text { Equivalent, } \\
\mathrm{mSv} / \mathrm{h} \\
\end{array}$ & $\begin{array}{c}\text { Dose } \\
\text { Distribution, } \\
\text { mGy/h } \\
\end{array}$ & $\begin{array}{c}\text { Dose } \\
\text { Equivalent } \\
\text { Distribution, } \\
\mathrm{mSv} / \mathrm{h} \\
\end{array}$ \\
\hline $\begin{array}{l}1 \\
2 \\
3 \\
4 \\
5 \\
6 \\
7 \\
8 \\
9 \\
10 \\
11 \\
12 \\
13 \\
14 \\
15 \\
16 \\
17 \\
18 \\
19 \\
20 \\
21 \\
22 \\
23 \\
24 \\
25 \\
26 \\
\text { Total }\end{array}$ & $\begin{array}{l}2.57 \mathrm{E}-07 \\
5.48 \mathrm{E}-07 \\
1.06 \mathrm{E}-06 \\
2.25 \mathrm{E}-06 \\
4.77 \mathrm{E}-06 \\
1.01 \mathrm{E}-05 \\
2.14 \mathrm{E}-05 \\
4.52 \mathrm{E}-05 \\
9.58 \mathrm{E}-05 \\
2.03 \mathrm{E}-04 \\
4.34 \mathrm{E}-04 \\
9.13 \mathrm{E}-04 \\
1.92 \mathrm{E}-03 \\
4.07 \mathrm{E}-03 \\
8.62 \mathrm{E}-03 \\
1.82 \mathrm{E}-02 \\
3.86 \mathrm{E}-02 \\
8.18 \mathrm{E}-02 \\
1.67 \mathrm{E}-01 \\
3.37 \mathrm{E}-01 \\
6.79 \mathrm{E}-01 \\
1.39 \mathrm{E}+00 \\
2.78 \mathrm{E}+00 \\
5.54 \mathrm{E}+00 \\
1.12 \mathrm{E}+01 \\
2.04 \mathrm{E}+01\end{array}$ & $\begin{array}{l}7.62 \mathrm{E}+00 \\
7.60 \mathrm{E}-01 \\
6.75 \mathrm{E}-01 \\
7.11 \mathrm{E}-01 \\
7.31 \mathrm{E}-01 \\
7.27 \mathrm{E}-01 \\
6.92 \mathrm{E}-01 \\
6.32 \mathrm{E}-01 \\
5.68 \mathrm{E}-01 \\
4.94 \mathrm{E}-01 \\
3.89 \mathrm{E}-01 \\
4.01 \mathrm{E}-01 \\
4.54 \mathrm{E}-01 \\
5.43 \mathrm{E}-01 \\
7.14 \mathrm{E}-01 \\
9.23 \mathrm{E}-01 \\
1.45 \mathrm{E}+00 \\
2.38 \mathrm{E}+00 \\
5.11 \mathrm{E}+00 \\
1.18 \mathrm{E}+01 \\
1.48 \mathrm{E}+01 \\
1.26 \mathrm{E}+01 \\
4.83 \mathrm{E}+00 \\
6.50 \mathrm{E}-01 \\
1.17 \mathrm{E}-02 \\
2.36 \mathrm{E}-05 \\
7.07 \mathrm{E}+04\end{array}$ & $\begin{array}{l}1.44 \mathrm{E}-04 \\
1.67 \mathrm{E}-05 \\
1.50 \mathrm{E}-05 \\
1.57 \mathrm{E}-05 \\
1.60 \mathrm{E}-05 \\
1.57 \mathrm{E}-05 \\
1.49 \mathrm{E}-05 \\
1.35 \mathrm{E}-05 \\
1.21 \mathrm{E}-05 \\
1.01 \mathrm{E}-05 \\
7.65 \mathrm{E}-06 \\
7.59 \mathrm{E}-06 \\
8.41 \mathrm{E}-06 \\
9.93 \mathrm{E}-06 \\
1.30 \mathrm{E}-05 \\
1.87 \mathrm{E}-05 \\
3.47 \mathrm{E}-05 \\
6.72 \mathrm{E}-05 \\
1.91 \mathrm{E}-04 \\
6.19 \mathrm{E}-05 \\
1.20 \mathrm{E}-03 \\
1.54 \mathrm{E}-03 \\
7.34 \mathrm{E}-04 \\
1.35 \mathrm{E}-04 \\
2.78 \mathrm{E}-06 \\
7.73 \mathrm{E}-09 \\
4.77 \mathrm{E}-04\end{array}$ & $\begin{array}{l}3.35 \mathrm{E}-04 \\
3.48 \mathrm{E}-05 \\
3.15 \mathrm{E}-05 \\
3.33 \mathrm{E}-05 \\
3.42 \mathrm{E}-05 \\
3.39 \mathrm{E}-05 \\
3.16 \mathrm{E}-05 \\
2.81 \mathrm{E}-05 \\
2.46 \mathrm{E}-05 \\
2.06 \mathrm{E}-05 \\
1.55 \mathrm{E}-05 \\
1.53 \mathrm{E}-05 \\
1.69 \mathrm{E}-05 \\
2.00 \mathrm{E}-05 \\
2.62 \mathrm{E}-05 \\
5.16 \mathrm{E}-05 \\
1.48 \mathrm{E}-04 \\
4.41 \mathrm{E}-04 \\
1.62 \mathrm{E}-03 \\
6.21 \mathrm{E}-04 \\
1.30 \mathrm{E}-02 \\
1.52 \mathrm{E}-02 \\
5.98 \mathrm{E}-03 \\
9.46 \mathrm{E}-04 \\
1.92 \mathrm{E}-05 \\
5.36 \mathrm{E}-08 \\
3.87 \mathrm{E}-02\end{array}$ & $\begin{array}{l}4.30 \mathrm{E}-03 \\
4.16 \mathrm{E}-03 \\
4.14 \mathrm{E}-03 \\
4.13 \mathrm{E}-03 \\
4.11 \mathrm{E}-03 \\
4.09 \mathrm{E}-03 \\
4.08 \mathrm{E}-03 \\
4.06 \mathrm{E}-03 \\
4.05 \mathrm{E}-03 \\
4.04 \mathrm{E}-03 \\
4.03 \mathrm{E}-03 \\
4.02 \mathrm{E}-03 \\
4.01 \mathrm{E}-03 \\
4.00 \mathrm{E}-03 \\
3.99 \mathrm{E}-03 \\
3.98 \mathrm{E}-03 \\
3.96 \mathrm{E}-03 \\
3.93 \mathrm{E}-03 \\
3.86 \mathrm{E}-03 \\
3.67 \mathrm{E}-03 \\
3.61 \mathrm{E}-03 \\
2.41 \mathrm{E}-03 \\
8.72 \mathrm{E}-04 \\
1.38 \mathrm{E}-04 \\
2.79 \mathrm{E}-06 \\
7.81 \mathrm{E}-09\end{array}$ & $\begin{array}{l}3.87 E-02 \\
3.84 E-02 \\
3.84 E-02 \\
3.83 E-02 \\
3.83 E-02 \\
3.83 E-02 \\
3.82 E-02 \\
3.82 E-02 \\
3.82 E-02 \\
3.81 E-02 \\
3.81 E-02 \\
3.81 E-02 \\
3.81 E-02 \\
3.81 E-02 \\
3.80 E-02 \\
3.80 E-02 \\
3.80 E-02 \\
3.78 E-02 \\
3.74 E-02 \\
3.58 E-02 \\
3.51 E-02 \\
2.21 E-02 \\
6.95 E-03 \\
9.65 E-04 \\
1.93 E-05 \\
5.67 E-08\end{array}$ \\
\hline
\end{tabular}


TABLE A.8. Neutron Flux, Absorbed Dose, and Dose Equivalent Distributions Determined from Multisphere Spectrometer Measurements at $100 \mathrm{~cm}$ (40 in.) from the PuF ${ }_{4}$ Source with 5-cm (2-in.) Acrylic Plastic Shield

\begin{tabular}{|c|c|c|c|c|c|c|}
\hline \multirow[b]{2}{*}{$\begin{array}{l}\text { Bin } \\
\text { Number }\end{array}$} & \multirow[b]{2}{*}{$\begin{array}{l}\text { Energy, } \\
\mathrm{MeV}\end{array}$} & \multirow[b]{2}{*}{$\begin{array}{l}\text { Flux, } \\
\text { N/S-cm }\end{array}$} & \multicolumn{2}{|c|}{ Differential } & \multicolumn{2}{|c|}{ Cumulative } \\
\hline & & & $\begin{array}{l}\text { Dose, } \\
\mathrm{mGy} / \mathrm{h}\end{array}$ & $\begin{array}{c}\text { Dose } \\
\text { Equivalent, } \\
\mathrm{mSv} / \mathrm{h} \\
\end{array}$ & $\begin{array}{c}\text { Dose } \\
\text { Distribution, } \\
\mathrm{mGy} / \mathrm{h} \\
\end{array}$ & $\begin{array}{c}\text { Dose } \\
\text { Equivalent } \\
\text { Distribution, } \\
\mathrm{mSv} / \mathrm{h} \\
\end{array}$ \\
\hline $\begin{array}{l}1 \\
2 \\
3 \\
4 \\
5 \\
6 \\
7 \\
8 \\
9 \\
10 \\
11 \\
12 \\
13 \\
14 \\
15 \\
16 \\
17 \\
18 \\
19 \\
20 \\
21 \\
22 \\
23 \\
24 \\
25 \\
26 \\
\text { Total }\end{array}$ & $\begin{array}{l}2.57 \mathrm{E}-07 \\
5.48 \mathrm{E}-07 \\
1.06 \mathrm{E}-06 \\
2.25 \mathrm{E}-06 \\
4.77 \mathrm{E}-06 \\
1.01 \mathrm{E}-05 \\
2.14 \mathrm{E}-05 \\
4.52 \mathrm{E}-05 \\
9.58 \mathrm{E}-05 \\
2.03 \mathrm{E}-04 \\
4.34 \mathrm{E}-04 \\
9.13 \mathrm{E}-04 \\
1.92 \mathrm{E}-03 \\
4.07 \mathrm{E}-03 \\
8.62 \mathrm{E}-03 \\
1.82 \mathrm{E}-02 \\
3.86 \mathrm{E}-02 \\
8.18 \mathrm{E}-02 \\
1.67 \mathrm{E}-01 \\
3.37 \mathrm{E}-01 \\
6.79 \mathrm{E}-01 \\
1.39 \mathrm{E}+00 \\
2.78 \mathrm{E}+00 \\
5.54 \mathrm{E}+00 \\
1.12 \mathrm{E}+01 \\
2.04 \mathrm{E}+01\end{array}$ & $\begin{array}{l}1.48 \mathrm{E}+01 \\
1.06 \mathrm{E}+00 \\
9.24 \mathrm{E}-01 \\
9.49 \mathrm{E}-01 \\
9.44 \mathrm{E}-01 \\
9.08 \mathrm{E}-01 \\
8.30 \mathrm{E}-01 \\
7.57 \mathrm{E}-01 \\
6.30 \mathrm{E}-01 \\
5.30 \mathrm{E}-01 \\
4.06 \mathrm{E}-01 \\
4.13 \mathrm{E}-01 \\
4.62 \mathrm{E}-01 \\
5.46 \mathrm{E}-01 \\
6.97 \mathrm{E}-01 \\
8.68 \mathrm{E}-01 \\
1.30 \mathrm{E}+00 \\
2.01 \mathrm{E}+00 \\
4.01 \mathrm{E}+00 . \\
9.11 \mathrm{E}+00 \\
1.19 \mathrm{E}+01 \\
8.31 \mathrm{E}+00 \\
2.25 \mathrm{E}+00 \\
1.95 \mathrm{E}-01 \\
2.51 \mathrm{E}-03 \\
4.44 \mathrm{E}-06 \\
6.48 \mathrm{E}+04\end{array}$ & $\begin{array}{l}2.80 \mathrm{E}-04 \\
2.33 \mathrm{E}-05 \\
2.05 \mathrm{E}-05 \\
2.10 \mathrm{E}-05 \\
2.06 \mathrm{E}-05 \\
1.96 \mathrm{E}-05 \\
1.78 \mathrm{E}-05 \\
1.62 \mathrm{E}-05 \\
1.34 \mathrm{E}-05 \\
1.09 \mathrm{E}-05 \\
7.98 \mathrm{E}-06 \\
7.81 \mathrm{E}-06 \\
8.56 \mathrm{E}-06 \\
9.99 \mathrm{E}-06 \\
1.26 \mathrm{E}-05 \\
1.76 \mathrm{E}-05 \\
3.11 \mathrm{E}-05 \\
5.69 \mathrm{E}-05 \\
1.50 \mathrm{E}-04 \\
4.77 \mathrm{E}-05 \\
9.58 \mathrm{E}-04 \\
1.02 \mathrm{E}-03 \\
3.41 \mathrm{E}-04 \\
4.05 \mathrm{E}-05 \\
5.98 \mathrm{E}-07 \\
1.46 \mathrm{E}-09 \\
3.50 \mathrm{E}-04\end{array}$ & $\begin{array}{l}6.51 E-04 \\
4.87 E-05 \\
4.31 E-05 \\
4.44 E-05 \\
4.42 E-05 \\
4.24 E-05 \\
3.79 E-05 \\
3.37 E-05 \\
2.73 E-05 \\
2.21 E-05 \\
1.62 E-05 \\
1.58 E-05 \\
1.72 E-05 \\
2.01 E-05 \\
2.56 E-05 \\
4.85 E-05 \\
1.33 E-04 \\
3.73 E-04 \\
1.27 E-03 \\
4.79 E-04 \\
1.04 E-02 \\
1.00 E-02 \\
2.78 E-03 \\
2.84 E-04 \\
4.13 E-06 \\
1.01 E-08 \\
2.69 E-02\end{array}$ & $\begin{array}{l}3.15 E-03 \\
2.87 E-03 \\
2.85 E-03 \\
2.83 E-03 \\
2.81 E-03 \\
2.79 E-03 \\
2.77 E-03 \\
2.75 E-03 \\
2.73 E-03 \\
2.72 E-03 \\
2.71 E-03 \\
2.70 E-03 \\
2.69 E-03 \\
2.68 E-03 \\
2.67 E-03 \\
2.66 E-03 \\
2.64 E-03 \\
2.61 E-03 \\
2.56 E-03 \\
2.41 E-03 \\
2.36 E-03 \\
1.40 E-03 \\
3.82 E-04 \\
4.11 E-05 \\
5.99 E-07 \\
1.57 E-09\end{array}$ & $\begin{array}{l}2.69 \mathrm{E}-02 \\
2.63 \mathrm{E}-02 \\
2.62 \mathrm{E}-02 \\
2.62 \mathrm{E}-02 \\
2.61 \mathrm{E}-02 \\
2.61 \mathrm{E}-02 \\
2.61 \mathrm{E}-02 \\
2.60 \mathrm{E}-02 \\
2.60 \mathrm{E}-02 \\
2.60 \mathrm{E}-02 \\
2.59 \mathrm{E}-02 \\
2.59 \mathrm{E}-02 \\
2.59 \mathrm{E}-02 \\
2.59 \mathrm{E}-02 \\
2.59 \mathrm{E}-02 \\
2.58 \mathrm{E}-02 \\
2.58 \mathrm{E}-02 \\
2.57 \mathrm{E}-02 \\
2.53 \mathrm{E}-02 \\
2.40 \mathrm{E}-02 \\
2.35 \mathrm{E}-02 \\
1.31 \mathrm{E}-02 \\
3.07 \mathrm{E}-03 \\
2.88 \mathrm{E}-04 \\
4.14 \mathrm{E}-06 \\
1.38 \mathrm{E}-08\end{array}$ \\
\hline
\end{tabular}


TABLE A.9. Neutron Flux, Absorbed Dose, and Dose Equivalent Distributions Determined from Multisphere Spectrometer Measurements at $100 \mathrm{~cm}$ (40 in.) from the PuF ${ }_{4}$ Source with 7.6-cm (3-in.) Acrylic Plastic Shield

\begin{tabular}{|c|c|c|c|c|c|c|}
\hline \multirow[b]{2}{*}{$\begin{array}{l}\text { Bin } \\
\text { Number }\end{array}$} & \multirow[b]{2}{*}{$\begin{array}{l}\text { Energy, } \\
\mathrm{MeV}\end{array}$} & \multirow[b]{2}{*}{$\begin{array}{c}\text { Flux, } \\
\mathrm{N} / \mathrm{S}-\mathrm{cm}^{2} \\
\end{array}$} & \multicolumn{2}{|c|}{ Differential } & \multicolumn{2}{|c|}{ Cumulative } \\
\hline & & & $\begin{array}{l}\text { Dose, } \\
\mathrm{mGy/h}\end{array}$ & $\begin{array}{l}\text { Dose } \\
\text { Equivalent, } \\
\mathrm{mSv} / \mathrm{h} \\
\end{array}$ & $\begin{array}{c}\text { Dose } \\
\text { Distribution, } \\
\text { mGy } / \mathrm{h} \\
\end{array}$ & $\begin{array}{c}\text { Dose } \\
\text { Equivalent } \\
\text { Distribution, } \\
\text { mSv/h } \\
\end{array}$ \\
\hline $\begin{array}{l}1 \\
2 \\
3 \\
4 \\
5 \\
6 \\
7 \\
8 \\
9 \\
10 \\
11 \\
12 \\
13 \\
14 \\
15 \\
16 \\
17 \\
18 \\
19 \\
20 \\
21 \\
22 \\
23 \\
24 \\
25 \\
26 \\
\text { Total }\end{array}$ & $\begin{array}{l}2.57 \mathrm{E}-07 \\
5.48 \mathrm{E}-07 \\
1.06 \mathrm{E}-06 \\
2.25 \mathrm{E}-06 \\
4.77 \mathrm{E}-06 \\
1.01 \mathrm{E}-05 \\
2.14 \mathrm{E}-05 \\
4.52 \mathrm{E}-05 \\
9.58 \mathrm{E}-05 \\
2.03 \mathrm{E}-04 \\
4.34 \mathrm{E}-04 \\
9.13 \mathrm{E}-04 \\
1.92 \mathrm{E}-03 \\
4.07 \mathrm{E}-03 \\
8.62 \mathrm{E}-03 \\
1.82 \mathrm{E}-02 \\
3.86 \mathrm{E}-02 \\
8.18 \mathrm{E}-02 \\
1.67 \mathrm{E}-01 \\
3.37 \mathrm{E}-01 \\
6.79 \mathrm{E}-01 \\
1.39 \mathrm{E}+00 \\
2.78 \mathrm{E}+00 \\
5.54 \mathrm{E}+00 \\
1.12 \mathrm{E}+01 \\
2.04 \mathrm{E}+01\end{array}$ & $\begin{array}{l}1.15 \mathrm{E}+01 \\
6.59 \mathrm{E}-01 \\
5.54 \mathrm{E}-01 \\
5.42 \mathrm{E}-01 \\
5.16 \mathrm{E}-01 \\
4.77 \mathrm{E}-01 \\
4.19 \mathrm{E}-01 \\
3.63 \mathrm{E}-01 \\
3.00 \mathrm{E}-01 \\
2.51 \mathrm{E}-01 \\
1.94 \mathrm{E}-01 \\
2.02 \mathrm{E}-01 \\
2.35 \mathrm{E}-01 \\
2.90 \mathrm{E}-01 \\
3.90 \mathrm{E}-01 \\
5.12 \mathrm{E}-01 \\
8.10 \mathrm{E}-01 \\
1.32 \mathrm{E}+00 \\
2.65 \mathrm{E}+00 \\
5.65 \mathrm{E}+00 \\
6.52 \mathrm{E}+00 \\
4.40 \mathrm{E}+00 \\
1.37 \mathrm{E}+00 \\
1.52 \mathrm{E}-01 \\
2.41 \mathrm{E}-03 \\
4.69 \mathrm{E}-06 \\
4.03 \mathrm{E}+04\end{array}$ & $\begin{array}{l}2.18 \mathrm{E}-04 \\
1.44 \mathrm{E}-05 \\
1.23 \mathrm{E}-05 \\
1.20 \mathrm{E}-05 \\
1.13 \mathrm{E}-05 \\
1.03 \mathrm{E}-05 \\
9.00 \mathrm{E}-06 \\
7.75 \mathrm{E}-06 \\
6.36 \mathrm{E}-06 \\
5.14 \mathrm{E}-06 \\
3.82 \mathrm{E}-06 \\
3.82 \mathrm{E}-06 \\
4.35 \mathrm{E}-06 \\
5.31 \mathrm{E}-06 \\
7.07 \mathrm{E}-06 \\
1.04 \mathrm{E}-05 \\
1.94 \mathrm{E}-05 \\
3.72 \mathrm{E}-05 \\
9.91 \mathrm{E}-05 \\
2.96 \mathrm{E}-05 \\
5.26 \mathrm{E}-04 \\
5.40 \mathrm{E}-04 \\
2.08 \mathrm{E}-04 \\
3.17 \mathrm{E}-05 \\
5.75 \mathrm{E}-07 \\
1.54 \mathrm{E}-09 \\
2.03 \mathrm{E}-04\end{array}$ & $\begin{array}{l}5.07 \mathrm{E}-04 \\
3.02 \mathrm{E}-05 \\
2.58 \mathrm{E}-05 \\
2.54 \mathrm{E}-05 \\
2.42 \mathrm{E}-05 \\
2.23 \mathrm{E}-05 \\
1.91 \mathrm{E}-05 \\
1.61 \mathrm{E}-05 \\
1.30 \mathrm{E}-05 \\
1.04 \mathrm{E}-05 \\
7.73 \mathrm{E}-06 \\
7.73 \mathrm{E}-06 \\
8.76 \mathrm{E}-06 \\
1.07 \mathrm{E}-05 \\
1.43 \mathrm{E}-05 \\
2.86 \mathrm{E}-05 \\
8.25 \mathrm{E}-05 \\
2.44 \mathrm{E}-04 \\
8.42 \mathrm{E}-04 \\
2.97 \mathrm{E}-04 \\
5.73 \mathrm{E}-03 \\
5.32 \mathrm{E}-03 \\
1.69 \mathrm{E}-03 \\
2.21 \mathrm{E}-04 \\
3.97 \mathrm{E}-06 \\
1.06 \mathrm{E}-08 \\
1.52 \mathrm{E}-02\end{array}$ & $\begin{array}{l}1.83 \mathrm{E}-03 \\
1.61 \mathrm{E}-03 \\
1.60 \mathrm{E}-03 \\
1.59 \mathrm{E}-03 \\
1.58 \mathrm{E}-03 \\
1.56 \mathrm{E}-03 \\
1.55 \mathrm{E}-03 \\
1.55 \mathrm{E}-03 \\
1.54 \mathrm{E}-03 \\
1.53 \mathrm{E}-03 \\
1.53 \mathrm{E}-03 \\
1.52 \mathrm{E}-03 \\
1.52 \mathrm{E}-03 \\
1.51 \mathrm{E}-03 \\
1.51 \mathrm{E}-03 \\
1.50 \mathrm{E}-03 \\
1.49 \mathrm{E}-03 \\
1.47 \mathrm{E}-03 \\
1.43 \mathrm{E}-03 \\
1.34 \mathrm{E}-03 \\
1.31 \mathrm{E}-03 \\
7.80 \mathrm{E}-04 \\
2.40 \mathrm{E}-04 \\
3.22 \mathrm{E}-05 \\
5.77 \mathrm{E}-07 \\
1.82 \mathrm{E}-09\end{array}$ & $\begin{array}{l}1.52 \mathrm{E}-02 \\
1.47 \mathrm{E}-02 \\
1.47 \mathrm{E}-02 \\
1.46 \mathrm{E}-02 \\
1.46 \mathrm{E}-02 \\
1.46 \mathrm{E}-02 \\
1.46 \mathrm{E}-02 \\
1.45 \mathrm{E}-02 \\
1.45 \mathrm{E}-02 \\
1.45 \mathrm{E}-02 \\
1.45 \mathrm{E}-02 \\
1.45 \mathrm{E}-02 \\
1.45 \mathrm{E}-02 \\
1.45 \mathrm{E}-02 \\
1.45 \mathrm{E}-02 \\
1.45 \mathrm{E}-02 \\
1.44 \mathrm{E}-02 \\
1.43 \mathrm{E}-02 \\
1.41 \mathrm{E}-02 \\
1.33 \mathrm{E}-02 \\
1.30 \mathrm{E}-02 \\
7.23 \mathrm{E}-03 \\
1.92 \mathrm{E}-03 \\
2.25 \mathrm{E}-04 \\
3.98 \mathrm{E}-06 \\
9.16 \mathrm{E}-09\end{array}$ \\
\hline
\end{tabular}


IABLE A.10. Neutron Flux, Absorbed Dose, and Dose Equivalent Distributions Determined from Multisphere Spectrometer Measurements at $100 \mathrm{~cm}$ (40 in.) from the $\mathrm{PuF}_{4}$ Source with 10-cm (4-in.) Acrylic Plastic Shield

\begin{tabular}{|c|c|c|c|c|c|c|}
\hline \multirow[b]{2}{*}{$\begin{array}{l}\text { Bin } \\
\text { Number }\end{array}$} & \multirow[b]{2}{*}{$\begin{array}{l}\text { Energy, } \\
\text { MeV }\end{array}$} & \multirow[b]{2}{*}{$\begin{array}{c}\text { Flux, } \\
\mathrm{N} / \mathrm{S}-\mathrm{cm}^{2}\end{array}$} & \multicolumn{2}{|c|}{ Differential } & \multicolumn{2}{|c|}{ Cumulative } \\
\hline & & & $\begin{array}{l}\text { Dose, } \\
\mathrm{mG} / \mathrm{h}\end{array}$ & $\begin{array}{l}\text { Dose } \\
\text { Equivalent, } \\
\mathrm{mSv} / \mathrm{h}\end{array}$ & $\begin{array}{l}\text { Dose } \\
\text { Distribution, } \\
\text { mGy/h }\end{array}$ & $\begin{array}{c}\text { Dose } \\
\text { Equivalent } \\
\text { Distribution, } \\
\mathrm{mSv} / \mathrm{h} \\
\end{array}$ \\
\hline $\begin{array}{l}1 \\
2 \\
3 \\
4 \\
5 \\
6 \\
7 \\
8 \\
9 \\
10 \\
11 \\
12 \\
13 \\
14 \\
15 \\
16 \\
17 \\
18 \\
19 \\
20 \\
21 \\
22 \\
23 \\
24 \\
25 \\
26 \\
\text { Total }\end{array}$ & $\begin{array}{l}2.57 \mathrm{E}-07 \\
5.48 \mathrm{E}-07 \\
1.06 \mathrm{E}-06 \\
2.25 \mathrm{E}-06 \\
4.77 \mathrm{E}-06 \\
1.01 \mathrm{E}-05 \\
2.14 \mathrm{E}-05 \\
4.52 \mathrm{E}-05 \\
9.58 \mathrm{E}-05 \\
2.03 \mathrm{E}-04 \\
4.34 \mathrm{E}-04 \\
9.13 \mathrm{E}-04 \\
1.92 \mathrm{E}-03 \\
4.07 \mathrm{E}-03 \\
8.62 \mathrm{E}-03 \\
1.82 \mathrm{E}-02 \\
3.86 \mathrm{E}-02 \\
8.18 \mathrm{E}-02 \\
1.67 \mathrm{E}-01 \\
3.37 \mathrm{E}-01 \\
6.79 \mathrm{E}-01 \\
1.39 \mathrm{E}+00 \\
2.78 \mathrm{E}+00 \\
5.54 \mathrm{E}+00 \\
1.12 \mathrm{E}+01 \\
2.04 \mathrm{E}+01\end{array}$ & $\begin{array}{l}1.04 \mathrm{E}+01 \\
4.19 \mathrm{E}-01 \\
3.73 \mathrm{E}-01 \\
4.05 \mathrm{E}-01 \\
4.28 \mathrm{E}-01 \\
4.41 \mathrm{E}-01 \\
4.35 \mathrm{E}-01 \\
4.39 \mathrm{E}-01 \\
3.90 \mathrm{E}-01 \\
3.53 \mathrm{E}-01 \\
2.87 \mathrm{E}-01 \\
3.06 \mathrm{E}-01 \\
3.51 \mathrm{E}-01 \\
4.16 \mathrm{E}-01 \\
5.18 \mathrm{E}-01 \\
6.19 \mathrm{E}-01 \\
8.74 \mathrm{E}-01 \\
1.23 \mathrm{E}+00 \\
2.12 \mathrm{E}+00 \\
4.06 \mathrm{E}+00 \\
4.83 \mathrm{E}+00 \\
3.29 \mathrm{E}+00 \\
9.67 \mathrm{E}-01 \\
9.62 \mathrm{E}-02 \\
1.38 \mathrm{E}-03 \\
2.56 \mathrm{E}-06 \\
3.41 \mathrm{E}+04\end{array}$ & $\begin{array}{l}1.97 \mathrm{E}-04 \\
9.18 \mathrm{E}-06 \\
8.29 \mathrm{E}-06 \\
8.95 \mathrm{E}-06 \\
9.36 \mathrm{E}-06 \\
9.54 \mathrm{E}-06 \\
9.36 \mathrm{E}-06 \\
9.39 \mathrm{E}-06 \\
8.28 \mathrm{E}-06 \\
7.23 \mathrm{E}-06 \\
5.64 \mathrm{E}-06 \\
5.79 \mathrm{E}-06 \\
6.51 \mathrm{E}-06 \\
7.61 \mathrm{E}-06 \\
9.40 \mathrm{E}-06 \\
1.26 \mathrm{E}-05 \\
2.09 \mathrm{E}-05 \\
3.49 \mathrm{E}-05 \\
7.90 \mathrm{E}-05 \\
2.13 \mathrm{E}-05 \\
3.90 \mathrm{E}-04 \\
4.03 \mathrm{E}-04 \\
1.47 \mathrm{E}-04 \\
2.00 \mathrm{E}-05 \\
3.30 \mathrm{E}-07 \\
8.38 \mathrm{E}-10 \\
1.60 \mathrm{E}-04\end{array}$ & $\begin{array}{l}4.58 \mathrm{E}-04 \\
1.92 \mathrm{E}-05 \\
1.74 \mathrm{E}-05 \\
1.90 \mathrm{E}-05 \\
2.01 \mathrm{E}-05 \\
2.06 \mathrm{E}-05 \\
1.99 \mathrm{E}-05 \\
1.96 \mathrm{E}-05 \\
1.69 \mathrm{E}-05 \\
1.47 \mathrm{E}-05 \\
1.14 \mathrm{E}-05 \\
1.17 \mathrm{E}-05 \\
1.31 \mathrm{E}-05 \\
1.53 \mathrm{E}-05 \\
1.90 \mathrm{E}-05 \\
3.47 \mathrm{E}-05 \\
8.91 \mathrm{E}-05 \\
2.29 \mathrm{E}-04 \\
6.72 \mathrm{E}-04 \\
2.13 \mathrm{E}-04 \\
4.25 \mathrm{E}-03 \\
3.97 \mathrm{E}-03 \\
1.20 \mathrm{E}-03 \\
1.40 \mathrm{E}-04 \\
2.28 \mathrm{E}-06 \\
5.81 \mathrm{E}-09 \\
1.15 \mathrm{E}-02\end{array}$ & $\begin{array}{l}1.44 \mathrm{E}-03 \\
1.24 \mathrm{E}-03 \\
1.23 \mathrm{E}-03 \\
1.23 \mathrm{E}-03 \\
1.22 \mathrm{E}-03 \\
1.21 \mathrm{E}-03 \\
1.20 \mathrm{E}-03 \\
1.19 \mathrm{E}-03 \\
1.18 \mathrm{E}-03 \\
1.17 \mathrm{E}-03 \\
1.16 \mathrm{E}-03 \\
1.16 \mathrm{E}-03 \\
1.15 \mathrm{E}-03 \\
1.15 \mathrm{E}-03 \\
1.14 \mathrm{E}-03 \\
1.13 \mathrm{E}-03 \\
1.12 \mathrm{E}-03 \\
1.10 \mathrm{E}-03 \\
1.06 \mathrm{E}-03 \\
9.82 \mathrm{E}-04 \\
9.60 \mathrm{E}-04 \\
5.70 \mathrm{E}-04 \\
1.67 \mathrm{E}-04 \\
2.03 \mathrm{E}-05 \\
3.31 \mathrm{E}-07 \\
1.14 \mathrm{E}-09\end{array}$ & $\begin{array}{l}1.15 \mathrm{E}-02 \\
1.10 \mathrm{E}-02 \\
1.10 \mathrm{E}-02 \\
1.10 \mathrm{E}-02 \\
1.10 \mathrm{E}-02 \\
1.10 \mathrm{E}-02 \\
1.09 \mathrm{E}-02 \\
1.09 \mathrm{E}-02 \\
1.09 \mathrm{E}-02 \\
1.09 \mathrm{E}-02 \\
1.09 \mathrm{E}-02 \\
1.09 \mathrm{E}-02 \\
1.08 \mathrm{E}-02 \\
1.08 \mathrm{E}-02 \\
1.08 \mathrm{E}-02 \\
1.08 \mathrm{E}-02 \\
1.08 \mathrm{E}-02 \\
1.07 \mathrm{E}-02 \\
1.04 \mathrm{E}-02 \\
9.77 \mathrm{E}-03 \\
9.56 \mathrm{E}-03 \\
5.31 \mathrm{E}-03 \\
1.34 \mathrm{E}-03 \\
1.42 \mathrm{E}-04 \\
2.29 \mathrm{E}-06 \\
5.85 \mathrm{E}-09\end{array}$ \\
\hline
\end{tabular}


TABLE A.11. Neutron Flux, Absorbed Dose, and Dose Equivalent Distributions Determined from Multisphere Spectrometer Measurements at $50 \mathrm{~cm}$ (20 in.) from the $\mathrm{Bare}^{\mathrm{PuO}} \mathrm{O}_{2}$ Source

\begin{tabular}{|c|c|c|c|c|c|c|}
\hline \multirow[b]{2}{*}{$\begin{array}{l}\text { Bin } \\
\text { Number }\end{array}$} & \multirow[b]{2}{*}{$\begin{array}{l}\text { Energy, } \\
\text { MeV }\end{array}$} & \multirow[b]{2}{*}{$\begin{array}{l}F 7 u x, \\
N / S-\mathrm{cm}^{2} \\
\end{array}$} & \multicolumn{2}{|c|}{ Differential } & \multicolumn{2}{|c|}{ Cumulative } \\
\hline & & & $\begin{array}{l}\text { Dose, } \\
\mathrm{mGy} / \mathrm{h}\end{array}$ & $\begin{array}{c}\text { Dose } \\
\text { Equivalent, } \\
\mathrm{mSv} / \mathrm{h} \\
\end{array}$ & $\begin{array}{c}\text { Dose } \\
\text { Distribution, } \\
\text { mGy/h } \\
\end{array}$ & $\begin{array}{c}\text { Dose } \\
\text { Equivalent } \\
\text { Distribution } \\
\mathrm{mSv} / \mathrm{h} \\
\end{array}$ \\
\hline $\begin{array}{l}1 \\
2 \\
3 \\
4 \\
5 \\
6 \\
7 \\
8 \\
9 \\
10 \\
11 \\
12 \\
13 \\
14 \\
15 \\
16 \\
17 \\
18 \\
19 \\
20 \\
21 \\
22 \\
23 \\
24 \\
25 \\
26 \\
\text { Total }\end{array}$ & $\begin{array}{l}2.57 \mathrm{E}-07 \\
5.48 \mathrm{E}-07 \\
1.06 \mathrm{E}-06 \\
2.25 \mathrm{E}-06 \\
4.77 \mathrm{E}-06 \\
1.01 \mathrm{E}-05 \\
2.14 \mathrm{E}-05 \\
4.52 \mathrm{E}-05 \\
9.58 \mathrm{E}-05 \\
2.03 \mathrm{E}-04 \\
4.34 \mathrm{E}-04 \\
9.13 \mathrm{E}-04 \\
1.92 \mathrm{E}-03 \\
4.07 \mathrm{E}-03 \\
8.62 \mathrm{E}-03 \\
1.82 \mathrm{E}-02 \\
3.86 \mathrm{E}-02 \\
8.18 \mathrm{E}-02 \\
1.67 \mathrm{E}-01 \\
3.37 \mathrm{E}-01 \\
6.79 \mathrm{E}-01 \\
1.39 \mathrm{E}+00 \\
2.78 \mathrm{E}+00 \\
5.54 \mathrm{E}+00 \\
1.12 \mathrm{E}+01 \\
2.04 \mathrm{E}+01\end{array}$ & $\begin{array}{l}6.01 \mathrm{E}-01 \\
7.97 \mathrm{E}-02 \\
6.76 \mathrm{E}-02 \\
6.20 \mathrm{E}-02 \\
5.64 \mathrm{E}-02 \\
5.05 \mathrm{E}-02 \\
4.38 \mathrm{E}-02 \\
3.77 \mathrm{E}-02 \\
3.21 \mathrm{E}-02 \\
2.73 \mathrm{E}-02 \\
2.15 \mathrm{E}-02 \\
2.26 \mathrm{E}-02 \\
2.60 \mathrm{E}-02 \\
3.15 \mathrm{E}-02 \\
4.08 \mathrm{E}-02 \\
5.10 \mathrm{E}-02 \\
7.52 \mathrm{E}-02 \\
1.11 \mathrm{E}-01 \\
2.00 \mathrm{E}-01 \\
4.11 \mathrm{E}-01 \\
6.45 \mathrm{E}-01 \\
1.09 \mathrm{E}+00 \\
9.85 \mathrm{E}-01 \\
3.17 \mathrm{E}-01 \\
1.07 \mathrm{E}-02 \\
2.59 \mathrm{E}-05 \\
5.09 \mathrm{E}+03\end{array}$ & $\begin{array}{l}1.14 \mathrm{E}-05 \\
1.75 \mathrm{E}-06 \\
1.50 \mathrm{E}-06 \\
1.37 \mathrm{E}-06 \\
1.23 \mathrm{E}-06 \\
1.09 \mathrm{E}-06 \\
9.42 \mathrm{E}-07 \\
8.07 \mathrm{E}-07 \\
6.80 \mathrm{E}-07 \\
5.60 \mathrm{E}-07 \\
4.23 \mathrm{E}-07 \\
4.27 \mathrm{E}-07 \\
4.83 \mathrm{E}-07 \\
5.76 \mathrm{E}-07 \\
7.39 \mathrm{E}-07 \\
1.03 \mathrm{E}-06 \\
1.80 \mathrm{E}-06 \\
3.14 \mathrm{E}-06 \\
7.46 \mathrm{E}-06 \\
2.15 \mathrm{E}-06 \\
5.21 \mathrm{E}-05 \\
1.33 \mathrm{E}-04 \\
1.50 \mathrm{E}-04 \\
6.59 \mathrm{E}-05 \\
2.56 \mathrm{E}-06 \\
8.49 \mathrm{E}-09 \\
4.92 \mathrm{E}-05\end{array}$ & $\begin{array}{l}2.64 \mathrm{E}-05 \\
3.65 \mathrm{E}-06 \\
3.15 \mathrm{E}-06 \\
2.90 \mathrm{E}-06 \\
2.64 \mathrm{E}-06 \\
2.36 \mathrm{E}-06 \\
2.00 \mathrm{E}-06 \\
1.68 \mathrm{E}-06 \\
1.39 \mathrm{E}-06 \\
1.14 \mathrm{E}-06 \\
8.57 \mathrm{E}-07 \\
8.62 \mathrm{E}-07 \\
9.72 \mathrm{E}-07 \\
1.16 \mathrm{E}-06 \\
1.50 \mathrm{E}-06 \\
2.85 \mathrm{E}-06 \\
7.67 \mathrm{E}-06 \\
2.06 \mathrm{E}-05 \\
6.34 \mathrm{E}-05 \\
2.16 \mathrm{E}-05 \\
5.68 \mathrm{E}-04 \\
1.31 \mathrm{E}-03 \\
1.22 \mathrm{E}-03 \\
4.61 \mathrm{E}-04 \\
1.76 \mathrm{E}-05 \\
5.88 \mathrm{E}-08 \\
3.75 \mathrm{E}-03\end{array}$ & $\begin{array}{l}4.43 \mathrm{E}-04 \\
4.32 \mathrm{E}-04 \\
4.30 \mathrm{E}-04 \\
4.29 \mathrm{E}-04 \\
4.27 \mathrm{E}-04 \\
4.26 \mathrm{E}-04 \\
4.25 \mathrm{E}-04 \\
4.24 \mathrm{E}-04 \\
4.23 \mathrm{E}-04 \\
4.23 \mathrm{E}-04 \\
4.22 \mathrm{E}-04 \\
4.22 \mathrm{E}-04 \\
4.21 \mathrm{E}-04 \\
4.21 \mathrm{E}-04 \\
4.20 \mathrm{E}-04 \\
4.19 \mathrm{E}-04 \\
4.18 \mathrm{E}-04 \\
4.16 \mathrm{E}-04 \\
4.13 \mathrm{E}-04 \\
4.06 \mathrm{E}-04 \\
4.04 \mathrm{E}-04 \\
3.52 \mathrm{E}-04 \\
2.18 \mathrm{E}-04 \\
6.85 \mathrm{E}-05 \\
2.56 \mathrm{E}-06 \\
8.54 \mathrm{E}-09\end{array}$ & $\begin{array}{l}3.75 \mathrm{E}-03 \\
3.72 \mathrm{E}-03 \\
3.72 \mathrm{E}-03 \\
3.72 \mathrm{E}-03 \\
3.71 \mathrm{E}-03 \\
3.71 \mathrm{E}-03 \\
3.71 \mathrm{E}-03 \\
3.71 \mathrm{E}-03 \\
3.70 \mathrm{E}-03 \\
3.70 \mathrm{E}-03 \\
3.70 \mathrm{E}-03 \\
3.70 \mathrm{E}-03 \\
3.70 \mathrm{E}-03 \\
3.70 \mathrm{E}-03 \\
3.70 \mathrm{E}-03 \\
3.70 \mathrm{E}-03 \\
3.69 \mathrm{E}-03 \\
3.69 \mathrm{E}-03 \\
3.67 \mathrm{E}-03 \\
3.60 \mathrm{E}-03 \\
3.58 \mathrm{E}-03 \\
3.01 \mathrm{E}-03 \\
1.70 \mathrm{E}-03 \\
4.79 \mathrm{E}-04 \\
1.77 \mathrm{E}-05 \\
5.92 \mathrm{E}-08\end{array}$ \\
\hline
\end{tabular}


TABLE A.12. Neutron Flux, Absorbed Dose, and Dose Equivalent Distributions Determined from Multisphere Spectrometer Measurements at $50 \mathrm{~cm}$ (20 in.) from the Bare Plutonium Metal Source

\begin{tabular}{|c|c|c|c|c|c|c|}
\hline \multirow[b]{2}{*}{$\begin{array}{l}\text { Bin } \\
\text { Number }\end{array}$} & \multirow[b]{2}{*}{$\begin{array}{l}\text { Energy, } \\
\mathrm{MeV} \\
\end{array}$} & \multirow[b]{2}{*}{$\begin{array}{r}F l u x_{3} \\
N / S-\mathrm{cm}^{2}\end{array}$} & \multicolumn{2}{|c|}{ Differential } & \multicolumn{2}{|c|}{ Cumulative } \\
\hline & & & $\begin{array}{l}\text { Dose, } \\
\mathrm{mGy} / \mathrm{h}\end{array}$ & $\begin{array}{l}\text { Dose } \\
\text { Equivalent, } \\
\mathrm{mSv} / \mathrm{h} \\
\end{array}$ & $\begin{array}{l}\text { Dose } \\
\text { Distribution, } \\
\text { mGy/h } \\
\end{array}$ & $\begin{array}{c}\text { Dose } \\
\text { Equivalent } \\
\text { Distribution } \\
\mathrm{mSv} / \mathrm{h} \\
\end{array}$ \\
\hline $\begin{array}{l}1 \\
2 \\
3 \\
4 \\
5 \\
6 \\
7 \\
8 \\
9 \\
10 \\
11 \\
12 \\
13 \\
14 \\
15 \\
16 \\
17 \\
18 \\
19 \\
20 \\
21 \\
22 \\
23 \\
24 \\
25 \\
26 \\
\text { Total }\end{array}$ & $\begin{array}{l}2.57 \mathrm{E}-07 \\
5.48 \mathrm{E}-07 \\
1.06 \mathrm{E}-06 \\
2.25 \mathrm{E}-06 \\
4.77 \mathrm{E}-06 \\
1.01 \mathrm{E}-05 \\
2.14 \mathrm{E}-05 \\
4.52 \mathrm{E}-05 \\
9.58 \mathrm{E}-05 \\
2.03 \mathrm{E}-04 \\
4.34 \mathrm{E}-04 \\
9.13 \mathrm{E}-04 \\
1.92 \mathrm{E}-03 \\
4.07 \mathrm{E}-03 \\
8.62 \mathrm{E}-03 \\
1.82 \mathrm{E}-02 \\
3.86 \mathrm{E}-02 \\
8.18 \mathrm{E}-02 \\
1.67 \mathrm{E}-01 \\
3.37 \mathrm{E}-01 \\
6.79 \mathrm{E}-01 \\
1.39 \mathrm{E}+00 \\
2.78 \mathrm{E}+00 \\
5.54 \mathrm{E}+00 \\
1.12 \mathrm{E}+01 \\
2.04 \mathrm{E}+01\end{array}$ & $\begin{array}{l}7.05 \mathrm{E}-01 \\
7.59 \mathrm{E}-02 \\
6.04 \mathrm{E}-02 \\
5.20 \mathrm{E}-02 \\
4.41 \mathrm{E}-02 \\
3.66 \mathrm{E}-02 \\
2.90 \mathrm{E}-02 \\
2.18 \mathrm{E}-02 \\
1.71 \mathrm{E}-02 \\
1.32 \mathrm{E}-02 \\
9.47 \mathrm{E}-03 \\
9.24 \mathrm{E}-03 \\
1.03 \mathrm{E}-02 \\
1.27 \mathrm{E}-02 \\
1.78 \mathrm{E}-02 \\
2.53 \mathrm{E}-02 \\
4.50 \mathrm{E}-02 \\
8.80 \mathrm{E}-02 \\
2.40 \mathrm{E}-01 \\
7.40 \mathrm{E}-01 \\
1.45 \mathrm{E}+00 \\
1.76 \mathrm{E}+00 \\
7.23 \mathrm{E}-01 \\
8.45 \mathrm{E}-02 \\
1.33 \mathrm{E}-03 \\
2.40 \mathrm{E}-06 \\
6.27 \mathrm{E}+03\end{array}$ & $\begin{array}{l}1.33 \mathrm{E}-05 \\
1.66 \mathrm{E}-06 \\
1.34 \mathrm{E}-06 \\
1.15 \mathrm{E}-06 \\
9.63 \mathrm{E}-07 \\
7.91 \mathrm{E}-07 \\
6.23 \mathrm{E}-07 \\
4.67 \mathrm{E}-07 \\
3.63 \mathrm{E}-07 \\
2.70 \mathrm{E}-07 \\
1.86 \mathrm{E}-07 \\
1.75 \mathrm{E}-07 \\
1.91 \mathrm{E}-07 \\
2.32 \mathrm{E}-07 \\
3.23 \mathrm{E}-07 \\
5.13 \mathrm{E}-07 \\
1.08 \mathrm{E}-06 \\
2.49 \mathrm{E}-06 \\
8.95 \mathrm{E}-06 \\
3.88 \mathrm{E}-06 \\
1.17 \mathrm{E}-04 \\
2.15 \mathrm{E}-04 \\
1.10 \mathrm{E}-04 \\
1.76 \mathrm{E}-05 \\
3.18 \mathrm{E}-07 \\
7.85 \mathrm{E}-10 \\
5.54 \mathrm{E}-05\end{array}$ & $\begin{array}{l}3.10 \mathrm{E}-05 \\
3.48 \mathrm{E}-06 \\
2.82 \mathrm{E}-06 \\
2.43 \mathrm{E}-06 \\
2.06 \mathrm{E}-06 \\
1.71 \mathrm{E}-06 \\
1.32 \mathrm{E}-06 \\
9.72 \mathrm{E}-07 \\
7.40 \mathrm{E}-07 \\
5.48 \mathrm{E}-07 \\
3.77 \mathrm{E}-07 \\
3.53 \mathrm{E}-07 \\
3.85 \mathrm{E}-07 \\
4.66 \mathrm{E}-07 \\
6.54 \mathrm{E}-07 \\
1.42 \mathrm{E}-06 \\
4.59 \mathrm{E}-06 \\
1.63 \mathrm{E}-05 \\
7.61 \mathrm{E}-05 \\
3.89 \mathrm{E}-05 \\
1.27 \mathrm{E}-03 \\
2.12 \mathrm{E}-03 \\
8.95 \mathrm{E}-04 \\
1.23 \mathrm{E}-04 \\
2.19 \mathrm{E}-06 \\
5.44 \mathrm{E}-09 \\
4.60 \mathrm{E}-03\end{array}$ & $\begin{array}{l}4.99 \mathrm{E}-04 \\
4.86 \mathrm{E}-04 \\
4.84 \mathrm{E}-04 \\
4.83 \mathrm{E}-04 \\
4.82 \mathrm{E}-04 \\
4.81 \mathrm{E}-04 \\
4.80 \mathrm{E}-04 \\
4.79 \mathrm{E}-04 \\
4.79 \mathrm{E}-04 \\
4.79 \mathrm{E}-04 \\
4.78 \mathrm{E}-04 \\
4.78 \mathrm{E}-04 \\
4.78 \mathrm{E}-04 \\
4.78 \mathrm{E}-04 \\
4.77 \mathrm{E}-04 \\
4.77 \mathrm{E}-04 \\
4.77 \mathrm{E}-04 \\
4.76 \mathrm{E}-04 \\
4.73 \mathrm{E}-04 \\
4.64 \mathrm{E}-04 \\
4.60 \mathrm{E}-04 \\
3.43 \mathrm{E}-04 \\
1.28 \mathrm{E}-04 \\
1.79 \mathrm{E}-05 \\
3.18 \mathrm{E}-07 \\
8.62 \mathrm{E}-10\end{array}$ & $\begin{array}{l}4.60 \mathrm{E}-03 \\
4.57 \mathrm{E}-03 \\
4.57 \mathrm{E}-03 \\
4.57 \mathrm{E}-03 \\
4.56 \mathrm{E}-03 \\
4.56 \mathrm{E}-03 \\
4.56 \mathrm{E}-03 \\
4.56 \mathrm{E}-03 \\
4.56 \mathrm{E}-03 \\
4.56 \mathrm{E}-03 \\
4.56 \mathrm{E}-03 \\
4.56 \mathrm{E}-03 \\
4.56 \mathrm{E}-03 \\
4.56 \mathrm{E}-03 \\
4.55 \mathrm{E}-03 \\
4.55 \mathrm{E}-03 \\
4.55 \mathrm{E}-03 \\
4.55 \mathrm{E}-03 \\
4.53 \mathrm{E}-03 \\
4.46 \mathrm{E}-03 \\
4.42 \mathrm{E}-03 \\
3.14 \mathrm{E}-03 \\
1.02 \mathrm{E}-03 \\
1.25 \mathrm{E}-04 \\
2.20 \mathrm{E}-06 \\
5.40 \mathrm{E}-09\end{array}$ \\
\hline
\end{tabular}




\section{DISTRIBUTION}

No. of

Copies

OFFSITE

12 Office of Scientific and Technical Information

K. H. Crase

Health Protection Department

Savannah River Site

B7dg. 735-11A

P.0. Box 616

Aiken, SC 29802

R. T. Devine

Los Alamos National Laboratory

P.0. Box 1663

Mail Stop 808

Los ATamos, NM 87544

D. A. Gonzales

Reynolds Electric \&

Engineering $\mathrm{Co}_{0}$, Inc.

P.0. Box 98521

Las Vegas, NV 89192-8521

C. L. Graham

Lawrence Livermore National Laboratory

P.0. Box L-383

Livermore, CA 94550

J. M. Hoffman

Los Alamos National Laboratory

P.0. Box 1663

Los Alamos, NM 87544

D. G. Linkenhei 1

Radiological Engineering

EG\&G Rocky Flats

P.0. Box 464

Golden, CO 80402-0464
No. of

Copies

R. M. Loesch

Office of Health (EH-40)

U.S. Department of Energy

Hashington, DC 20545

K. L. McMahan

Oak Ridge National Laboratory

Martin Mariette Energy

Systèms, Inc.

P.0. Box 2008

Oak Ridge, TN 37831-6105

\section{FOREIGN}

R. V. Griffith

Department of Nuclear

IAEA

Energy and Safety

P.0. Box 100

A-1000 Vienna

AUSTRIA

\section{ONSITE}

$3 \quad$ U.S. Department of Energy Richland Field office

T. L. Aldridge

H. D. Groce

D. L. Rice

1 Bechte] Hanford Incorporated

E. W. Carlson

1 MAC Technical Services Company

G. R. Yesberger

Distr.1 
No. of

Copies

7 Westinghouse Hanford Company

L. K. Aldrich

D. S. Cunningham

H. A. Decker, Jr.

L. R. McKay

D. B. Ottley

R. B. Sitsler
No. $0 f$

Copies

33 Pacific Northwest National Laboratory

W. V. Baumgartner

L. H. Brackenbush

A. W. Endres (10)

G.W.R. Endres

J. J. Fix

M. E. Hevi and

D. P. Higby

M. Lyon

J. C. McDonald

M. A. Parkhurst

B. A. Rathbone

R. I. Scherpelz

K. L. Soldat

J. E. Tanner

Health Physics Library

External Dosimetry Project

Fite

Historical Files

(c/o V. L. Berndt)

Information Release (7) 